\title{
Tetrahydrobiopterin in Cardiovascular Health and Disease
}

\author{
Jennifer K. Bendall, ${ }^{*}$ Gillian Douglas, ${ }^{\star}$ Eileen McNeill, ${ }^{*}$ Keith M. Channon, and Mark J. Crabtree
}

\section{Abstract}

Tetrahydrobiopterin (BH4) functions as a cofactor for several important enzyme systems, and considerable evidence implicates BH4 as a key regulator of endothelial nitric oxide synthase (eNOS) in the setting of cardiovascular health and disease. BH4 bioavailability is determined by a balance of enzymatic de novo synthesis and recycling, versus degradation in the setting of oxidative stress. Augmenting vascular BH4 levels by pharmacological supplementation has been shown in experimental studies to enhance NO bioavailability. However, it has become more apparent that the role of BH4 in other enzymatic pathways, including other NOS isoforms and the aromatic amino acid hydroxylases, may have a bearing on important aspects of vascular homeostasis, inflammation, and cardiac function. This article reviews the role of BH4 in cardiovascular development and homeostasis, as well as in pathophysiological processes such as endothelial and vascular dysfunction, atherosclerosis, inflammation, and cardiac hypertrophy. We discuss the therapeutic potential of BH4 in cardiovascular disease states and attempt to address how this modulator of intracellular NO-redox balance may ultimately provide a powerful new treatment for many cardiovascular diseases. Antioxid. Redox Signal. 20, 3040-3077.

I. Introduction

II. Biochemistry

A. Tetrahydrobiopterin

1. De novo synthesis of $\mathrm{BH} 4$ by guanosine triphosphate cyclohydrolase I

2. Role of BH4 in NOS catalysis

3. BH4 bioavailability and eNOS uncoupling

4. Allosteric regulation of GTPCH by GTPCH feedback regulatory protein 3044

5. $\mathrm{BH} 4$ recycling

3046

B. Dihydrofolate reductase

3046

C. Dihydropteridine reductase

3046

D. Sepiapterin reductase

3046

3047

III. Homocysteine, Folate, and ADMA

$\begin{array}{lr}\text { IV. Role of BH4 in Cardiovascular Development } & 3048 \\ \text { V. BH4 in the Vascular System } & 3049\end{array}$

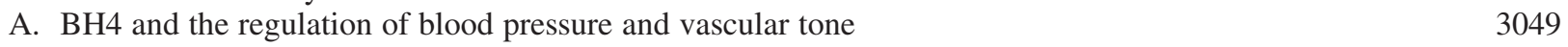

B. Role of $\mathrm{NO}$ and $\mathrm{BH} 4$ in endothelial cell proliferation and survival $\quad 3050$

C. Sepsis

3051

D. BH4 therapy

1. Animal models of chronic BH4 supplementation 3053

2. Clinical studies of acute BH4 supplementation 3053

3. Clinical studies of chronic BH4 supplementation 3054

Reviewing Editors: Markus Bachschmid, Sergey Dikalov, Sampath Parthasarathy, and Jean-Sebastien Silvestre

Division of Cardiovascular Medicine, British Heart Foundation Centre of Research Excellence, University of Oxford, John Radcliffe Hospital, Oxford, United Kingdom.

*These authors contributed equally to this work. 
E. Alternative strategies to increase BH4

VI. BH4 in Vascular Inflammation and Atherosclerosis 3054

A. Regulation of BH4 availability by inflammatory stimuli 3055

B. Regulation of BH4 levels in atherosclerosis 3055

C. The role of BH4 and NOSs in atherosclerosis 3056

D. BH4 supplementation in models of atherosclerosis 3057

E. Vascular injury models 3058

F. Tetrahydrobiopterin in human cardiovascular inflammation 3060

VII. Cardiac BH4 3060

A. NO in the heart $\quad 3060$

B. BH4 in the heart 3061

C. BH4 in cardiac pathologies 3061

D. Ischemia/reperfusion injury an infarction 3061

E. Cardiac hypertophy and function 3062

F. Cardiac autonomic function 3064

VIII. Concluding Remarks 3064

\section{Introduction}

(6R) 5,6,7,8-TETRAHYDROBIOPTERIN (BH4) is a pteridine that is defined by its unique heterocyclic ring structure and is now known to have a plethora of cofactor and antioxidant roles in a whole host of biological processes, including pathological states associated with cardiovascular and endothelial dysfunction, monoamine neurotransmitter formation, the immune response, and pain sensitivity. This range of biological systems comes from the essential cofactor roles of $\mathrm{BH} 4$ for a set of enzymes that are of central metabolic importance, including the three nitric oxide synthases (NOS), four aromatic amino acid hydroxylases (AAAH), and alkylglycerol mono-oxygenase (AGMO)(Fig. 1)(315).

The biological synthesis of pteridines was first discovered in 1889, when Sir Fredrick Gowland Hopkins isolated the yellow pigments from the wings of English butterflies (114). The identity of these compounds was not recognized until the 1940s, when three compounds were isolated and shown to share a novel pyrimidine ring system. The name pterin was given to these compounds after the Greek name Ptera, meaning wing, from which these molecules were first isolated.

Kaufman and coworkers were the first to demonstrate a cofactor function for $\mathrm{BH} 4$ in mammalian biology. In the liver, BH4 was shown to be an essential cofactor for the metabolism of phenylalanine to tyrosine by phenylalanine hydroxylase (187) and was later found to play a similar cofactor role for the two other mammalian AAAH, tyrosine hydroxylase and tryptophan hydroxylase (24). These findings implicated BH4 in the biosynthesis of neurotransmitters, including epinephrine, norepinephrine, dopamine, and 5-HT (Fig. 2). The observation that BH4 synthesis is dramatically induced in mammalian cells by cytokines puzzled researchers for many years, as there was no known enzyme that was both inducible and dependent on $\mathrm{BH} 4$. This led to the discovery that BH4 is an essential cofactor for inducible NOS (iNOS) activity $(146,270)$. With the groundbreaking discovery of the endothelial-derived relaxing factor (EDRF), and subsequently the critical role for BH4 in the synthesis of EDRF, the investigation of BH4 and its implication in cardiovascular homeostasis soared-indeed, to date, more than 650 publications are highlighted using the search term "cardiovascular tetrahydrobiopterin" in PubMed.
Cardiovascular disease is the largest cause of mortality and morbidity in Western societies, and it is also emerging as a major health burden in developing countries. This comprehensive review will discuss the physiological and pathophysiological roles of $\mathrm{BH} 4$ in cardiovascular health and disease. We will describe the mechanistic importance of BH4 to NOS catalysis that underlies NOS uncoupling, the role of $\mathrm{BH} 4$ in the maintenance of cardiac and vascular homeostasis, and describe in detail the deleterious effects of diminished BH4 levels on cardiovascular pathophysiology and inflammation. We will then consider how alterations in $\mathrm{BH} 4$ bioavailability may modulate the development of cardiovascular diseases such as atherosclerosis, heart failure, and hypertension (Fig. 3). This review brings together the biochemical and mechanistic roles of $\mathrm{BH} 4$ in the cardiovascular health, inflammation, and disease states, and discusses current BH4-based therapeutic strategies and methods that are used to alleviate vascular and cardiac dysfunction. More focused reviews of NOS biochemistry and regulation can be found elsewhere and will, therefore, not be discussed in further detail here.

\section{Biochemistry}

\section{A. Tetrahydrobiopterin}

The pterins were first described by Hopkins in 1895 (114) and characterized by Watt in the 1960s (304). Initially identified as a cofactor for the AAAH (phenylalaninehydroxylase (EC 1.14.16.1), tyrosine 3-hydroxylase (EC 1.14.16.2), and tryptophan 5-hydroxylase (EC 1.14.16.4)), BH4 was revealed as a required cofactor for the NOS enzymes by Stuehr and coworkers (146) and Tayeh and Marletta (270) in 1989. BH4 is also a cofactor for AGMO, which is the only enzyme known to cleave the ether bond of alkylglycerols and lyso-alkylglycerol phospholipids, including lyso-platelet activating factor (PAF), and current studies are only now unraveling the physiological role of this enzyme $(302,303)$. Although currently not implicated in cardiovascular homeostasis or disease, future investigations and the development of AGMO knockout mice may reveal a cardiovascular role for this protein.

1. De novo synthesis of $\mathrm{BH} 4$ by guanosine triphosphate cyclohydrolase I. $\mathrm{BH} 4$ is synthesized de novo from 


\section{De novo synthetic pathway}<smiles>Nc1nc2c(ncn2C2CCCCC2)c(=O)[nH]1</smiles>

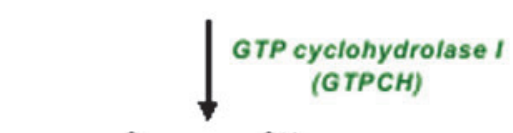<smiles>Nc1nc2c(c(=O)[nH]1)C(C(O)C(O)COP)=NCC2</smiles>

Dihydroneopterin triphosphate

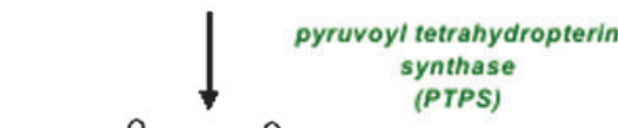

\section{'Salvage pathway'}<smiles>CC(=O)C1CNc2nc(N)[nH]c(=O)c2N1</smiles>

'seplapterin synthase'<smiles>CC(O)C(=O)C1=Nc2c(nc(N)[nH]c2=O)NC1</smiles>

6.Pyruvoyl tetrahydropterin

$?$

Sepiaplerin
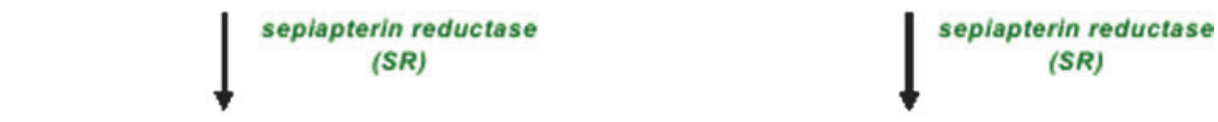<smiles>CC(O)C(O)C1CNc2nc(N)[nH]c(=O)c2N1</smiles>

Dihydrofolate reductase (DHFR)<smiles>CC(O)C(O)C1=Nc2c(nc(N)[nH]c2=O)NC1</smiles>

$5,6,7,8 \cdot$ Tetrahydrobiopterin

7,8-Dinydrobiopterin

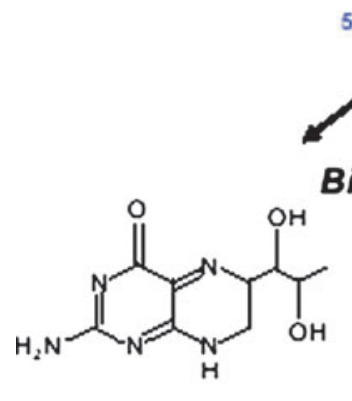

Quinonoid dihydrobioplerin

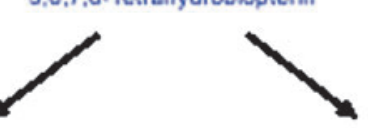

Biopterin recycling

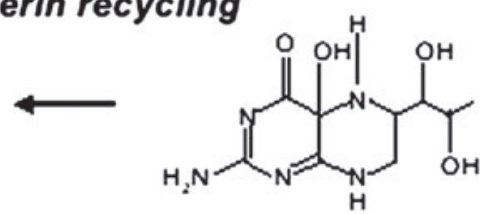

Tetrahydrobiopterin 4a-carbinolamine

FIG. 1. 5,6,7,8-tetrahydrobiopterin (BH4) biosynthesis proceeds from guanosine triphosphate (GTP) via 7,8-dyhydroneopterin triphosphate and 6-pyruvoyl-5,6,7,8-tetrahydropterin. The first and rate-limiting step in the pathway is GTP cyclohydrolase I (GTPCH). The following steps are catalyzed by the enzymes 6-pyruvoyl tetrahydropterin synthase (PTPS) and sepiapterin reductase (SR). An alternative pathway for BH4 synthesis has been documented by which 6pyruvoyl-5,6,7,8-tetrahydrobiopterin is converted into sepiapterin by an enzyme termed "sepiapterin synthase". Exogenous sepiapterin can be reduced in all cells by SR to $\mathrm{BH}$, and further by dihydrofolate reductase (DHFR) to form BH4, the socalled "salvage pathway." The principle oxidant species leading to $\mathrm{BH} 4$ oxidation to $\mathrm{BH} 2$ is peroxynitrite. As a cofactor for the aromatic amino acid hydroxylases (AAAH) in the liver and neurons, but not as a cofactor for NOS, BH4 is converted into tetrahydrobiopterin-4a-carbinolamine, which is recycled to BH4 by the actions of pterin-4a-carbinolamine dehydratase (PCD) and DHPR. To see this illustration in color, the reader is referred to the web version of this article at www.liebertpub.com/ars 


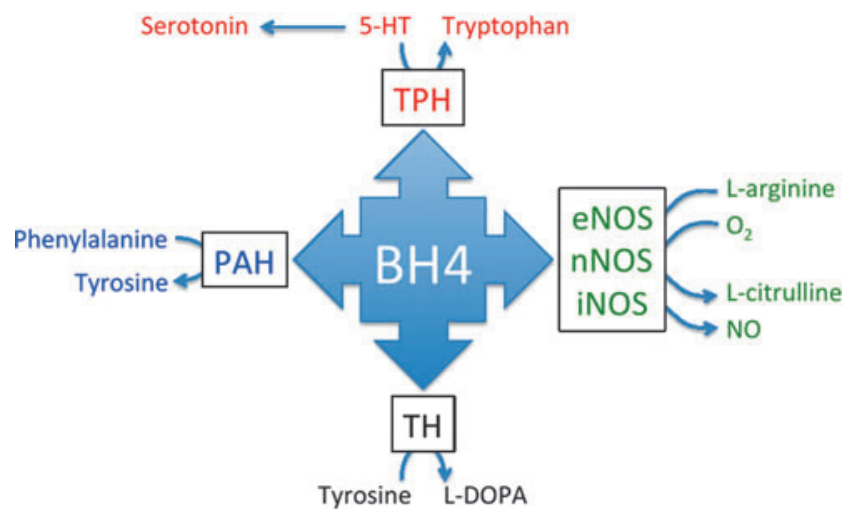

FIG. 2. Enzyme cofactor activity of BH4. BH4 is required for NO production by all three nitric oxide synthase isoforms. Under normal conditions, these enzymes couple oxidation of the amino acid substrate L-arginine with the reduction of molecular oxygen to form $\mathrm{NO}$ and L-citrulline. $\mathrm{BH} 4$ also has cofactor activity for the AAAH, resulting in neurotransmitter synthesis and preventing the accumulation of phenylalanine. To see this illustration in color, the reader is referred to the web version of this article at www.liebertpub.com/ars

guanosine triphosphate (GTP) by the sequential action of three enzymes: GTP cyclohydrolase I (GTPCH, EC 3.5.4.16), 6-pyruvoyl tetrahydropterin synthase (PTPS, EC 4.6.1.10), and sepiapterin reductase (SR, EC 1.1.1.153). Outlined in Figure 1, the first and rate-limiting reaction is catalyzed by GTPCH, producing 7,8-dihydroneopterin triphosphate (DNTP) from GTP. This pivotal first step in BH4 biosynthesis is complex and highly regulated at the transcriptional, translational, and post-translational levels (93). GTPCH-catalyzed formation of DNTP is a common initial step in the biosynthesis of unconjugated pterins, folates, and riboflavin, but not molybdopterin (a cofactor of sulfite oxidase, xanthine dehydrogenase, and aldehyde oxidase in man).

Continuing along the de novo $\mathrm{BH} 4$ synthesis pathway, H2NTP is next converted to 6-pyruvoyl tetrahydropterin by the zinc-dependent enzyme, PTPS. Although GTPCH is rate limiting to BH4 synthesis in most cells, PTPS has been suggested to be rate limiting in some, most notably human hepatocytes. PTPS may become rate limiting in other tissues and cells, after stimulation with cytokines and other immunological stimuli that induce BH4 synthesis by up-regulation of GTPCH expression (274).

The final reaction in the pathway is catalyzed by SR and involves two sequential NADPH-dependent reductions; a side-chain carboxyl of 6-pyruvoyl tetrahydropterin is initially reduced and rearranged to form the intermediate 6- lactoyl tetrahydropterin, and then reduced on a second side-chain carboxyl to BH4 (274).

2. Role of $\mathrm{BH} 4$ in NOS catalysis. The role of $\mathrm{BH} 4$ in the catalysis of the AAAH enzymes for the synthesis of tyrosine, L-3,4-dihydroxyphenylalanine (L-DOPA), and serotonin is well established; is excellently described in several key reviews $(274,315)$; and, therefore, will not be further discussed in the review.

The three isoforms of NOS are encoded by distinct mammalian genes (328). Two of the three isoforms are constitutively expressed in cells and synthesize NO primarily in response to transient elevations in intracellular $\mathrm{Ca}^{2+}$ levels, a process that is mediated by the binding of calciumcalmodulin (CaM) (74). These constitutive enzymes are designated neuronal NOS (nNOS or NOS I) and endothelial NOS (eNOS or NOS III) after the cell type and order in which they were discovered. The third isoform, or inducible NOS (iNOS or NOS II), is typically synthesized in response to inflammatory stimuli, but has been shown to be constitutively expressed in some tissues, such as lung epithelium (63). The main difference between iNOS and the constitutive NOS isoforms is the high-affinity binding of CaM to iNOS such that it remains bound even at subnanomolar levels of $\mathrm{Ca}^{2+}$, rendering iNOS constitutively active (35).

The first NOS to be isolated, nNOS, was purified from rat brain (22). nNOS was found to be dimeric, with each monomer consisting of an N-terminal oxygenase domain and a C-terminal reductase domain, bridged by a short $(\sim 30$ amino acid) calmodulin-binding peptide. The oxygenase domain contains binding sites for heme, the required cofactor tetrahydrobiopterin (BH4) and L-arginine, forming the active site where NO synthesis takes place. The reductase domain shares $\sim 40 \%$ sequence homology with NADPH cytochrome P450 reductase (22) and contains binding sites for FMN, FAD, and NADPH $(23,260)$. During NO synthesis, the flavins in the reductase domain of NOS serve to transfer electrons from NADPH to heme iron in the oxygenase domain (triggered by CaM binding in nNOS and eNOS), enabling the activation of heme-bound molecular oxygen for NO synthesis $(169,170)$. Subsequent purification and cloning of the two other NOS isoforms showed that they share the same basic bidomain structure where each is an obligate dimer, with the reductase domain of one monomer supplying electrons to the oxygenase domain of the other (Fig. 4).

After the discovery of BH4 as an essential cofactor in NOS catalysis, it became clear that $\mathrm{BH} 4$ adopted a different role in NOS catalysis when it was discovered that NOS contained a cytochrome P450-type heme, a moiety which was able to support the activation of oxygen without the need for a pterin cofactor. The main evidence against a direct redox role for $\mathrm{BH} 4$ came from the observation that citrulline formation is not stoichiometric with $\mathrm{BH} 4$ consumption and the fact that $\mathrm{BH} 4$ had little effect on the initial rate of NOS catalysis (88). A comparison of eNOS $(72,213)$, iNOS (46), and nNOS (287) oxygenase domains with crystal structures of the AAAHs has revealed fundamental structural differences between the BH4 binding sites. In NOSs, BH4 functions, in part, as an allosteric modulator of arginine binding. The binding of $\mathrm{BH} 4$ to NOS elicits a conformational change that increases the affinity for the binding of arginine-based ligands $(139,158)$. Support for an allosteric role of BH4 was confirmed by spectrophotometric and electron paramagnetic resonance (EPR) studies, which show that BH4 binding converts the heme iron from a low-spin to a high-spin state (90). Another possible role of BH4 was considered in dimer assembly (86). Although proved not to be essential for dimer assembly (221), BH4 binding plays a role in dimer stabilization (140).

The allosteric effects mentioned earlier do not fully explain the essential role of $\mathrm{BH} 4$ in $\mathrm{NO}$ synthesis, and electron donation from $\mathrm{BH} 4$ to the heme iron remains almost certain. Indeed, only fully reduced pterins such as tetrahydrobiopterin have ever been shown to support catalysis (212, 219, 288). Moreover, tetrahydrobiopterins with modifications that 
Inhibition of platelet aggregation

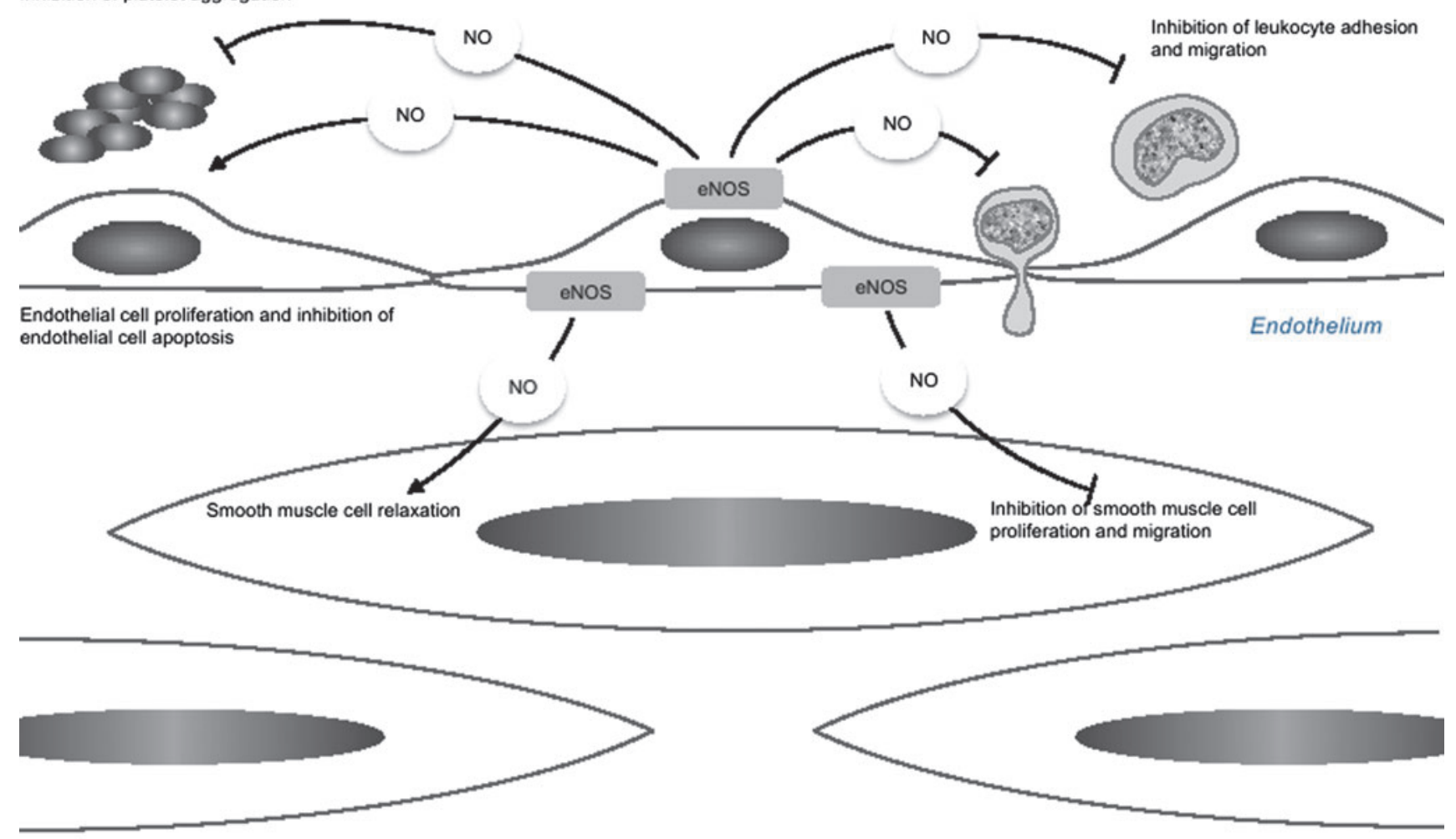

Smooth muscle cells

FIG. 3. Antiatherogenic and antithrombotic properties of endothelial NO. NO is produced in the endothelium by endothelial nitric oxide synthase (eNOS). It diffuses into the vessel wall, leads to the relaxation of vascular smooth muscle cells, and also inhibits the proliferation and migration of smooth muscle cells. On the luminal surface of the blood vessel, NO inhibits leucocyte adhesion to endothelial cells and migration into the vascular wall as well as platelet aggregation and adhesion. NO further mediates VEGF-induced endothelial cell proliferation and plays a critical role in the prevention of endothelial cell senescence and apoptosis. To see this illustration in color, the reader is referred to the web version of this article at www.liebertpub.com/ars

would cause them to be redox silent are unable to catalyze NO synthesis $(107,310)$. Spectral and EPR studies have revealed the presence of a trihydrobiopterin $\left(\cdot \mathrm{BH}_{3}\right)$ radical intermediate, which strongly supports a redox role for $\mathrm{BH} 4$ in NOS catalysis and may explain the ability of eNOS-bound $\mathrm{BH} 4$ to limit the release of oxygen as $\mathrm{O}_{2}{ }^{-}$(17).

3. BH4 bioavailability and eNOS uncoupling. Many studies have focused on the potential role of BH4 oxidation to $\mathrm{BH} 2$ and other oxidized biopterin species in reducing $\mathrm{BH} 4$ bioavailability for eNOS. Although superoxide $\left(\mathrm{O}_{2}{ }^{-}\right)$can, indeed, react directly with $\mathrm{BH} 4$, the rate constant of this reaction $\left(3.9 \times 10^{5} M^{-1} . \mathrm{s}^{-1}\right)(290)$ is many orders of magnitude lower than that for $\mathrm{NO}$ with $\mathrm{O}_{2}{ }^{-}\left(6.7 \times 10^{9} M^{-1} . \mathrm{s}^{-1}\right)$ (119). A more likely mechanism for $\mathrm{BH} 4$ oxidation is the interaction with peroxynitrite $\left(\mathrm{ONOO}^{-}\right.$; generated from the interaction between $\mathrm{NO}$ and $\mathrm{O}_{2}{ }^{-}$). Experiments in vitro (178) and ex vivo (345) indicate that $\mathrm{ONOO}^{-}$can oxidize $\mathrm{BH} 4$ within minutes at physiologically relevant concentrations. EPR spectroscopy experiments have demonstrated that $\mathrm{ONOO}^{-}$ oxidizes BH4 to the (nonprotonated) BH3 (trihydrobiopterin) radical, and then to $\mathrm{BH} 2$, with a rate constant estimated to be $6 \times 10^{3} M^{-1} . s^{-1}$, several-fold higher than reactions between $\mathrm{ONOO}^{-}$and ascorbate, glutathione or thiol groups (145). Oxidation not only directly reduces $\mathrm{BH} 4$ bioavailability, but also the oxidation products themselves (such as BH2), which have no cofactor activity, may compete with $\mathrm{BH} 4$ for binding to eNOS (42)(Fig. 5).

Depletion of BH4 in oxidatively stressed endothelial cells can result in eNOS "uncoupling," where electron transfer from NOS flavins becomes "uncoupled" from L-arginine oxidation, the ferrous-dioxygen complex dissociates, and $\mathrm{O}_{2}{ }^{-}$is produced from the oxygenase domain $(258,287,293$, 294). Indeed, it is now believed that the intracellular $\mathrm{BH} 4: \mathrm{BH} 2$ ratio, rather than absolute concentrations of $\mathrm{BH} 4$, is the key determinant of eNOS uncoupling $(42,43,287$, 292).

$\mathrm{O}_{2}{ }^{-}$generation by eNOS has been implicated in a variety of experimental and clinical vascular disease states of the heart and vascular system, including heart failure, ischaemia reperfusion injury, atrial fibrillation $(\mathrm{AF})$, diabetes $(39,95)$, cigarette smoking (104), hypertension (148), and atherosclerosis (163), shown in Figure 5 and described in greater detail throughout this review.

4. Allosteric regulation of GTPCH by GTPCH feedback regulatory protein. It was appreciated for many years that GTPCH is subject to feedback inhibition by the pathway endproduct, BH4 (237). However, it was the demonstration that the activity of pure recombinant GTPCH protein was not 


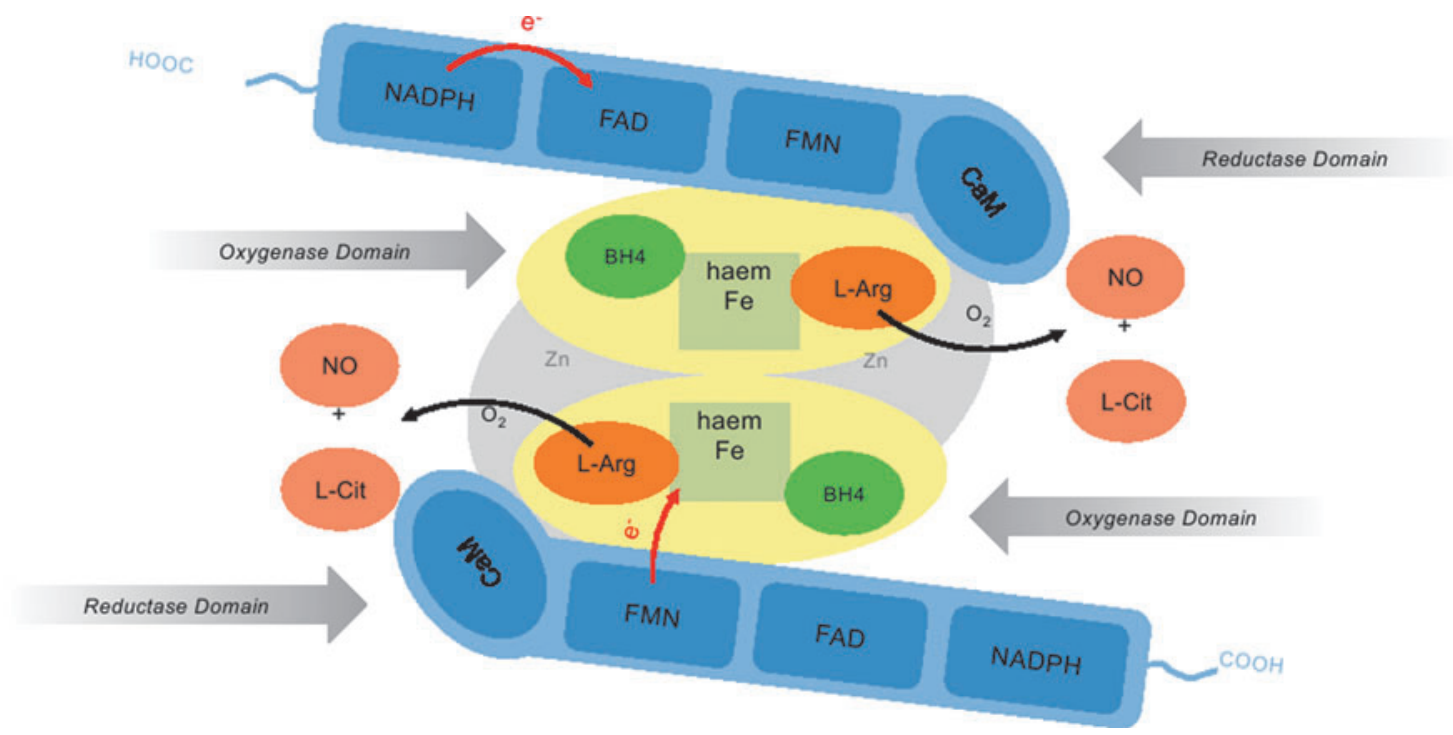

FIG. 4. NOS catalysis. All three isoforms of NOS function as homodimers. Each monomer consists of a reductase domain with binding sites for NADPH, FAD, FMN, and calmodulin (CaM) and an oxygenase domain containing an iron haem group and binding sites for L-arginine (L-Arg) and BH4. Starting from NADPH, electrons flow to the flavins FAD and FMN of the reductase domain, to the iron of the haem in the oxygenase domain. CaM regulates electron flow between the reductase and oxygenase domain. BH4 seems to be essential to donate electrons to the haem group in the oxygenase domain in order to oxidize L-arginine. To see this illustration in color, the reader is referred to the web version of this article at www.liebertpub.com/ars

inhibited in vitro by $\mathrm{BH} 4$ (97) that proved to be the most interesting. This led to the discovery of a novel protein which co-purifies from rat liver with GTPCH that, when added to purified recombinant GTPCH in the presence of $\mathrm{BH} 4$, is able to reconstitute feedback inhibition (97) - this protein was named GFRP, for GTPCH Feedback Regulatory Protein (177). In the presence of recombinant rat GFRP, BH4 elicits a concentration-dependent inhibition of GTPCH activity, confirming that GFRP is both necessary and sufficient for BH4-mediated feedback inhibition of GTPCH (334). Stimulation of GTPCH activity is apparently specific to Phe and can occur in the presence or absence of bound BH4.

Immunostimulant-induced $\mathrm{NO}$ synthesis was found to be markedly suppressed in many cell types when de novo syn- thesis of BH4 was inhibited at the level of GTPCH. It seemed unlikely that the GFRP feedback inhibition mechanism was functioning to influence NOS activity under these conditions, given that the $\mathrm{Km}$ of $\mathrm{BH} 4$ for NOS is very low (30-100 $\mathrm{n} M)$ compared with threshold BH4 levels reported to be necessary for the engagement of feedback inhibition $(1-10 \mu M)(97,177)$. Nonetheless, GFRP mRNA was detectable by RT-PCR at basal levels in RASMCs, apparently inducible by immunostimulants, and Phe was observed to increase $\mathrm{BH} 4$ synthesis, suggestive of basal GFRP-dependent inhibition of GTPCH (327). In contrast, levels of GFRP mRNA in human myelomonocytoma cells, measured by northern blotting, were reported to be significantly down-regulated after lipopolysaccharide (LPS)

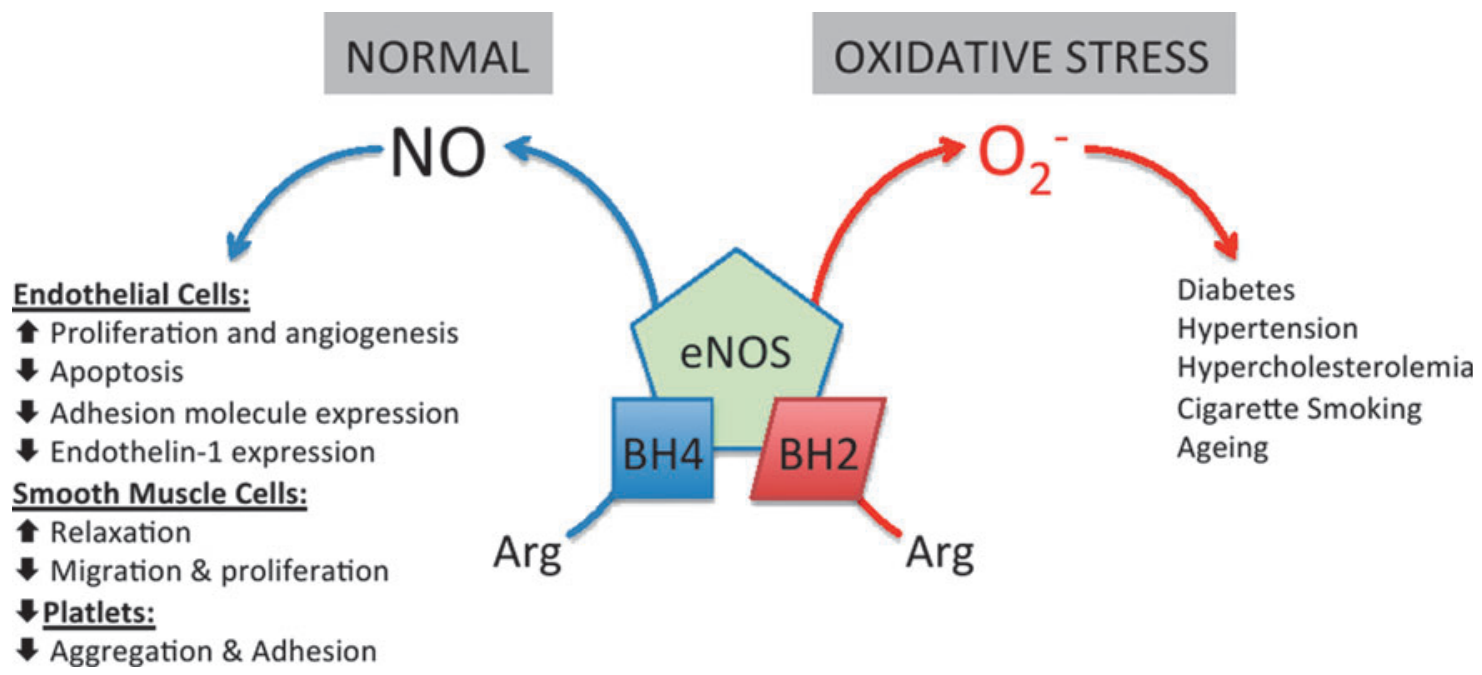

FIG. 5. Normal and dysfunctional roles of eNOS coupling. To see this illustration in color, the reader is referred to the web version of this article at www.liebertpub.com/ars 
treatment (314). qRT-PCR analysis of GFRP mRNA in LPS-treated human umbilical vein endothelial cells (HUVEC), and in various tissues extracted from rats treated with LPS, also indicated down-regulation of GFRP mRNA (314). Recently, it was shown that NO can suppress GFRP protein expression in hepatocytes, resulting in the activation of GTPCH and increased immunostimulant-induced NO production due to increased iNOS subunit dimerization and elevated levels of intracellular BH4 (201).

5. BH4 recycling. Depending on its cofactor function for the AAAH versus the NOS enzymes, BH4 turnover products and regeneration reactions differ. In the aromatic amino acid hydroxylase reactions, $\mathrm{BH} 4$ is oxidized to tetrahydrobiopterin-4a-carbinolamine; $\mathrm{BH} 4$ is subsequently regenerated in a two-step process. Actions of pterin-4acarbinolamine dehydratase (EC 4.2.1.96; PCD) lead to the production of the quinonoid dihydrobiopterin intermediate, which is subsequently reduced by dihydropteridine reductase (EC 1.6.99.7; DHPR). Both enzymes are expressed in mammalian liver (100), kidney, and brain (54), and mutations in the PCD and DHPR genes are associated with clinical systemic BH4 deficiency and hyperphenylalaninemia.

As a cofactor for NOS, BH4 is not oxidized to tetrahydrobiopterin-4a-carbinolamine but, during the transfer of electrons to the ferrous-dioxygen complex in the NOS active site, it forms the protonated trihydrobiopterin cation radical $(\mathrm{BH} 3 . \mathrm{H}+)$, which is subsequently reduced in the next catalytic cycle by electron transfer from eNOS flavins $(120,290)$. Since the BH3.H + radical returns to the $\mathrm{BH} 4$ state after each electron transfer step, continuous $\mathrm{BH} 4$ regeneration by $\mathrm{PCD}$ and DHPR is not a requirement for short-term eNOS activity in endothelial cells. However, ultimately, this regenerative cycle is not sufficient to maintain cellular BH4 levels, and on activation, eNOS is reliant on the intracellular $\mathrm{BH} 4$ pool and, therefore, the presence of these recycling enzymes becomes critical.

\section{B. Dihydrofolate reductase}

In addition to key roles in folate metabolism, dihydrofolate reductase (DHFR; E.C. 1.5.1.3) can reduce BH2, regenerating BH4 $(173,194)$. Thus, it is likely that net $\mathrm{BH} 4$ cellular bioavailability reflects the balance between de novo $\mathrm{BH} 4$ synthesis, loss of $\mathrm{BH} 4$ by oxidation to $\mathrm{BH} 2$, and the regeneration of BH4 by DHFR, shown in Figure 1. In human liver extracts, DHFR has been shown to reduce $\mathrm{BH} 2$ to $\mathrm{BH} 4$ as a part of the salvage pathway for biopterin synthesis (51). Several studies implicate the biopterin recycling pathway in the regulation of steady-state BH4 levels-In a Chinese hamster ovary cell mutant lacking dihydrofolate reductase (DUKX-BII), endogenous formation of $\mathrm{BH} 4$ proceeds normally, but unlike the parent cells that express DHFR, extracts do not convert sepiapterin or BH2 to BH4 (190). In vitro and in vivo studies reveal that this $\mathrm{BH} 2$ reductase activity of DHFR is crucial in determining cellular BH4 homeostasis, NO bioavailability, and, ultimately, eNOS coupling in cultured endothelial cells (44). Exposure to angiotensin II downregulated DHFR expression, decreased BH4 levels, and increased eNOS uncoupling, which was restored by overexpression of DHFR (32). Pharmacological inhibition of DHFR activity by methotrexate (MTX), or genetic knock- down of DHFR by RNA interference, reduced intracellular BH4 and increased $\mathrm{BH} 2$ levels, resulting in enzymatic uncoupling of eNOS in endothelial cells. In cells expressing eNOS with low biopterin levels, DHFR inhibition or knockdown further diminished the $\mathrm{BH} 4: \mathrm{BH} 2$ ratio and exacerbated eNOS uncoupling $(44,262)$.

The importance of DHFR activity in vivo was has been investigated in mice after the inhibition of DHFR with MTX. In these studies, using models of BH4-deficiency (hph-1 mice, developed by ENU mutagenesis, have diminished GCH1 mRNA and total GTPCH protein, leading to approximately 90\% decrease in GTPCH activity) and GTPCH-1 overexpression specifically within the endothelium (GCH-Tg mice), DHFR activity was required to maintain eNOS coupling in vivo and this effect was more prominent in conditions of overall $\mathrm{BH} 4$ deficiency. $\mathrm{BH} 4$ augmentation protected against these deleterious effects of DHFR inhibition by MTX. Moreover, it has also been observed that MTX treatment in patients with inflammatory disease leads to a striking accumulation of $\mathrm{BH} 2$ in plasma, further illustrating the requirement for DHFR activity in the maintenance of BH4 homeostasis in humans in vivo (45).

Interestingly, some previous studies have shown that DHFR levels or activity are diminished in experimental models of cardiovascular disease states, suggesting that insufficient recycling of $\mathrm{BH} 2$ to $\mathrm{BH} 4$ by DHFR is at least, in part, responsible for the reduced $\mathrm{BH} 4$ levels and the accumulation of BH2, leading to eNOS uncoupling. For example, DHFR protein levels are significantly decreased in streptozotocin (STZ)-induced diabetic mice, and diabetes-induced impairment of cardiac myocyte function is exacerbated after treatment of mice with the DHFR inhibitor, MTX (216). Furthermore, reduced DHFR activity in adult cardiac myocytes underlies their limited capacity to synthesize BH4 after cytokine stimulation after treatment of rat cardiac allograft recipients with sepiapterin (126). Insufficient DHFR activity might also explain impaired vasorelaxation in atherosclerotic vessels from hypercholesterolemic rabbits, as exposure to sepiapterin that increases BH4 levels through the DHFRdependent conversion of $\mathrm{BH} 2$ failed to reverse the impairment (291).

\section{Dihydropteridine reductase}

DHPR, along with PCD, is critical for the regeneration of $\mathrm{BH} 4$ that is required for activity of the AAAHs. DHPR concentrations compared with those of the AAAHs are relatively high. The enzyme is almost ubiquitously expressed, and its presence in tissues lacking enzymes of the AAAHs suggests that DHPR may be involved in other metabolic processes. DHPR may preserve tetrahydrofolate levels in the brain, where the concentration of DHFR is comparatively low (135). The presence of DHPR in the lung and liver may be protective in $\mathrm{BH} 4$ homeostasis, catalyzing the reduction of q-BH2 to BH4 to maintain NO production by NOS. Deficiency in DHPR is an autosomal recessive condition, and it has been shown to cause hyperphenylalaninemia due to $\mathrm{BH} 4$ deficiency.

\section{Sepiapterin reductase}

In contrast to other BH4 metabolic enzymes, SR is involved in both the synthetic and salvage pathways of BH4 


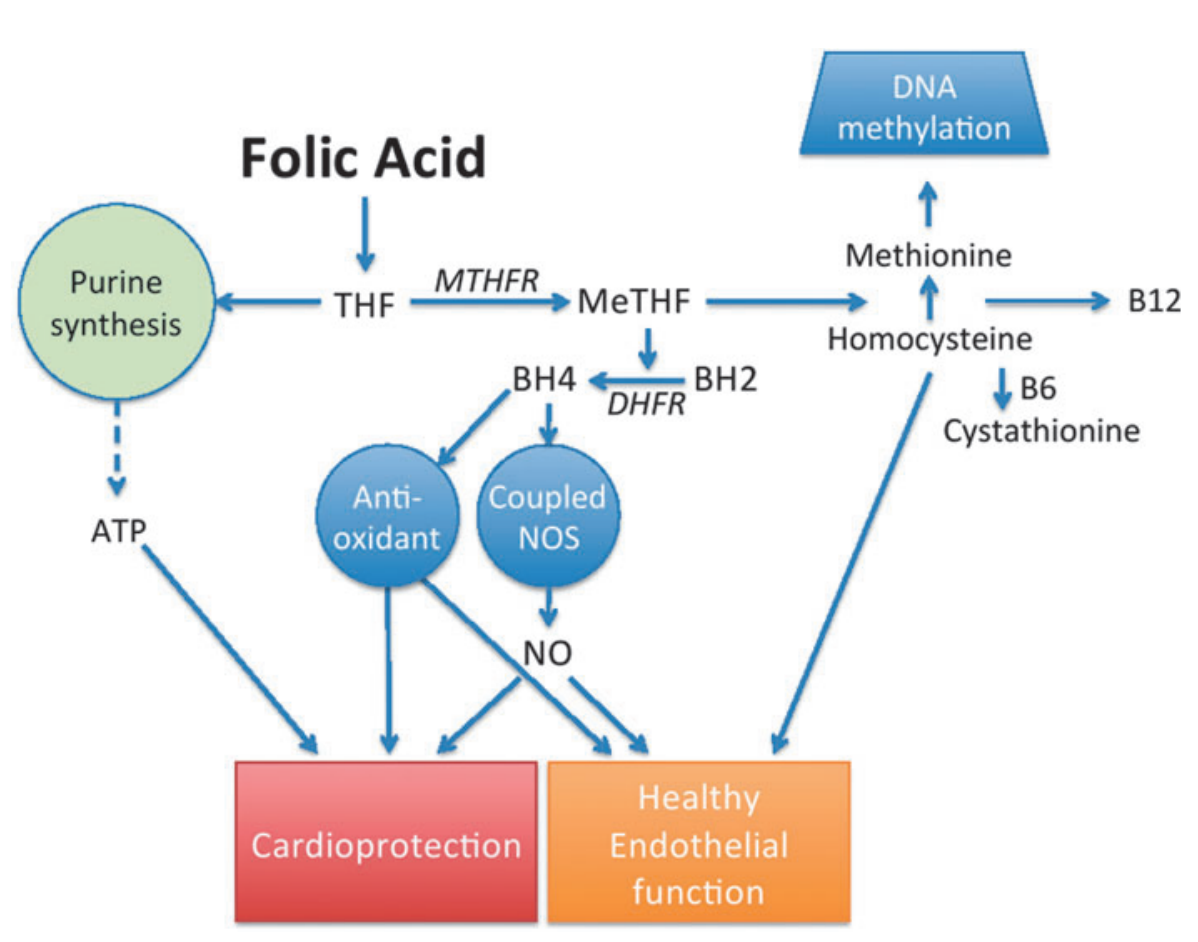

FIG. 6. The role of folic acid in 1-carbon metabolism and its potential mechanisms for cardiac protection. The active metabolites of folic acid serve functional roles in purine synthesis and methylation reactions. Besides converting homocysteine to methionine, 5-methyl THF improves vascular endothelial function by enhancing nitric oxide bioavailability and protects against oxidative injury. To see this illustration in color, the reader is referred to the web version of this article at www.liebertpub.com/ars

synthesis (Fig. 1). SR was first discovered in chicken and rat liver by Matsubara and Akino, and purification of SR from rat erythrocytes showed it to consist of two 28-kDa sub units (171). Exogenous sepiapterin can be reduced in all cells by SR to 7,8-dihydrobiopterin (BH2) and further by DHFR to form BH4. Known as the salvage pathway, this has been exploited by many investigators as an approach to increase BH4 levels by pharmacological supplementation of sepiapterin (190).

Little is known about the expression and regulation of mammalian SR. The only evidence for a regulatory role of SR in NO synthesis comes from a study by Gao and coworkers, where knockdown of SR in endothelial cells was associated with dramatic decreases in both $\mathrm{BH} 4$ content and NO levels (82). Evidence for the sepiapterin synthesis pathway in humans comes from a recent study of rare patients with SR deficiency, in which sepiapterin levels were elevated in cerebrospinal fluid (CSF), which suggests endogenous production of sepiapterin (344).

\section{Homocysteine, Folate, and ADMA}

Homocysteine is dependent on S-adenosyl-methionine, which is responsible for many intracellular methylation reactions. The by-product of these reactions, S-adenosylhomocysteine, is then hydrolyzed to form homocysteine. When there is an excess of methionine, homocysteine is metabolized via trans-sulfurylation, producing cystathionine and, eventually, cysteine. Cystathionine b-synthase converts homocysteine to cystathione and requires vitamin B6 as an essential co-factor. Under conditions of methionine deficiency, homocysteine is remethylated into methionine in the liver via betaine-homocysteine-methyltransferase; however, in most tissues, homocysteine is remethylated into methionine by methionine synthase, which uses vitamin B12 as a cofactor and 5-methyltetrahydrofolate (5-MTHF) as a substrate.
5-MTHF synthesis is catalyzed by methyltetrahydrofolate reductase, which uses tetrahydrofolate as a substrate (Fig. 6).

Plasma levels of homocysteine and folate are related to cardiovascular risk and endothelial dysfunction, which may, in part, be mediated by their influence on BH4. Homocysteine decreases $\mathrm{BH} 4$ levels as well as its synthesis by GTPCH, and clinical trials have demonstrated that decreasing homocysteine levels with folate supplementation may retard developing atherosclerosis. However, three largerscale clinical trials in patients with stable coronary artery disease, myocardial infarction, or in patients with stroke have found that folate treatment failed to improve clinical outcome, thus suggesting the possibility that the increased risk may only be a marker for a related pathophysiological process. Some studies have shown that mechanisms alternative to homocysteine lowering may be important factors in the relationship between folate and cardiovascular disease. The close association between homocysteine and endothelial dysfunction is largely dependent on its impact on eNOS activity. An observed decrease in arginine availability that has been demonstrated to accompany elevated homocysteine levels has been shown to induce eNOS uncoupling in vascular endothelial cells in culture. Furthermore, the conversion of methionine to homocysteine is associated with an activation of arginine-protein-methyltransferases, the group of enzymes responsible for the methylation of L-arginine and the subsequent formation of asymmetric dimethyl arginine (ADMA), which is a known endogenous inhibitor of eNOS. ADMA represents a novel independent predictor for all-cause cardiovascular mortality. The activities of both protein arginine N-methyltransferase (PRMT, type I) and the ADMA-degrading enzyme dimethylarginine dimethylaminohydrolase (DDAH) are redox sensitive. In cultured endothelial cells, rat models, and humans, oxidative stress has been shown to increase the activity of PRMT(s) and decrease that of DDAH, leading to increased concentrations 
of ADMA. Thus, an increased production of reactive oxygen species (ROS) could be the reason for increased ADMA levels. Elevated ADMA may inhibit NO synthesis by eNOS or even result in eNOS uncoupling, which would further enhance oxidative stress (75). Chronic ADMA treatment inhibits NOS enzymes with the expected effects of a nonselective NOS inhibitor; elevating blood pressure, causing vasoconstriction, impairing endothelium-dependent relaxation, and increasing endothelial cell adhesiveness. Animal models of prolonged treatment with ADMA have the potential to have similar effects to other NOS inhibitors, enhancing atherogenesis and sustained hypertensive organ damage. In the heart, ADMA reduces heart rate and cardiac output (283).

\section{Role of BH4 in Cardiovascular Development}

BH4 is an essential co-factor for multiple enzymes that play a key role in embryonic development. Indeed, BH4 levels are higher at birth and during development than in adults $(18,335)$. Loss-of-function mutations in the GCH1 gene lead to rare congenital neurological diseases such as dystonia, DOPA-responsive dystonia, and hyperphenylalaninemia. The majority of mutations are heterozygous autosomal dominant with a smaller number of autosomal recessive mutations (275). Both disorders are characterized by low CSF levels of BH4 (80). Due to the critical role for $\mathrm{BH} 4$ in the function of multiple enzymes, it is unsurprising that nonfunctional mutations resulting in complete deficiency of BH4 have not been described. This interesting observation perhaps indicates that absolute loss of $\mathrm{BH} 4$ is embryonically lethal.

Mouse models of BH4 deficiency, and those models where the enzymes responsible for the biosynthesis of BH4 have been knocked out, indicate a key role for BH4 in embryonic development (Table 3). Although a knockout mouse model of $\mathrm{GCH}$ deficiency is not currently available, mice deficient in other synthetic enzymes, including PTPS, have been created. PTPS knockout mice are born with the expected medelian ratio but die within $48 \mathrm{~h}$ of birth. As expected, knockout mice have low levels of biopterin and catecholamines compared with wild type (WT) litter mates, but perhaps surprisingly show no gross organ defects. Postpartum lethality in PTPS pups can be rescued with $\mathrm{BH} 4$ and neurotransmitter replacement therapy $(64,263)$. This supports studies of mutations in the human $\mathrm{GCH} 1$ gene in patients in whom symptoms of $\mathrm{GCH}$ deficiency can be significantly improved with BH4 therapy (9).

Despite no obvious gross organ defects at birth, PTPS knockout mice are significantly bradycardic when compared with their WT littermates (263). It is thought that the bradycardia observed in PTPS knockout mice is due to a deficiency in catecholamine levels, as tyrosine hydroxylase (TH) knockout mice (L-DOPA, dopamine, noradrenaline, and adrenaline) show significant bradycardia at E12.5 (342). As in the PTPS knockout mice, TH knockout embryos are deficient in catecholamine synthesis and show no gross organ abnormalities, hinting that that cause of lethality is physiological rather than anatomical $(263,273,342)$. Other studies of catecholamine-deficient mice have indicated that during development, catecholamines are released by the embryo in response to in utero stress such as hypoxia which acts to increase heart rate via the $\beta$-adrenergic receptor (211). TH knockout mice and dopamine $\beta$-hydroxylase knockout mice show a more severe phenotype than PTPS knockout mice with significant embryo lethality noted and the majority of knockout embryos dead by E16.5-E18.5 (141, 273, 342). Catecholamine-deficient embryos also show signs of an altered development of the vasculature and the myocardium, along with blood congestion and thinning of the myocardium. There is also a greater heterogeneity in cardiac myocyte size and cellular orientation in catecholamine-deficient embryos (273, 342).

Since BH4 is critical for the function of $\mathrm{TH}$, it may be expected that the PTPS knockout mouse would also be embryonically lethal. However, this is not the case and may be explained by observations from several studies that BH4 can cross the placenta (295), is also found in breast milk (306) and that maternal transfer of both $\mathrm{BH} 4$ and catecholamines can occur (273).

Dysfunctional development of the cardiovascular system is not restricted to mouse models of cofactor production and, indeed, is also observed in the eNOS knockout mouse. Unlike the PTPS and TH knockout mice, eNOS knockout mice are viable, although significantly more embryos were found to be reabsorbed between days E8.5 and 13.5 (198). eNOS knockout mice display cardiovascular abnormities in utero; at E12.5, eNOS knockout mice have coronary artery hypoplasia, thus indicating poor cardiac perfusion (159). Moreover, elevated cardiomyocyte apoptosis and myocardial caspase-3 activity are also observed in the myocardium of eNOS knockout mice (70). At birth, cardiovascular defects persist; with reports of spontaneous myocardial infarction in eNOS knockout mice postpartum most likely due to a combination of reduced coronary artery diameter, vessel density, and volume, as well as increases in ventricular wall thickness and myocardial volume (159). In neonates, congenital atrial and ventricular septal defects have been observed, along with heart shortening (70). Vascular defects in eNOS knockout mice are also observed within the pulmonary circulationsevere pulmonary congestion has been described along with a lack of distal arterial branches and regions of capillary hypoperfusion. This occurs in conjunction with a misalignment of the pulmonary veins $(96,159)$. From E17.5 and after birth, eNOS knockout mice are significantly smaller than WT mice, indicating in utero growth restriction in knockout embryos $(102,284)$. Restricted growth in utero may be due to maladaptation of the uterine artery to pregnancy, as uterine arteries from eNOS knockout dams are significantly smaller and show signs of impaired smooth muscle cell dedifferentiation and proliferation (284).

Models of BH4 deficiency and studies of genetic mutation in human subjects have indicated that even a partial diminution in the levels of $\mathrm{BH} 4$ during development can lead to the onset of cardiovascular abnormalities. The hph-1 mouse, developed by ENU mutagenesis, has diminished GCH1 mRNA and total GTPCH protein, leading to a $90 \%$ decrease in GTPCH activity in the heart of adult mice (2). hph-1 mice have higher pulmonary vascular resistance, increased media thickness, and pulmonary hypertension at birth (18).

In summary, BH4 has been demonstrated to play a critical role in cardiovascular development while having both NOSdependent and -independent roles with the production of catecholamines shown to be critical to maintain heart rate in the developing heart. Generation of a tissue-specific $\mathrm{GCH}$ knockout mouse model would elucidate any cell autonomous 
role of $\mathrm{BH} 4$ in developmental biology and define whether there is an absolute requirement for $\mathrm{BH} 4$ in development.

\section{BH4 in the Vascular System}

\section{A. BH4 and the regulation of blood pressure and vascular tone}

Regulation of blood pressure and vascular tone is critical for the maintenance of proper organ perfusion, and one of the key regulators of blood pressure and organ perfusion is vascular resistance. A decrease in the diameter of the blood vessel due to increased sympathetic drive and/or decreased production of vasodilators results in an increased vascular resistance, causing an increased blood pressure upstream, and reduced blood flow downstream of the constriction.

Physiological stimuli, such as laminar shear stress, and receptor-mediated agonists such as bradykinin, estrogen, and acetylcholine, act on endothelial cells to increase the production of NO. The locally produced NO diffuses into the vascular smooth muscle cells of the vessel wall, where it activates multiple second messenger pathways through the activation of guanylate cyclase and direct S-nitrosylation of cysteine residues (76).

Endothelial dysfunction is a hallmark of multiple disease states such as diabetes, atherosclerosis, and hypertension, and it is characterized by impaired endothelial dependent vasodilatation (69). Given the key role of $\mathrm{BH} 4$ in the production of vasoactive substances such as NO and noradrenaline, it is not surprising that alteration in the bioavailability of $\mathrm{BH} 4$ alters blood pressure and endothelial function. A common GCH1 variant, $\mathrm{C}+243 \mathrm{~T}$ in the $3^{\prime}$ untranslated region, has been reported to be associated with decreased NO production, increased blood pressure and heart rate, and a dysfunction of baroreflex coupling (305). Studies of a haplotype defined by three single nucleotide polymorphisms (SNP) have shown that the $\mathrm{X}$ haplotype is associated with lower vascular levels of GCH1 mRNA and decreased levels of BH4 in plasma and the vasculature. This attenuation of BH4 is associated with increased vascular $\mathrm{O}_{2}{ }^{-}$production and reduced endothelial dependent vasodilatation in arterial and venous segments from coronary artery disease patients (7).

As previously discussed, very few genetic models of GTPCH deficiency exist_-in animal models, the treatment of 2,4-diamino-6-hydroxypyrimidine (DAHP), a selective inhibitor of $\mathrm{BH} 4$, leads to a significant increase in blood pressure and, ultimately, endothelial cell dysfunction. Endothelial dysfunction, characterized by reduced endothelial cell-dependent aortic relaxation, could be reversed by incubation with the $\mathrm{BH} 4$ precursor sepiapterin (179). siRNA knockdown of $\mathrm{GCH} 1$ in mice has been shown to result in endothelial dysfunction, increase vascular $\mathrm{O}_{2}{ }^{-}$production, increase the expression of adhesion molecules, and significantly increase blood pressure (299). Studies in the hph-1 mouse, with globally diminished BH4 levels, have shown that these mice have increased blood pressure compared with WT, nonlittermate controls (40). However, another study has not been able to replicate this finding and shows no difference in blood pressure between hph-1 mice and littermate controls (326); however, hph-1 mice develop pulmonary hypertension (137). A summary of the key reports using the hph-1, BH4deficient mouse is shown in Figure 7. These studies have highlighted the importance of $\mathrm{BH} 4$ in the maintenance of normal vascular function. The generation of a tissue-specific GCH knockout model would help elucidate the role of GTPCH in vascular function.

$\mathrm{BH} 4$ availability is regulated at both the gene and protein levels, and GTPCH protein expression has been shown to be altered by both physiological and pathophysiological stimuli.

\section{$\beta$-adrenergic control of heart rate \\ Adlam et al. Cardiovosc Res. 2012 Mar 15;93:694-701}

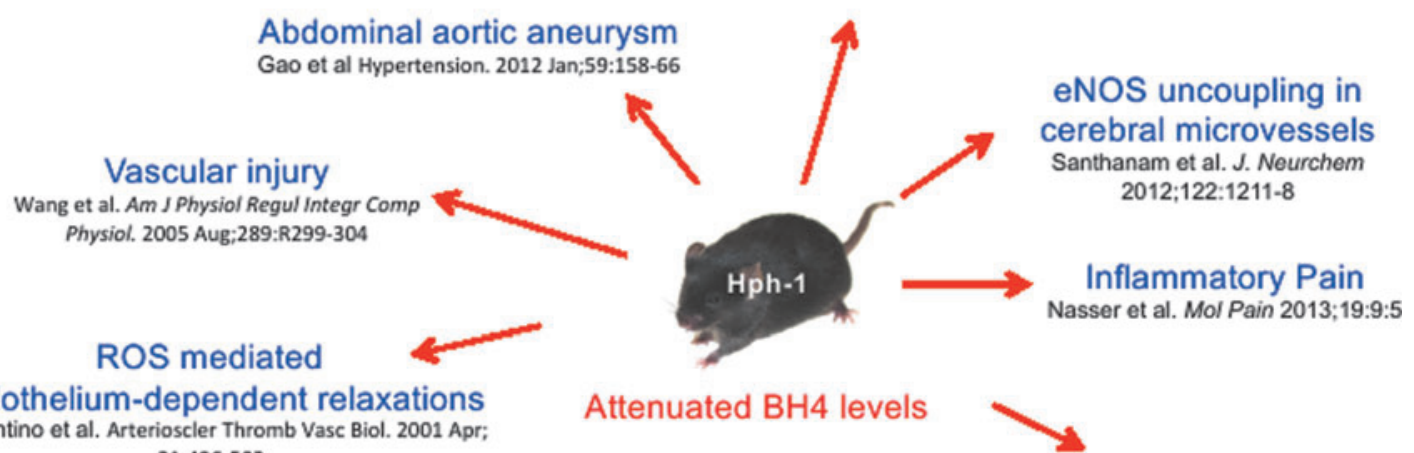
21:496-502.

Hypoxic pulmonary vasoconstriction

Efrancis et al. Eur Respir J. 2010 Aug:36:323-30

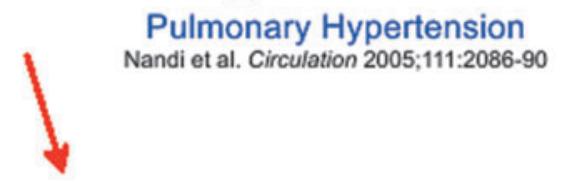

Pulmonary hypertension

Khoo et al. Circulation 2005;111:2126-33.

FIG. 7. The Hph-1 mouse model of BH4 deficiency. The Hph-1 mouse model of BH4 deficiency has been used in a number of studies to illustrate the importance of BH4 in various vascular disease states. To see this illustration in color, the reader is referred to the web version of this article at www.liebertpub.com/ars 
ROS such as $\mathrm{H}_{2} \mathrm{O}_{2}$ and $\mathrm{ONOO}^{-}$increase $\mathrm{GCH}$ expression in a concentration-dependent manner, leading to an increase in cellular BH4 levels after a transient decrease (243). $\mathrm{H}_{2} \mathrm{O}_{2-}$ mediated induction of GCH has been shown to be mediated, in part, by the JAK2-Stat1 pathway (244), and it is implicated in endothelial cell growth, proliferation, and survival (282). Numerous studies have shown that $\mathrm{GCH}$ expression is increased by inflammatory cytokines such as TNF- $\alpha$ (222) and pathogen-associated stimuli such as LPS (297), discussed in greater detail later in this review. Laminar shear stress is an important regulator of basal NO production within the vessel, and it acts as a stimulus to increase vasorelaxant production in response to increased blood flow. Laminar but not oscillatory shear stress has been shown to increase GTPCH protein expression, cellular $\mathrm{BH} 4$ and prevent eNOS uncoupling $(154,317)$. As previously discussed, GFRP has been shown to be a negative regulator of GTPCH activity. GFRP has an important regulatory role in endothelial cells-in vitro studies in HUVEC have shown that GFRP modulates phosphorylation of GTPCH and BH4 levels. In these cells, laminar shear stress promotes the dissociation of GFRP from GTPCH, elevated phosphorylation resulting in increased enzymatic activity, and, subsequently, $\mathrm{BH} 4$ production (154). In vivo models have confirmed a critical role for GTPCH in the response to shear stress-Oscillatory shear stress decreases phosphorylation of GTPCH and decreases $\mathrm{BH} 4$ levels (154). In contrast, increased vascular flow in vivo has been shown to increase $\mathrm{GCH} 1$ expression, BH4 levels, and eNOS expression (147). Increased $G C H 1$ expression in response to flow is critical to maintain normal vascular function by optimizing the generation of NO from eNOS, preventing eNOS uncoupling, the production of $\mathrm{O}_{2}{ }^{-}$, and further diminished NO bioavailability.

The importance of $\mathrm{BH} 4$ availability in disease conditions has been highlighted within conditions such as diabetes. In the coronary artery endothelial cells from diabetic rats, eNOS levels remain unchanged; however, NO production is decreased compared with endothelial cells from nondiabetic rats. This diminished production of $\mathrm{NO}$ can be restored by the supplementation of BH4 (175). Reduced vascular BH4 levels have also been shown in other experimental animal models of vascular disease such as the spontaneously hypertensive mouse (113), DOCA salt-induced hypertension (148), spontaneously hypertensive rats (150), STZ-induced diabetes (29), insulin-resistant fructose-fed rats (245), and in arteries from models of aging $(248,332)$. However, it is not just the level of $\mathrm{BH} 4$ that is critical-studies also suggest that the ratio of $\mathrm{BH} 4$ to $\mathrm{BH} 2$ can also have a significant impact on eNOS function. Increasing cellular $\mathrm{BH} 2$ levels in the presence of a constant eNOS:BH4 ratio have been shown to be sufficient to induce eNOS uncoupling (20). It has been suggested that since the $\mathrm{Km}$ values of $\mathrm{BH} 4$ and $\mathrm{BH} 2$ are similar for eNOS, BH2 may compete with $\mathrm{BH} 4$ for the binding site (43). Thus, significant eNOS uncoupling in disease may still be observed in parallel with no change in absolute BH4 levels if $\mathrm{BH} 2$ accumulation becomes excessive.

The importance of eNOS in the vasculature is highlighted by the finding that both pharmacological $(214,253)$ and genetic $(118,142,286)$ inhibition of eNOS activity results in elevated blood pressure. Evidence for eNOS uncoupling has been observed in animal models of impaired vascular function; for example, in mesenteric arteries from young versus old mice (332), hyperlipidemic mice (149), stroke-prone SHR rats (136), angiotensin-II-induced hypertension (183), DOCA-salt hypertension (148), and streptozotcin-induced diabetes (110).

eNOS uncoupling has also been observed in clinical conditions that are commonly associated with impaired endothelial cell function - saphenous veins and internal mammary arteries from patients with diabetes mellitus have increased endothelial-dependent $\mathrm{O}_{2}{ }^{-}$production compared with nondiabetic controls. This enhanced $\mathrm{O}_{2}{ }^{-}$production was, in part, inhibited by the NOS inhibitor N(G)-nitro-L- arginine methyl ester (L-NAME), indicating NOS uncoupling. Critically, the NOS-dependent $\mathrm{O}_{2}{ }^{-}$production could be inhibited by incubation with sepiapterin, indicating a role for $\mathrm{BH} 4$ in regulating eNOS coupling (95). In vascular tissue obtained during coronary artery bypass graft surgery, decreased vascular BH4 content is associated with increased NOS-dependent $\mathrm{O}_{2}{ }^{-}$production and attenuated endothelial-dependent relaxation (6).

Given the information indicating the pathological consequences of reduced BH4 levels, animal studies have aimed at determining whether vascular disease states can be improved by increasing vascular GCH expression. The treatment of Zucker fatty rats with adenovirally delivered $\mathrm{GCH}$ plasmid has been shown to improve aortic $\mathrm{GCH}$ expression and $\mathrm{BH} 4$ levels, and this was associated with improved endothelialdependent relaxation, decreased aortic $\mathrm{O}_{2}{ }^{-}$levels, and augmented eNOS activity (246). Mice that overexpress GCHI specifically within the endothelial cell layer (GCH-Tg mice) have been used to investigate the effects of increased endothelial BH4 on vascular function. GCH-Tg mice have significantly elevated aortic BH4 and eNOS activity, as measured by arginine to citruline conversion (60). In healthy animals, no difference in $\mathrm{O}_{2}{ }^{-}$production is detected between GCH-Tg mice and their WT littermates; however, in disease states such as diabetes, atherosclerosis, and DOCA saltinduced hypertension (326), GCH-Tg mice show significantly decreased ROS production versus WT mice. In diabetic mice and in the apolipoprotein E knockout mouse model of atherosclerosis (ApoE ${ }^{-/-}$mice) (5), overexpression of GCH-Tg is associated with reversal of diabetes and atherosclerosisinduced endothelial dysfunction (14). Improved endothelial function is observed in GCH-Tg mice, which also have a significant abrogation of hypertension in response to DOCA salt compared with the control group (326). Endotheliumspecific overexpression of GCHI has also been shown to reverse the pulmonary hypertension in hph-1 mice (137). Endothelial-specific overexpression of GCH has been shown to not alter blood pressure compared with WT littermates, thus indicating that in healthy vessels with normal vascular function, increasing vascular BH4 levels is not a potential hazard and is unlikely to cause aberrant hypotension (1). A summary of studies showing the importance of the GCH-Tg mouse is depicted in Figure 8.

\section{B. Role of $\mathrm{NO}$ and $\mathrm{BH} 4$ in endothelial cell proliferation and survival}

eNOS, or NO-mediated signaling pathways have been demonstrated to regulate endothelial progenitor cell (EPC) mobilization and function, participating in vasculogenesis by differentiating into endothelial cells and enhancing 


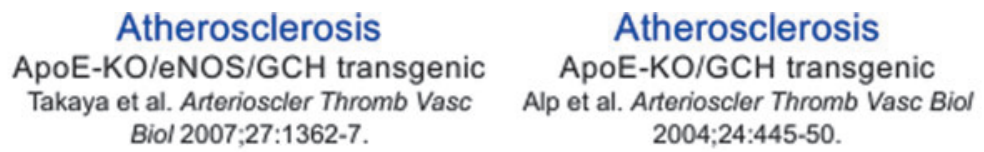

Biol 2007;27:1362-7.

\author{
Atherosclerosis \\ ApoE-KO/GCH transgenic \\ 2004;24:445-50.
}

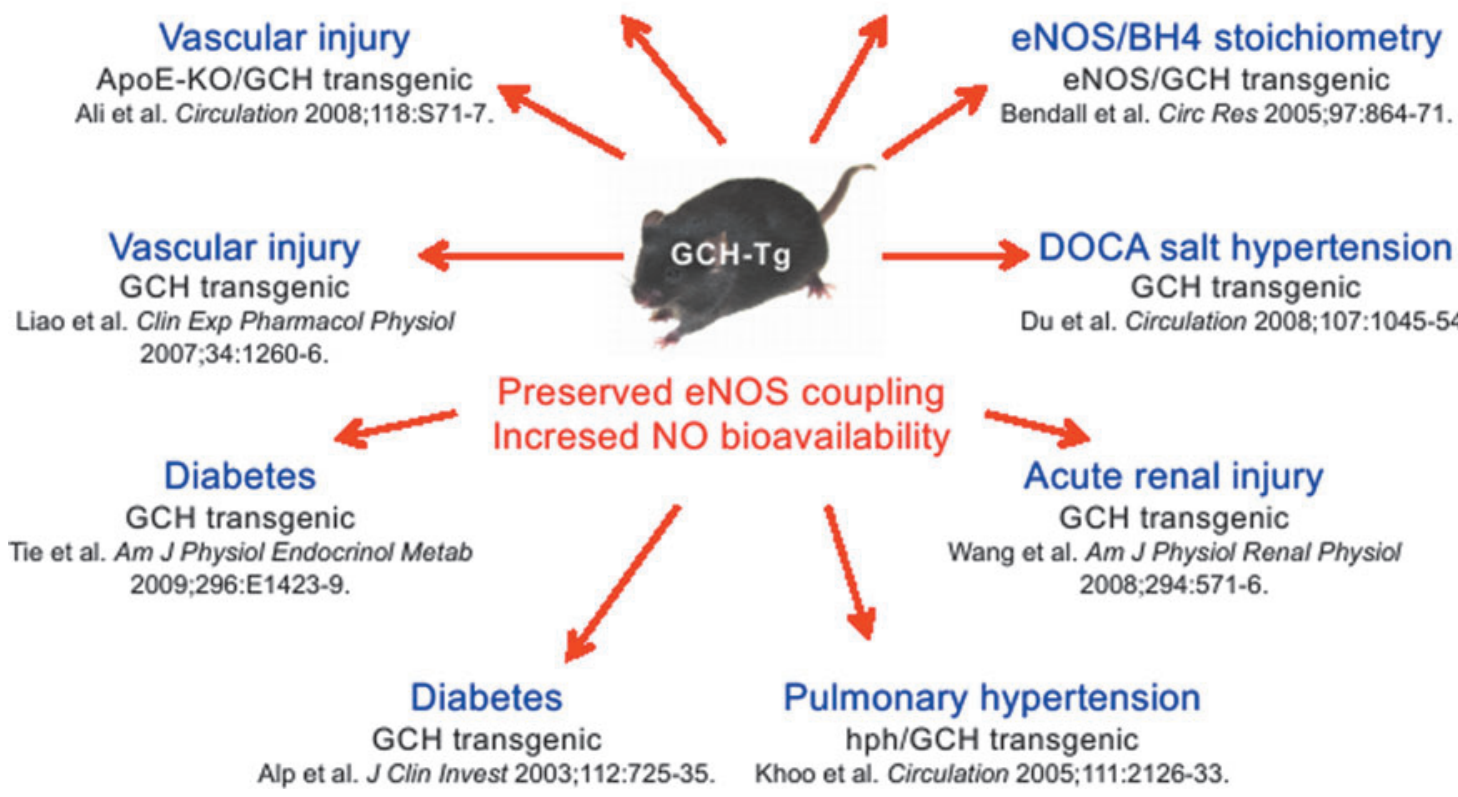

FIG. 8. The GCH transgenic mouse. Endothelial-specific GCH overexpression in the GCH transgenic mouse has been shown to be sufficient to restore eNOS coupling and NO bioavailability in various vascular disease states. To see this illustration in color, the reader is referred to the web version of this article at www.liebertpub.com/ars

angiogenesis under ischemia. Several recent studies indicate that the number of EPCs may serve as a surrogate marker for cardiovascular risk, affecting the progression of cardiovascular diseases, including hypertension. Re-endothelialization has been shown to be a key event in vascular repair after vascular injury $(89,164,255)$, reducing the risk of thrombosis and the development of neointimal hyperplasia; whereas accelerated endothelial cell apoptosis and endothelial denudation are linked to the formation of thrombotic atherosclerotic plaques $(162,265)$.

eNOS and NO have been shown to mediate VEGF-induced endothelial cell proliferation $(153,200)$ and angiogenesis $(185,200)$ and to play a critical role in the prevention of endothelial cell senescence $(196,279)$ and apoptosis (58, $131,224,322)$. These critical roles of eNOS in endothelial cell growth and survival also implicate $\mathrm{BH} 4$ in angiogenesis. There is increasing evidence that $\mathrm{BH} 4$, as an essential eNOS cofactor, improves endothelial cell proliferation $(81,87,165$, $241)$ and tube formation $(81,87)$. In vitro supplementation with the BH4 precursor sepiapterin has been shown to enhance proliferation in coronary endothelial cell from diabetic rats (165), bovine aortic endothelial cells (241), and HUVEC (87). These effects may be mediated by either a direct antioxidant effect of BH4 or/and improved eNOS function with increased NO availability and reduced production of ROS. Indeed, eNOS uncoupling impairs EPC number and function in diabetes and in the $\mathrm{GCH}$ transgenic mouse, endothelial BH4 augmentation reduces neointima formation that is induced by vascular injury with endothelial denudation (148). Moreover, EPC number is decreased and angiogenesis is impaired in both the hph-1 and DOCA-salt mouse models, which can be rescued by endothelial overexpression of
GTPCH in GCH-Tg mice (326). In genetic models of colon cancer, GTPCH inhibition either by DAHP or by GCHtargeted siRNAs markedly attenuated tumor cell proliferation and survival, as well as inhibited tube formation of HUVEC in response to hypoxia (204).

These studies provide important evidence that BH4 is not only critical for the effects of NO on vascular reactivity, but also BH4 plays a key role in other functions of NO and NOmediated pathways such as the formation of new blood vessels and the proliferation of endothelial cells within the vasculature; thus, the benefits of $\mathrm{BH} 4$ supplementation on the vasculature may be, at least in part, due to its pro-vasculaogenic or pro-angiogenic effects.

\section{Sepsis}

In contrast to the benefit of increasing $\mathrm{BH} 4$ to offset the pathological effects of restricted endothelial bioavailability in the context of vascular disease, under conditions of septic shock, restricting the availability of $\mathrm{BH} 4$ may be beneficial. Within intensive care medicine, septic shock is a leading cause of mortality (202). Sepsis is a systemic inflammatory reaction to bacterial products and endotoxins such as LPS. The presence of LPS and the cardinal cytokines induced by this potent pro-inflammatory mediator (IL-6, TNF- $\alpha$, and IFN $\gamma$ ) cause a widespread induction of iNOS, including within the vessel wall (138). This induction of iNOS expression within the vascular system, particularly within endothelial cells and smooth muscle cells, is associated with a profound hypotension that can be largely refractory to aggressive fluid resuscitation and treatment with cardiac inotropes and vasopressors (55). 
The role of BH4 is mediating septic pathology by iNOS has been highlighted by a number of studies. The addition of LPS to ex-vivo rat aorta was shown to cause a strong induction of both iNOS and GCH1 mRNA and biopterins, and to cause the generation of an L-Arg inducible relaxation in vessel rings, which could be prevented using DAHP (240). In a model of Staphylococcus aureus postburn sepsis, rat $\mathrm{GCHI}$ mRNA was induced in multiple tissues and significantly correlated with multiple organ dysfunction (240). Septic patients have been shown to have significant elevations in plasma biopterins as well as nitrites and nitrates (115). A similar pattern is seen in LPS-treated rats, and is reduced when following plasma endotoxin adsorption onto polymyxin B fibers (115).

Strategies to reduce $\mathrm{BH} 4$ availability in animal models have been assessed as potential interventions to limit the profound hypotension seen in septic patients. Treatment of rats with the GTPCH inhibitor 2,4-Diamino-6-hydroxyoyrimidine (DAHP) reduces plasma nitrate and nitrite levels and nitric oxide production in response to LPS treatment (27), coincident with reduced biopterin levels. This intervention was sufficient to reduce the degree of hypotension seen at $6 \mathrm{~h}$ after LPS administration.

The use of a 4-amino analogue of BH4 (4-ABH4), which acts as a competitive inhibitor of $\mathrm{BH} 4$ binding to NOS, improves survival in a 6 day model of endotoxaemia, being more potent than the NOS inhibitor NMMA (13). Follow-up studies using 4-ABH4 observed improvements in cardiac index and stroke volume, but did not reproduce the positive effects on blood pressure (73). However, 4-ABH4 reduced LPS-induced damage to liver, lung edema, and intestinal necrosis.

The disconnect in these studies between effects on survival and on hypotension may be due to opposing local effects in the microcirculation. Perturbation of organ microcirculation or local deficiency of $\mathrm{NO}$ within the microcirculation causes hypoperfusion, exacerbates organ failure, and can manifest as a worsening of outcome following strategies to inhibit NO production in sepsis (160). This phenomenon would, in contrast to the original rationale for targeting nitric oxide production in sepsis, support local supplementation of nitric oxide function. To address whether $\mathrm{BH} 4$ has any potential to cause a positive modification of sepsis through effects on the microcirculation, tetrahydrobiopterin supplementation in an ovine model of peritoneal sepsis has been evaluated. Sheep received two bolus treatments with $\mathrm{BH} 4$ during the induction of sepsis through an injection of fecal material into the peritoneum (101). BH4 treatment, in addition to attenuating the decreases in cardiac index and blood pressure, maintained small vessel perfusion and microvascular flow index. Increased survival in the BH4-treated animals was accompanied by preserved gas exchange and kidney function (101).

These data underline that nitric oxide biology in sepsis is complex, but that achieving the right balance between reducing hypotension, while maintaining organ microcirculation may have significant therapeutic potential in the treatment of septic patients.

\section{BH4 therapy}

Given the evidence for a critical role of $\mathrm{BH} 4$ in vascular function, it is unsurprising that studies supplementing BH4, by either genetic or pharmacological means, have shown improvements in vascular function (Table 1).

Treatment with $\mathrm{BH} 4$ has been shown to reverse the disease-related redox disequilibrium observed with $\mathrm{BH} 4$ deficiency. For example, high glucose treatment of human aortic endothelial cells results in the uncoupling of eNOS and profound $\mathrm{BH} 4$ oxidation, both of which were reversed after transfection with GCH1 DNA. (29). Similarly, in isolated vessels, incubation with $\mathrm{BH} 4$ improves endothelial functionisolated coronary arterioles from pigs fed a high-fat diet, versus

Table 1. Overview of Current Translational Studies That Demonstrate the Potential of BH4 Therapy in Vascular Disease

\begin{tabular}{lll}
\hline Setting & & Effect \\
Hypercholesterolemia & & $(256)$ \\
Hypercholesterolemia & & $(79)$ \\
Coronary artery disease & & $(163)$ \\
Chronic smokers & & $(105)$ \\
Long-term smokers & Prevents endothelial dysfunction & $(280)$ \\
Coronary risk factors & & $(233)$ \\
Angina & & $(78)$ \\
Chronic heart failure & & $(124)$ \\
Glucose challenge & & $(109)$ \\
Aging & & $(172)$ \\
Ischemia reperfusion & Improves flow mediated dilatation \\
Aging & Improves arterial compliance & $(66)$ \\
Aging & Prevents erectile dysfunction & $(206)$ \\
Erectile dysfunction & Does not improve endothelial function & $(320)$ \\
Atherosclerosis & Augments endothelium-dependent vasodilatation & $(108)$ \\
Hypertension & Prevents endothelial dysfunction and decreases arterial blood pressure \\
Hypertension & Prevents endothelial dysfunction and decreases oxidative stress & $(210)$ \\
Hypercholesterolemia & Improves dysfunction of coronary microcirculation & $(41)$ \\
Hypercholesterolemia & Increases insulin sensitivity but does not improve endothelial function \\
Type 2 diabetes & Prevents endothelial dysfunction & $(324)$ \\
Type 2 diabetes & & $(193)$ \\
\hline
\end{tabular}


pigs fed standard chow show a significant improvement in endothelial-dependent relaxation on incubation with sepiapterin (277). Treatment of arteries from both streptozotcin-induced diabetic rats (205) and spontaneously hypertensive rats $(94,113$, 191) with BH4 ex vivo improves endothelial dependent relaxation but does not affect relaxation of control vessels. Incubation with $\mathrm{BH} 4$ has also been shown to increase NO production by aortas from DOCA-salt hypertensive mice (336). Studies utilizing diseased arteries and veins from patients have also demonstrated beneficial effects of acute ex vivo incubation with BH4-. Coronary arterioles from patients with coronary artery disease have significantly reduced endothelial-dependent relaxation compared with controls (aortic value replacement patients), which could be increased in arteries from atherosclerotic patients by treatment with sepiapterin (277). This finding was confirmed by a second study which showed that mammary arteries and saphenous veins from patients with coronary artery disease demonstrated a significant improvement in endothelial-dependent relaxation after exposure to $\mathrm{BH} 4$ (296).

1. Animal models of chronic $\mathrm{BH} 4$ supplementation. Chronic BH4 treatment has been shown to reduce angiotensin-II-induced hypertension and endothelial dysfunction $(130,133)$, and to decrease blood pressure while improving endothelial-dependent relaxation in SHR rats (113). Renal failure-induced hypertension, due to partial nephrectomy, has also been shown to be reduced with chronic BH4 treatment $(166,329)$, which promotes an increase of resistance artery eNOS protein expression levels (166). Chronic BH4 treatment also improves metabolic endothelial dysfunction-improving endothelial function in insulinresistant fructose fed rats $(245,300)$ and the ob/ob mouse model of obesity (148). Improved endothelial-dependent relaxation was also observed in hyperlipademic $\mathrm{ApoE}^{-1-}$ mice, along with an attenuation of aortic $\mathrm{O}_{2}{ }^{-}$levels and decreased expression of $\mathrm{O}_{2}{ }^{-}$generating NADPH oxidase (Nox2) (99).

Not all studies have shown that chronic BH4 therapy improves blood pressure and endothelial function. Indeed, chronic oral treatment with BH4 neither altered blood pressure in $\mathrm{ApoE}^{-1-}$ mice (226) nor reduced the hypertension observed in fructose-fed rats (300), although improved endothelial function was observed. This could, in part, be due to the use of eNOS-derived $\mathrm{H}_{2} \mathrm{O}_{2}$ from uncoupled NOS as an endothelial-dependent vasodilator. A shortage in vascular BH4 may shift the balance from the use of eNOS-derived NO to eNOS-derived $\mathrm{H}_{2} \mathrm{O}_{2}$ as vasodilators. In the hph-1 mouse, endothelial-dependent relaxation was found to be abolished by inhibition with L-NAME; however, this relaxation was also inhibited by the $\mathrm{H}_{2} \mathrm{O}_{2}$ scavenger catalase and was enhanced by superoxide dismutase, presumably due to the conversion of $\mathrm{O}_{2}{ }^{-}$to $\mathrm{H}_{2} \mathrm{O}_{2}(40) . \mathrm{H}_{2} \mathrm{O}_{2}$-mediated relaxation was found to be inhibitable by L-NAME in rabbit aortic rings (338) and in rat aorta (333). In canine arteries, incubation with DAHP (to inhibit GTPCH) significantly reduced endothelial-dependent vasodilatation, indicating a dependence on $\mathrm{H}_{2} \mathrm{O}_{2}$ as a vasodilator (38). In DOCA salt-induced hypertension, endothelial-dependent relaxation also appears to be mediated, at least in part, by $\mathrm{H}_{2} \mathrm{O}_{2}$ derived from uncoupled NOS (148). Care should be taken in the interpretation of these studies - due to the near diffusion reaction rate between NO and superoxide, it is unlikely that eNOS produces solely $\mathrm{H}_{2} \mathrm{O}_{2}$, and catalase has recently been shown to decompose peroxynitrite (85), which provides a constant "peroxide tone" (12) through its action on cyclooxygenase.

The relative contribution of $\mathrm{NO}$ or $\mathrm{H}_{2} \mathrm{O}_{2}$ to vasorelaxation may be, in part, determined by eNOS protein levels - in the early stages of hypertension, there is a compensatory increase in eNOS levels due to decreased NO production resulting from increased ROS production (61), leading to an elevation in $\mathrm{NO}$ synthesis in the presence of $\mathrm{BH} 4$, or $\mathrm{H}_{2} \mathrm{O}_{2}$ in the absence of sufficient $\mathrm{BH} 4$. In more advanced disease where $\mathrm{BH} 4$ is limiting and hence a greater proportion of eNOS is uncoupled, this $\mathrm{O}_{2}{ }^{-}$production could become pathological and, thus, lead to the down-regulation of eNOS expression as a compensatory mechanism to decrease the pathological production of ROS.

2. Clinical studies of acute $\mathrm{BH} 4$ supplementation. Clinical studies have used acute pharmacological BH4 supplementation to assess whether treatment with $\mathrm{BH} 4$ has the capacity to reverse endothelial dysfunction. Treatment of $\mathrm{BH} 4$, either orally or by infusion, usually through the brachial artery has marked positive effects on endothelium-dependent vasodilatation and vessel relaxation in several models $(66,105,108,109,124,206,256,280)$. For example, in chronic smokers, acute BH4 administration improves endothelial-dependent relaxation (280) and in patients with type II diabetes, an augmented acetylcholine-mediated dilation after infusion of the brachial artery with BH4 $(500 \mu \mathrm{g} /$ min) is observed. Furthermore, BH4 improved the postprandial endothelial-dependent vasodilatation in healthy subjects after an oral glucose challenge (124). In the heart, coronary artery infusion of $\mathrm{BH} 4$ in patients with coronary artery disease $(79,163,233,320)$, chronic heart failure (234), and vasospastic angina (78) has been shown to improve acetylcholine response in the coronary artery.

There are several unifying features of these studies that are of concern and should be considered. These studies of acute supplementation of $\mathrm{BH} 4$ are done with super-physiological concentrations of $\mathrm{BH} 4$, which are much higher than those found in healthy subjects and patients with atherosclerosis, which may mean that $\mathrm{BH} 4$ has nonspecific effects other than those purely of an NOS cofactor (6). The beneficial effects of $\mathrm{BH} 4$ are also not sustained and often disappear a few minutes after withdrawal of exogenous BH4. This is surprising, as it would be expected that if vasodilatation is determined by eNOS coupling, and the beneficial effects observed are through the restoration of eNOS-derived NO production, then the effects of BH4 on vasodilatation would be prolonged. BH4 is a potent antioxidant, and it may also be possible that these improvements could be due to the anti-oxidant capacity of BH4 rather than its role as an NOS cofactor. This is supported by a study in healthy volunteers which shows that acute beneficial effects of $\mathrm{BH} 4$ may be due to scavenging of ROS - this study found no effect of BH4 on acetycholinemediated dilation at baseline; however, ischemia reperfusion (which is associated with increased ROS)-induced decreases in dilation responses to acetylcholine can be rescued by the infusion of BH4 $(500 \mu \mathrm{g} / \mathrm{min})$. This dilatory response could be restored by both $6 \mathrm{R}$ - and $6 \mathrm{~S}-\mathrm{BH} 4$, as well as by amino$\mathrm{BH} 4$ (NH4) that has the same ROS scavenging capacity as $\mathrm{BH} 4$ while being unable to catalyze the production of NO, 
thus indicating that the improvement observed in this study was likely due to the scavenging of ROS (172).

Most attention for the investigation of $\mathrm{BH} 4$ in the cardiovascular system focuses on how alterations in BH4 levels or oxidation state alter eNOS function. However, more recent evidence has also shown that nNOS may also have a role in maintaining basal vascular NO production (230). It is, therefore, relevant to consider that $\mathrm{BH} 4$ may both enhance agonist-induced vasodilatation via eNOS and improve basal nitric oxide production via its action on nNOS.

3. Clinical studies of chronic BH4 supplementation. The breadth of preclinical and acute clinical data implicating $\mathrm{BH} 4$ as a key regulator in endothelial function suggests that oral $\mathrm{BH} 4$ therapy may be able to prevent or treat cardiovascular disease. Although acute studies have provided valuable data on the role of BH4 in vascular health and disease states, these studies do not inform us of the efficacy of BH4 treatments after chronic administration. Long-term studies of $\mathrm{BH} 4$ have been hampered by its chemical instability; however, a recent preparation of oral $\mathrm{BH} 4$ has been developed by BioMarin, which has significantly improved stability at room temperature compared with $\mathrm{BH} 4$ available from other sources (152). This new preparation could potentially make future longerterm studies of BH4 more viable.

Chronic treatment with $\mathrm{BH} 4$ has been shown to improve hypertension. Hypertensive subjects receiving 5 or $10 \mathrm{mg} /$ $\mathrm{Kg}$ /day for 8 weeks, or 400 but not $200 \mathrm{mg} / \mathrm{Kg} /$ day for 4 weeks showed a significant decrease in blood pressure and improved endothelial function. However, care should be taken when interpreting these results, as this was a relatively small study (8-16 patients per group) and did not have a placebo control (210). In hypercholesterolaemic patients (low-density lipoprotein, LDL $>4.5 \mathrm{~m} M$ ), 4-week oral treatment with BH4 (400 mg twice daily) or placebo (11 BH4 vs. 10 placebo) significantly improved endothelial-dependent vasodilatation (41). The oxidative stress marker $8-\mathrm{F}_{2}$ isoprostane was decreased in the plasma of BH4-treated patients. BH4 therapy (dose escalation $2.5-20 \mathrm{mg} / \mathrm{kg}$ ) has also been found to improve 6 min walking distance in patients with pulmonary hypertension at doses more than $5 \mathrm{mg} / \mathrm{kg}$, although care should be taken, as this study was primarily designed to address safety, not efficacy and no placebo was used (220).

A recent randomized placebo-controlled trial of oral $\mathrm{BH} 4$ in patients with coronary artery disease has shown no benefit of BH4 therapy (50). In this study, treatment with low (400 mg/day) or high $(700 \mathrm{mg} /$ day) BH4 for 2-6 weeks did not alter arterial stiffness, endothelial-dependent relaxation, or $\mathrm{O}_{2}{ }^{-}$production. Treatment with $\mathrm{BH} 4$ significantly increased plasma and saphenous vein BH4 levels; however, it also significantly increased levels of the oxidized pterin product $\mathrm{BH} 2$ that lacks eNOS cofactor activity. Thus systemic oxidative stress may play a critical role in determining the degree of oxidation of $\mathrm{BH} 4$ to $\mathrm{BH} 2$ and, hence, the ratio of $\mathrm{BH} 4: \mathrm{BH} 2$ and the efficacy of the treatment (50).

A discordance has been shown between plasma BH4 levels and endothelial function, with increased plasma BH4 levels being associated with decreased endothelial-dependent relaxations (6). This indicates a differential regulation of plasma and vascular BH4 levels. Total biopterins, including all oxidized species, have been shown to be correlated with the inflammatory biomarker C-reactive protein (CRP) (6). This is interesting, as multiple studies have shown that the stimulation of primary endothelial cells with inflammatory cytokines such as TNF- $\alpha$, INF- $\gamma$, and/or pathogen-associated stimuli such as LPS results in increased GCH expression and, therefore, GTPCH protein activity and increased BH4 levels $(222,316)$. However, as previously discussed, many vascular disease states are associated with reduced vascular BH4 levels. It could be that systemic inflammation leads to a cytokine-induced increase in plasma BH4 levels, whereas inflammation within the vessel wall may result in loss of $\mathrm{BH} 4$, possibly due to oxidation by ROS.

\section{E. Alternative strategies to increase $\mathrm{BH} 4$}

Studies discussed in the previous section have used chronic supplementation with $\mathrm{BH} 4$ to re-couple NOS and improve vascular function. However, there are alternative pharmacological approaches that may reverse eNOS uncoupling by preventing $\mathrm{BH} 4$ oxidation, increasing $\mathrm{BH} 4$ biosynthesis, or augmenting the regeneration of $\mathrm{BH} 4$ from $\mathrm{BH} 2$.

In HUVECs, treatment with fluvastatin and cerivastatin increases GTPCH mRNA and intracellular BH4 levels (98). In STZ-induced diabetic rats, atorvastatin results in an increased expression of $\mathrm{GCH}$ and normalized vascular dysfunction (307). In rats, treatment with simvastatin has been shown to increase GTPCH activity, BH4 production, and nitric oxide levels in the kidney-clip model of hypertension (340). In patients with cardiovascular disease, atrovastatin has been shown to improve flow-mediated dilation in association with an increase in plasma $\mathrm{BH} 4 / \mathrm{BH} 2$ ratio (269). Patients with coronary artery disease treated with atrovastatin have increased vascular $\mathrm{BH} 4$ levels, improved vascular nitric oxide bioavailability, and reduced vascular $\mathrm{O}_{2}{ }^{-}$; while ex vivo atrovastatin was found to increase GTPCH expression and activity, independently of its action on LDL (8). In $\mathrm{ApoE}^{-/-}$mice, treatment with resveratrol (a natural phenol) was associated with increased expression of $\mathrm{GCH}$, increased cardiac expression of $\mathrm{GCH}$, and a reversal of eNOS uncoupling (325).

Inhibition of Angiotensin I receptor has also been shown to increase GCH expression and to improve eNOS coupling. In STZ-induced diabetic rats, treatment with the AT-1 receptor antagonist telmisartan resulted in increased aortic expression of $\mathrm{GCH}$, decreased aortic $\mathrm{O}_{2}{ }^{-}$production, and improved endothelial-dependent vasodilatation (308). Treatment with the AT-1 receptor antagonist losartan has also been shown to increase serum $\mathrm{BH} 4$ levels and to increase $\mathrm{GCH}$ expression in the glomerulus of STZ-induced diabetic rats (225). Finally, exercise may also improve eNOS coupling by increasing $\mathrm{BH} 4$ levels-exercise was found to increase flow-stimulated nitric oxide production and to increase $\mathrm{BH} 4$ content in arteries from old rats versus old sedentary rats (248).

\section{BH4 in Vascular Inflammation and Atherosclerosis}

Atherosclerotic vascular disease is typified by the accumulation of lipid-laden macrophage foam cells in the arterial wall. The vascular endothelium at atherosclerosis prone sites shows increased expression of cell adhesion molecules. This expression supports the recruitment of mononuclear phagocytic cells to the vessel wall, where they accumulate oxidized lipids (68). The uptake of lipid causes cellular activation and 
further local inflammation within the vessel wall. This inflammation progresses through the production of cytokine and chemokine signals that cause the recruitment of further inflammatory cells, both monocytes and other leukocytes, including adaptive immune cells such as $\mathrm{T}$ lymphocytes (174). While atherosclerotic disease causes a defined local inflammation driven by the oxidized lipid, cytokine production, and cell death within the core of the plaque, atherosclerotic disease is also accompanied by systemic inflammation. Systemic inflammation has been linked to atherosclerosis not only in general terms, with the correlation of inflammatory biomarkers such as CRP with disease burden and risk $(132,218)$, but also as a specific driver of disease, as is demonstrated by the strong relationship of chronic inflammatory conditions such as arthritis and systemic lupus erythematosus with high disease risk and severe disease pathogenesis $(223,238)$. The complexities of how local and systemic aspects of inflammation are involved in the disease process are paralleled by the biology of $\mathrm{BH} 4$ in inflammatory vascular disease. While atherosclerotic sites are assumed to lack sufficient BH4, causing NOS uncoupling, many inflammatory signals up-regulate $\mathrm{BH} 4$ levels and systemic markers of the $\mathrm{BH} 4$ biosynthetic pathway, namely neopterin levels, are robustly elevated in CAD patients (228).

\section{A. Regulation of BH4 availability by inflammatory stimuli}

GTPCH gene and protein expression are induced by multiple inflammatory stimuli in many of the key cells types involved in cardiovascular inflammation, including endothelial cells, leukocytes, and smooth muscle cells $(92,312)$. BH4 biosynthesis is induced by inflammatory stimuli such as TNF- $\alpha$, LPS, and hydrogen peroxide $(134,242)$. Cytokine induction of $\mathrm{GCH} 1$ gene and GTPCH protein expression is minimal when individual cytokines such as TNF- $\alpha$, IL- 1 , or interferon- $\gamma$ are applied, but the application of cytokine cocktails causes robust induction of $\mathrm{BH} 4$ biosynthesis through elevations in GTPCH protein levels (117). This reliance on multiple activation pathways was shown to be due to a requirement for both $\mathrm{NF}-\kappa \mathrm{B}$ and STAT1 transcription factors (117). The use of knockout cells and specific inhibitors has demonstrated that activation of the cardinal proinflammatory transcription factor $\mathrm{NF}-\kappa \mathrm{B}$ alone does not cause GTPCH protein production, while signaling via the Jak/STAT pathway can cause some GTPCH production. The co-ordinated activation of both pathways was shown to cause robust elevations in biopterins.

While the association of BH4 production and iNOS induction, a hallmark of inflammatory M1 macrophages, has been studied in detail, the expression of GTPCH in other leukocyte subsets has been less fully explored. The recent observation is that a macrophage cell line could express AGMO, and that this enzyme may be controlling production of the important inflammatory mediator PAF (278). This study indicated that the down-regulation of AGMO by LPS resulted in a decreased metabolism of Lyso-PAF, meaning that more Lyso-PAF was available for conversion into PAF. Given that this regulation requires $\mathrm{BH} 4$ in macrophages before inflammatory activation (and resulting iNOS expression) indicates that the exploration of GTPCH expression and $\mathrm{BH} 4$ levels may reveal other NOS-independent roles for $\mathrm{BH} 4$ in macrophage biology. A recent study from the cancer field has shown that treatment of tumor-bearing mice with DAHP, thus inhibiting GCH1, resulted in an increase in CXCL10 and CCL5 in the plasma and a decrease in IL-10, hallmarks of a switch away from an M2 phenotype (204). This change in systemic markers was accompanied by a reduction in tumor macrophages of an M2-like phenotype. This study implicates that GTPCH may, indeed, have important roles in other cell types than in controlling iNOS activity in inflammatory M1 macrophages. Given this finding, more investigation of monocytes, the cells from which macrophages arise, may reveal altered expression and regulation in the different monocyte subpopulations $\mathrm{Ly}-6 \mathrm{C}^{\mathrm{HI}}$ and $\mathrm{Ly}-6 \mathrm{C}^{\mathrm{LO}}$, both of which have been implicated in experimental atherosclerosis models (116).

In addition to activation by these cardinal cytokines, $\mathrm{GCH} 1$ gene expression is also regulated within the adaptive immune system with induction by IL-2 or Phytohaemagglutin, both of which are potent inducers of lymphocyte activation and division, in T-cell lines (OVA) or human $\mathrm{T}$ cells $(227,343)$. Recent studies have shown that $\mathrm{BH} 4$ synthesis is also induced by T-cell activation via CD3 and the co-stimulatory signal (33). In addition to the regulation of $\mathrm{BH} 4$ levels through the control of GTPCH, pro-inflammatory signals can also modulate $\mathrm{BH} 4$ availability through the control of other elements of the biosynthetic pathway, such as PTPS, which is induced in endothelial cells by IL-1 beta or via GFRP, which is down-regulated in monocytic cells by LPS (77, 313).

\section{B. Regulation of BH4 levels in atherosclerosis}

Atherosclerotic disease occurs at sites of disturbed blood flow, typically in the curvature of vessels or at branching points $(125,188,189)$. In other sites, smooth laminar blood flow induces nitric oxide production, which has multiple anti-atherosclerotic functions such as suppressing adhesion molecule expression by endothelial cells, inhibiting platelet aggregation, and inhibiting inflammatory cytokine production (123). This protection is reduced or absent at atherosclerosis-prone sites. Laminar sheer stress has been shown to enhance tetrahydrobiopterin levels through phosphorylation of GTPCH protein (317). Oscillatory sheer stress, however, reduces this phosphorylation event, meaning that endothelial cells at atherosclerosisprone sites have lower intracellular BH4 content (154). In vivo studies using partial ligation of the left common carotid artery to model low and oscillatory sheer stress have demonstrated that NOS uncoupling occurs at sites of disturbed flow, as shown by reduced eNOS dimer formation and enhanced L-NAME inhibitable $\mathrm{O}_{2}{ }^{-}$production (155). This uncoupling was attributed to insufficient BH4 levels by the restoration of normal NOS function by tetrahydrobiopterin supplementation (155).

Genetic models of atherosclerotic disease such as the $\mathrm{ApoE}^{-/-}$mouse are typified by a chronic inflammation in the vessel wall that is associated with high levels of local oxidative stress (28). The induction of NADPH oxidases in multiple plaque cell types, including endothelial cells and macrophages, by plaque components such as oxidized LDL $(11,103)$ causes a high local production of ROS. The net effect of atherogenesis on cellular and tissue BH4 levels is the integration of competing stimuli that have well-defined 
positive and negative effects of $\mathrm{BH} 4$ availability. While proinflammatory stimuli can increase $G C H 1$ gene expression, oscillatory sheer stress decreases $\mathrm{GCH} 1$ gene expression, GTPCH enzymatic activity, and the increased oxidative stress within the vascular wall can cause an oxidative loss of BH4. Accordingly, contrasting findings are found in experimental tissues, possibly relating the stage and severity of disease. Since multiple plaque-derived cells are potential sources of $\mathrm{BH} 4$, the relative contribution of each may vary according to local plaque biology.

When $\mathrm{BH} 4$ levels and those of the oxidized form $\mathrm{BH} 2$ are studied in young versus older animals, disease burden increases total biopterin levels in many tissues such as the lung and heart, as would be expected given the induction tetrahydrobiopterin by inflammatory stimuli (281). BH4 levels are unchanged, whereas there is a dramatic increase in $\mathrm{BH} 2$ levels (281). This demonstrates increased oxidation of BH4 and thus a loss of the NOS-catalyzing form of the molecule. The up-regulation of tetrahydrobiopterin in atherosclerotic disease has also been addressed in the diseased organ itself (52). When BH4 levels, GTPCH protein, activity, and gene expression are measured in the aorta, all are increased as the animal ages and the disease progresses. This time-dependent regulation of aortic BH4 is not seen in normal C57bl6/J animals till 14 months of age. In this study, no increased level of oxidized biopterins was seen in the older diseased animals. Removal of the endothelium demonstrates that medial $\mathrm{BH} 4$ production is increased eight-fold in $\mathrm{ApoE}^{-1-}$ animals, whereas $80 \%$ of the aortic $\mathrm{BH} 4$ production is localized to the endothelial cell layer in normal mice (52). Contrastingly, Ozaki et al. showed a $50 \%$ loss of aortic BH4 in fat-fed $\mathrm{ApoE}^{-1-}$ compared with WT mice (197). These data on high-fat-fed $\mathrm{ApoE}^{-1-}$ mice show a far less dramatic regulation of $\mathrm{BH} 4$ levels by atherosclerosis than the findings in rabbits fed a high-fat diet for 10 weeks (291). In that study, aortic segments from lipid-fed animals showed a 27 -fold decrease in $\mathrm{BH} 4$ levels and an increase in the $\mathrm{BH} 2$ content from $30 \%$ of total biopterins to $63 \%$ and were associated with marked alterations in ex vivo vascular function.

To assess the degree to which $\mathrm{BH} 4$ levels are negatively affected by oxidative stress in atherosclerotic disease, studies of long-term supplementation with Vitamin $\mathrm{C}$ have been undertaken in wild-type and $\mathrm{ApoE}^{-/-}$mice. These studies demonstrate that vitamin $\mathrm{C}$ could increase aortic $\mathrm{BH} 4$ availability in C57bl/6J mice. Decreased accumulation of oxidized biopterins in $\mathrm{ApoE}^{-1-}$ mice was also observed, although without a corresponding increase in aortic $\mathrm{BH} 4$ (268). However, the net effect was to improve the BH4 ratio. This improvement was accompanied by increased eNOS activity without an alteration in eNOS protein levels and a significant improvement in NO-mediated endotheliumdependent relaxations in the $\mathrm{ApoE}^{-/-}$animals.

Most of the existing atherosclerosis studies have been limited to experimental models of atherogenesis and disease progression. The Reversa mouse is a genetic model of atherosclerosis regression in which Apob ${ }^{100}$-driven hyperlipidemia can be reversed by inducible knockout of Mttp, thus switching off hepatic lipoprotein secretion (157). This model enables the effect of disease reversal to be elucidated. Normalizing hypercholesterolemia reduced impairment of endothelial function in ex vivo studies after prolonged periods of high-fat feeding (176). High-fat feeding in this model caused increased expression of GTPCH and reduced DHFR expression, and these changes were not seen when mice underwent a 6 month period of reversal compared with expression levels before reversal or in age-matched high-fat-fed controls (176). These data show that the changes in BH4 biosynthesis in atherosclerosis are not irreversible.

\section{The role of BH4 and NOSs in atherosclerosis}

BH4 availability can impact atherogenesis through the modulation of all three members of NOS enzymes. While eNOS is the predominant form of NOS detected in normal blood vessels, all forms of NOS are expressed in atherosclerotic vessels (319). A lack of eNOS in atherogenic models causes an exacerbation of disease and an increase in aortic lesion area, abdominal aneurysm, and cardiac fibrosis when mice are fed a high-fat diet (143). Despite the proatherogenic potential of uncoupled eNOS, $\mathrm{eNOS}^{-/-} / \mathrm{ApoE}^{-/-}$ mice demonstrate that eNOS has a net protective effect with these mice showing increased leukocyte-endothelial cell interactions, vascular cell adhesion molecule 1 (VCAM-1) expression, and macrophage infiltration into the vessel wall (209). Deficiency in $n N O S \alpha$ causes an exacerbation of disease, with increased lesion area seen in $\mathrm{ApoE}^{-1-} / \mathrm{nNOS}^{-1-}$ animals (144), although nNOS $\gamma$ expression remains, indicating a possible further function for nNOS in atherogenesis that cannot be studied using this partial knockout. In contrast to the protective roles of eNOS and nNOS, as seen by the exacerbation of disease in their absence, iNOS expression is deleterious in atherosclerotic disease. iNOS RNA and protein is reported in human atherosclerotic lesions (319), where its presence has been shown to co-localize with areas of lipid oxidation and protein nitration $(47,161)$. In experimental $\mathrm{ApoE}^{-1-}$ models of atherosclerosis, iNOS expression has been found to exacerbate disease, with iNOS ${ }^{-/-}$animals showing a decreased disease burden after high-fat feeding $(34,56,142,181)$. iNOS is expressed by multiple cell types within atherosclerotic plaque, including both macrophages and smooth muscle cells (161), with data from bone marrow chimera showing that iNOS expression by both leukocytes and parachenymal cells is proatherogenic (208). The proinflammatory role of iNOS has been ascribed to the high enzymatic output of nitric oxide, which can, in turn, react with ROS to produce damaging reactive nitrogen species (RNS). While a lack of iNOS expression has been shown to cause a decrease in 3-nitrotyrosine levels and lipid peroxidation after high-fat feeding (281) (142), the source of $\mathrm{O}_{2}{ }^{-}$ that is required to produce RNS is assumed to be traditional ROS-producing enzymes. More recent studies have shown that $\mathrm{O}_{2}{ }^{-}$production itself is reduced in the atherosclerotic vasculature when iNOS protein is acutely inhibited or absent (208). This provides some in vivo evidence that iNOS uncoupling may play a pathological role in vascular disease as an additional source of ROS. Given the opposing roles of NOS enzymes in disease pathogenesis and how the coupled and uncoupled forms of NOS alter output species, the regulation of BH4 availability is likely the key in controlling disease (Fig. 9).

Transgenic overexpression of eNOS in the endothelium has dramatically shown the importance of $\mathrm{BH} 4$ availability in vascular disease (197). In $\mathrm{ApoE}^{-/-}$mice harboring the transgene, rather than seeing a beneficial effect of increasing 
Endothelial Cells:

- BH4 maintains NO production by eNOS

- NO production from eNOS reduces leukocyte recruitment and maintains normal vascular function

- Sub-optimal levels of BH4 cause eNOS

- uncoupling leading to ROS production

- Plaque prone areas coincide with zones of eNOS uncoupling in experimental models

- BH4 levels increase in response to inflammation to preserve eNOS function

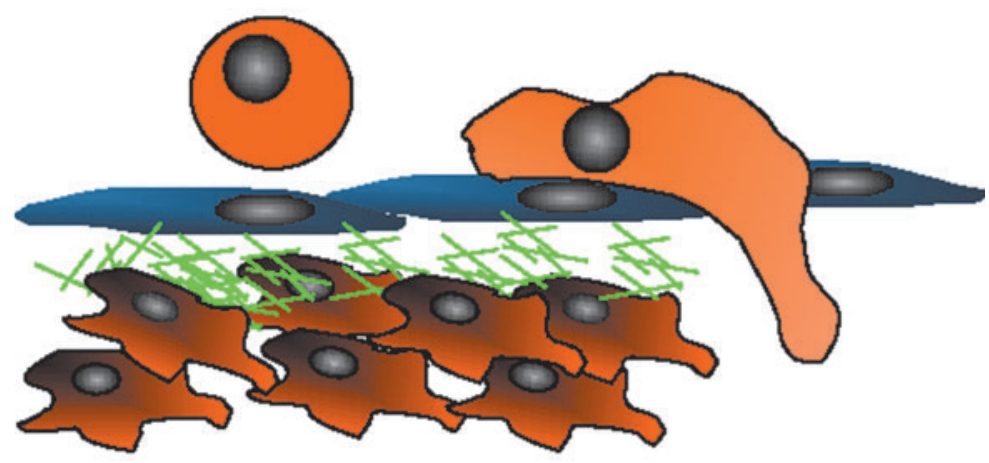

Monocyte/Macrophages:

- BH4 and iNOS induced by inflammatory stimuli.

- iNOS expression co-localised with lipid peroxidation in human atherosclerotic plaque.

- iNOS expression is pro-atherogenic in experimental models.

- NO production by iNOS allows production of inflammatory species such as peroxynitrite through reaction with ROS.

- Macrophage iNOS may serve as an additional source of ROS in atherosclerotic plaque

FIG. 9. Cell specific roles of BH4 and NOS isoforms in atherosclerosis. BH4 has distinct roles in different cell types that are implicated in atherosclerosis, in particular in endothelial cells (blue), and monocyte/macrophages (orange), which are recruited to atherosclerotic plaque and migrate into the vascular wall. The contrasting expression of eNOS in endothelial cells and inducible NOS (iNOS) in macrophages may lead to the opposing effects of BH4 deficiency in leukocytes and endothelial cells. To see this illustration in color, the reader is referred to the web version of this article at www.liebertpub .com/ars

expression of the "atheroprotective", eNOS molecule, a histological examination of the aortic root showed a two-fold or greater increase in plaque burden in both male and female animals. This was despite an evident decrease in blood pressure and an increase in NOS enzymatic activity. The involvement of uncoupling in this phenomenon is demonstrated by the absence of any increase in NO-producing activity in the aorta of eNOS transgenic mice and instead a 3.3-fold increase in aortic $\mathrm{O}_{2}{ }^{-}$production (197). That this pathological phenotype was driven by a disparity in NOS enzyme expression and available $\mathrm{BH} 4$ co-factor is underlined by the effect of crossing this mouse with one overexpressing $\mathrm{GCH}$ in the endothelium. The endothelial GCH transgenic mouse (GCH-Tg) has endothelial specific overexpression of the human GCH1 gene (14). When crossed with an ApoE ${ }^{-1-}$ mouse, the animals carrying the $\mathrm{GCH} 1$ transgene show both an increased aortic BH4 content and an improved ratio of BH4:total biopterins. These animals show the hallmarks of improved NOS function, namely reduced vascular $\mathrm{O}_{2}{ }^{-}$ production and improved vascular function. Atherosclerotic disease in these animals has been shown to be reduced by $28 \%$ in the aortic root. However, it is the cross of this animal with the eNOS transgenic that shows the power of $\mathrm{BH} 4$ to limit inflammation due to eNOS uncoupling (268). In these animals, the pathological effect of eNOS overexpression is completely reversed when GCH1 is co-expressed in the endothelium. Key figures from these very important reports are compared in Figure 10.

\section{BH4 supplementation in models of atherosclerosis}

The beneficial effects of BH4 mediated through eNOS have led to multiple studies attempting to "improve" eNOS function by enhancing BH4 availability using supplementation approaches. Short-term and acute protocols have been extensively used in vascular function studies, as discussed in the "BH4 in the vascular system" section, but some studies have addressed the ability of BH4 to modify vascular disease (Table 2).

The ability of exogenous BH4 to have positive effects on plaque biology has been shown by the increase in vascular $\mathrm{NO}$ production and reduced $\mathrm{O}_{2}{ }^{-}$levels when $\mathrm{ApoE}{ }^{-/-}$ eNOS overexpressing mice were supplemented with $10 \mathrm{mg} /$ $\mathrm{kg} /$ day BH4 (197). This study also demonstrated that BH4 supplementation could reduce plaque formation in $\mathrm{ApoE}^{-/-} /$ eNOS transgenic mice. While this study also showed some positive effect of $\mathrm{BH} 4$ supplementation on atherosclerosis in female $A p o E^{-1-}$ mice, it has been later studies that have probed the ability of $\mathrm{BH} 4$ to reduce atherosclerosis in the absence of NOS manipulation. Hattori et al. showed that supplementation with $10 \mathrm{mg} / \mathrm{kg} /$ day $\mathrm{BH} 4$ in drinking water caused both rescue of impaired acetylcholine-induced vasodilatation to wild-type levels and a reduction in lesion area in the aortic root by $25 \%$ (99). A similar study by Schmidt et al. showed that a pharmaceutical preparation of $10 \mathrm{mg} / \mathrm{kg} /$ day BH4 dosed daily by gavage also caused the expected attenuation of atherosclerotic disease seen in the earlier study (226). This study profiled the effect of BH4 supplementation on the inflammatory biology of atherosclerosis in greater detail showing decreased plaque macrophage and T-cell content as well as a supporting decrease in aortic VCAM-1 expression (226). Hattori et al. also described a positive modification of inflammatory gene expression, with reduced expression of adhesion molecules, MCP-1 and NADPH oxidase subunits. This demonstrates that increasing $\mathrm{BH} 4$ levels in the diseased tissue enables a correction of upstream disease events such as the endothelial cell activation which supports leukocyte recruitment. This finding is strengthened by the observation that leukocyte content in atherosclerotic plaque is reduced when $\mathrm{BH} 4$-deficient $\mathrm{hph}-1 / \mathrm{ApoE}^{-/-}$animals are crossed with mice overexpressing GCH1 in the endothelium (226). 

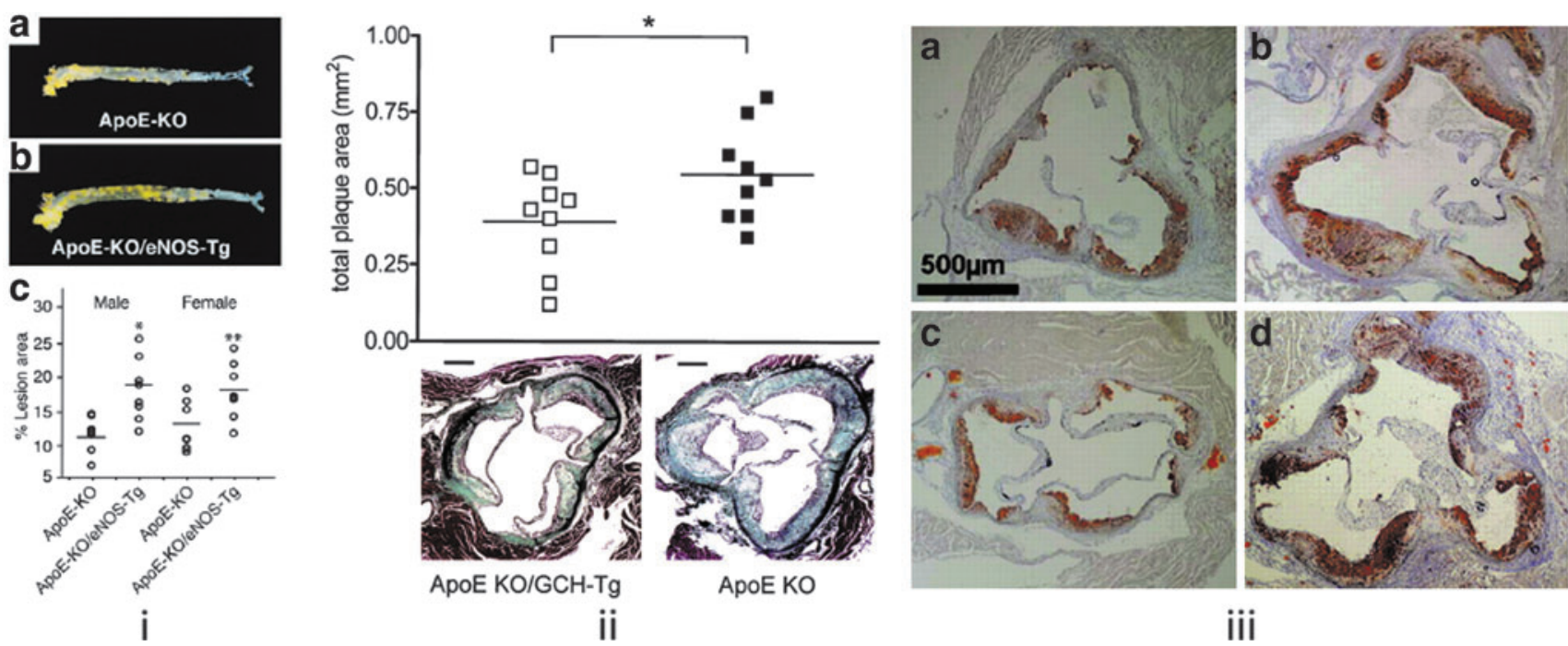

iii

FIG. 10. A comparison of three key findings demonstrating eNOS uncoupling and the ability of the GCH-Tg mouse to retard plaque progression. (i) Overexpression of eNOS accelerates atherosclerotic lesion formation in apoE-deficient mice-atherosclerotic lesions in aortas are markedly worsened in ApoE-KO/eNOS-Tg vs. ApoE-KO mice at 16 weeks of age. (a and b) Sudan III-stained, longitudinally opened aortas from apoE-KO (a) and apoE-KO/eNOS-Tg mice (b) at the age of 16 weeks. (c) Quantitative analysis of atherosclerotic lesion size in 16-week-old mice. After 12 weeks on a highcholesterol diet, the lesion size in apoE-KO/eNOS-Tg mice was significantly greater than that in apoE-KO mice. Reproduced with permission from the Journal of Clinical Investigation, Ozaki et al. (197). (ii) Increased endothelial tetrahydrobiopterin synthesis by targeted transgenic GTP-cyclohydrolase I overexpression reduces endothelial dysfunction and atherosclerosis in ApoE-knockout mice-GCH overexpression reduces aortic root plaque area in ApoE-KO mice. Aortic root plaque area in ApoE-KO/GCH-Tg (white squares) and ApoE-KO mice (black squares), with representative aortic root sections from each group, stained with Elastic and Masson's trichrome stain (elastic laminae stain black, collagen green, and cardiac myocytes red). ( $* P<0.05)$ Taken with permission from the American Heart Association, Alp et al. (5). (iii) Augmenting $\mathrm{BH} 4$ levels in the endothelium by $\mathrm{GCH}$ overexpression reduced the accelerated atherosclerotic lesion formation in ApoE-KO/eNOS-Tg mice-Overexpression of GTPCH atherosclerotic lesion formation at the aortic sinus. (a), Representative figures $(\times 40)$ of Sudan III-stained atherosclerotic lesion at the aortic sinus (a, ApoE-KO mice; b, ApoEKO/eNOS-Tg mice; c, ApoE-KO/eNOS-Tg/GCH-Tg mice; d, vitamin C-treated ApoE-KO/eNOS-Tg mice). A black bar indicates $500 \mu \mathrm{m}$. Reproduced with permission from the American Heart Association, Takaya et al. (268). To see this illustration in color, the reader is referred to the web version of this article at www.liebertpub.com/ars

\section{E. Vascular injury models}

The formation of neointima and restenosis after vascular injury and stenting are another model of vascular inflammation in which BH4 and NOS biology play a key role. One of the simplest experimental models of this type is femoral wire injury. In the wire injury model, endothelial cells lining the vessel are denuded, and neointima formation develops over 14 weeks after injury. The expression of both eNOS and iNOS is seen after vascular injury, with eNOS expression predominating (298). The response to vascular injury encompasses macrophage recruitment to the media, smooth muscle cell hyperplasia, and re-endothelialization. A deficiency of BH4, in this case the hph-1 mouse model, is associated with enhanced intimal and advential macrophage accumulation and increased cell proliferation, resulting in a seven-fold increase in neointimal area (298). Treatment with $10 \mathrm{mg} / \mathrm{kg} /$ day $\mathrm{BH} 4$ ip caused a significant blunting of the enhanced injury response in the hph-1 mice; however, whether BH4 supplementation was sufficient to reduce vascular injury in this model under wild-type conditions was not studied. Similar studies have been performed using the carotid artery wire injury model. In this model, reendothelialization occurs between 3 and 7 days post injury, as measured by Evans blue staining in vivo (156). In this model, overexpression of GCH in the endothelial cell layer resulted in a smaller medial and intimal area post injury (156). Whether these effects were manifested through reduced inflammation or by positive effects on re-endothelialization was not directly assessed.

More extensive studies of the effect of endothelial GTPCH overexpression have been performed in vein-graft accelerated arteriosclerosis. Wild-type and GCH transgenic mice underwent carotid interposition bypass grafting using the vena cava from $\mathrm{ApoE}^{-1-}$ or $\mathrm{ApoE} \mathrm{E}^{-/-} / \mathrm{GCH}-\mathrm{Tg}$ mice (4). Vessel wall area was reduced by $69 \% 28$ days postinjury and by $53 \% 56$ days post injury in mice overexpressing $\mathrm{GCH}$. Vein graft tissue showed decreased macrophage infiltration and decreased tissue MCP-1 levels, indicating that elevated endothelial $\mathrm{BH} 4$ content had an anti-inflammatory effect in this model (4). Apart from protective effects being mediated through the effects on inflammatory gene expression and leukocyte recruitment, the overexpression of $\mathrm{GCH}$ has also been shown to reduce vascular injury by promoting endothelial cells repopulation in a model of stent deployment (60). Ex vivo aortic segments undergo balloon angioplasty or the placement of stainless steel stents before carotid-interposition grafting in the murine arterial stentgraft model. Endothelial cell repopulation was significantly increased in GCH-Tg ApoE ${ }^{-/-}$mice compared with 


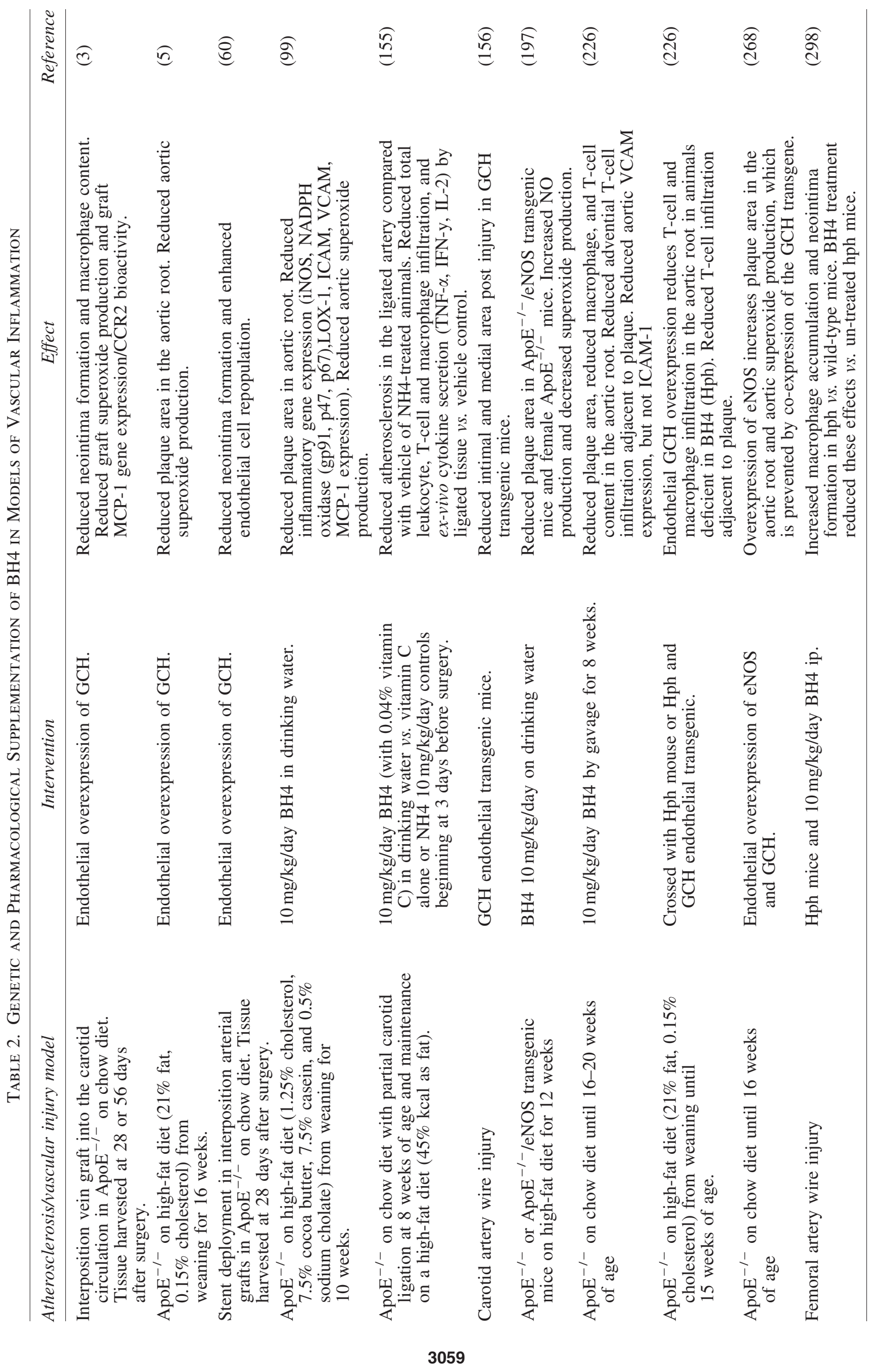


$\mathrm{ApoE}^{-/-}$littermates, in addition to significantly diminished formation of neointima (60). This study shows that elevated endothelial BH4, in addition to reducing inflammatory pathways, can mediate enhanced endothelial cell repopulation after injury.

An acute model of atherogenesis is partial carotid ligation; in this model, approximately three of the four caudal branches of the common carotid artery are ligated, causing altered blood flow and sheer stress and resulting in occlusive atherosclerotic plaque formation within 3 weeks of surgery. As discussed earlier, this is associated with NOS uncoupling through limiting $\mathrm{BH} 4$ availability. In this model, treatment with $10 \mathrm{mg} / \mathrm{kg}$ day $\mathrm{BH} 4$ in drinking water prevented plaque formation, as compared with vehicle (vitamin C) controls (155). To further demonstrate that BH4 had an effect through NOS-dependent activity, the authors used NH4 (a chemically similar compound with similar antioxidant but no NOS-binding activity) and this had no ability to prevent plaque formation. Conversely, $\mathrm{BH} 4$ treatment was shown to reduce the infiltration of both lymphocytes and myeloid cells (155).

\section{F. Tetrahydrobiopterin in human cardiovascular inflammation}

Addressing the regulation of tetrahydrobiopterin in human vascular inflammation is limited by the availability of relevant tissue samples. Many studies draw parallels between plasma biopterin levels and CAD pathologies; however, the systemic and local vascular regulation of $\mathrm{BH} 4$ levels may be different. The relationship between plasma and vascular biopterins was directly assessed using patients undergoing elective coronary artery bypass grafting (CABG). Samples of saphenous vein or internal mammary artery were obtained during the $\mathrm{CABG}$ procedure along with fasted preoperative plasma samples (6). These samples revealed an inverse relationship between plasma and vessel BH4 levels, despite a positive correlation of plasma BH4 levels with CRP. In these patients, low vascular $\mathrm{BH} 4$ was associated not only with decreased vascular function and increased vascular $\mathrm{O}_{2}{ }^{-}$, but also with elevated plasma BH4 and CRP levels. These data would indicate that plasma $\mathrm{BH} 4$ is associated with systemic inflammation, in a similar manner to the use of neopterin as a biomarker in cardiovascular diseases (261).

That plasma biopterins are driven by systemic inflammation was established using innoculation with Salmonella typhi vaccine as an acute stimulus of systemic inflammation (9). Vaccination caused an acute peak in both markers of inflammation, IL-6 and CRP, and in plasma biopterins. This peak in inflammation was associated with a decrease in vascular function, with flow-mediated dilatation (FMD) in the brachial artery being reduced by $50 \% 8 \mathrm{~h}$ post inoculation.

Genetic variation in the GCH1 gene is associated with alterations in the regulation of $\mathrm{BH} 4$ availability by inflammation. Individuals harboring the XX haplotype first described in Tegeder et al. $(271,272)$ are unable to increase biopterins in response to inflammation (9) when compared with the OO haplotype. This is not caused by a generalized lack of response to inflammatory stimuli, as XX patients had a similar induction of IL-6 to the OO individuals. These individuals showed a more dramatic drop in FMD after vaccination, indicating that the ability to up-regulate $\mathrm{BH} 4$ levels acts to preserve vascular function in the context of inflammation (9). These data would indicate that biopterin are induced both locally and systemically by inflammatory stimuli, with the local induction acting to maintain vascular function in the face of inflammation.

\section{Cardiac BH4}

\section{A. NO in the heart}

It is well known that NO generated constitutively by eNOS in endothelial cells influences vascular homeostasis and function. Ever since, it has been established that agoniststimulated release of NO in the coronary endothelium exerts paracrine effects on cardiomyocytes, affecting both cardiac morphometric and functional properties. A significant recent advance has been the finding that $\mathrm{NO}$ is also generated in the heart not just by the coronary endothelium but by myocytes themselves, making us rethink previous interpretations of studies undertaken in the intact heart (15). Furthermore, unlike in vascular and inflammatory cells, nNOS is expressed in cardiomyocytes. eNOS is found in coronary and endocardial endothelial cells and cardiomyocytes (71), and nNOS has been localized to cardiac autonomic nerves, ganglia, and cardiomyocytes $(53,71)$. iNOS is not expressed in the myocardium under normal circumstances, although it may be induced under certain stress conditions, such as ischemia (48). The effects of changes in NOS function on myocardial contractile function may, therefore, reflect changes in coronary flow, myocyte function, and/or autonomic transmission. By virtue of their distinct subcellular locales within the cardiomyocyte, eNOS and nNOS are likely to couple to distinct effector molecules and to elicit quite different responses after enzyme activation $(53,71,254)$. This is because the diffusion distance of NO within cardiac myocytes is limited to a local environment by both a high cytoplasmic concentration of myoglobin (which has a high affinity for NO) and, particularly in disease states, an abundance of $\mathrm{O}_{2}{ }^{-}$, which reacts with NO to limit its bioavailability $(203,229,236)$.

It is well established that NO influences myocardial function and morphometry through its activation of soluble guanylate cyclase (sGC), leading to an increase in cyclic guanosine monophosphate (cGMP) production and subsequent PKG activation. NO binds to the heme moiety of sGC to provoke a conformational change, thereby increasing its affinity for MgGTP, which gets converted to cGMP (252). Intracellular accumulation of cGMP in cardiomyocytes leads to negative inotropy, possibly due to reduced myofilament $\mathrm{Ca}^{2+}$ responsiveness (289) and enhanced relaxation (309). Evidence suggests that the NO-elicited effects on cardiac inotropy are biphasic. Low levels of NO stimulate adenylyl cyclase and increase cyclic adenosine monophosphate (cAMP) levels, therefore increasing $\mathrm{Ca}^{2+}$ levels (311). In contrast, high levels of NO cause sGC activation, thus reducing myofilament $\mathrm{Ca}^{2+}$ sensitivity (289).

Recently, NO has been shown to elicit effects on cardiac contractility independent of sGC activation and cGMP production through s-nitrosylation (167) [the nonenzymatic attachment of NO to a reduced thiol, causing post-translational modification of protein conformation and function, akin to those induced by phosphorylation (249)]. Although sGC activation produces profound biological effects, it is now considered that the majority of the biological actions of NO in 
the heart are via SNO modification due to the relatively short half life of NO $(167,266)$. The most prominent targets of s-nitrosylation in the heart are the ion channels, particularly the ryanodine receptor $\mathrm{Ca}^{2+}$ release channel (RyR2) (122, 266), SR Ca ${ }^{2+}$ ATPase (SERCA) (26), and the L-type $\mathrm{Ca}^{2+}$ channel $(217,323)$.

A change in NOS activity can lead to a dysregulation of snitrosylation in the heart. Knockout of s-nitrosoglutathione reductase has been shown to increase cardiac levels of SNO proteins and to significantly attenuate heart failure in mice (10).

\section{B. $\mathrm{BH} 4$ in the heart}

Comparatively few studies have focused on the role of $\mathrm{BH} 4$ in the heart; investigations to date have largely focused on its role in inflammation, vascular function, and vascular pathologies. However, BH4 is likely to play a very specific role in the cardiomyocyte by virtue of the fact that (i) this cell type has a unique function which is regulated by NOSderived NO as outlined earlier; (ii) its basal levels are relatively low compared with in other cell types (126), indicating that it delicately regulates NOS coupling/uncoupling (rather than being in excess); (iii) both eNOS and nNOS are expressed, unlike as in vascular and inflammatory cells (19); and (iv) eNOS and nNOS have distinct subcellular localizations where their derived NO or ROS may modify key target proteins nearby, such as calcium handling proteins, to influence cellular function (121).

To investigate the impact of $\mathrm{BH} 4$ on the myocardial NO-redox balance, contractile function, and calcium fluxes, Carnicer et al. (30) generated a cardiomyocyte-specific GCH1-overexpressing mouse (mGCH-Tg). mGCH-Tg mice had an increase not only in BH4 but also in the levels of oxidized products such that the ratio of $\mathrm{BH} 4: \mathrm{BH} 2+\mathrm{B}$ was actually reduced compared with wild types. However, myocardial nNOS activity was still elevated and $\mathrm{O}_{2}{ }^{-}$production was attenuated in the transgenic mice, with eNOS activity largely unchanged. Furthermore, NOS inhibition had no effect on $\mathrm{O}_{2}{ }^{-}$levels, indicating that NOS remained coupled under these conditions. Functionally, both the speed of relaxation and the rate of decay of the $\left[\mathrm{Ca}^{2+}\right]_{i}$ transient were faster in $\mathrm{mGCH}$ $\mathrm{Tg}$ mice that were associated with an nNOS-dependent increase in PKA-mediated PLB phosphorylation at serine16. These findings suggest that GCH1 and BH4 may be therapeutic targets for the treatment of diastolic dysfunction.

\section{BH4 in cardiac pathologies}

An increase in ROS production and diminished NO bioavailability have been associated with many cardiac diseases. Since NOS uncoupling leads to both of these phenomena, recent studies have focused on the role of $\mathrm{BH} 4$ in many heart diseases, including ischemia/reperfusion (49, 239), cardiac hypertrophy (182), diabetes $(14,25)$, and hypertension $(91$, $128,151,341)$ with the hypothesis that reversing myocardial NOS uncoupling could be a therapeutic tool. However, the cardiomyocyte-specific roles of BH4 in cardiac pathologies remain uncertain, as targeted gene deletion models are lacking and, as this review highlights, the requirements for $\mathrm{BH} 4$ in cardiovascular diseases are cell specific with divergent mechanisms and effects in different cells, such as endothelial and inflammatory cells. Furthermore,
NOS knockout models are unable to provide us critical information on the role of $\mathrm{BH} 4$, as neither the consequences of NOS coupling nor NOS uncoupling, a potential redox switch, can be assessed.

\section{Ischemia/reperfusion injury and infarction}

Myocardial ischemia-reperfusion (I/R) injury occurs commonly in the clinical setting after pharmacological or mechanical reperfusion, such as during angioplasty, thrombolysis, and cardiac bypass. I/R injury is characterized by myocardial apoptosis, necrosis, and endothelial dysfunction that are associated with an increased production of ROS. Many cardioprotective strategies to counter perioperative I/R have focused on the NO pathway, and, recently, the effects of $\mathrm{I} / \mathrm{R}$ on $\mathrm{BH} 4$ oxidation and the therapeutic potential of $\mathrm{BH} 4$ supplementation have been examined. Dumitrescu et al. (62) demonstrated that cardiac ischemia followed by reperfusion resulted in significant $\mathrm{BH} 4$ oxidation, NOS uncoupling, endothelial dysfunction in coronary arterioles, and impaired coronary blood flow in isolated rat hearts. Exogenous BH4 supplementation partially inhibited $\mathrm{O}_{2}{ }^{-}$production and restored NO production (Fig. 11). Yamashiro et al. (330) also reported that treatment with $\mathrm{BH} 4$ or sepiapterin restored endothelium-dependent vasorelaxation in isolated coronary arterioles and improved ventricular function of rat hearts subjected to I/R. However, the ability of $\mathrm{BH} 4$ to restore NO production decreased after $30 \mathrm{~min}$ and was absent after $90 \mathrm{~min}$ of ischemia in isolated rat hearts, suggesting that mechanisms in addition to $\mathrm{BH} 4$ depletion also contribute to NOS uncoupling induced by prolonged ischaemia (62). Similarly, postischemic coronary endothelial dysfunction was ameliorated by $\mathrm{BH} 4$ analogues ex vivo in pigs (276), and oral $\mathrm{BH} 4$ increased the eNOS monomer/dimer ratio, reduced ROS production, LV size, and posterior wall thickness, and preserved cardiac function after MI in rats (168).

Diabetic hearts are known to be particularly susceptible to $\mathrm{I} / \mathrm{R}$ injury due to elevated oxidative stress that is associated with this condition (31). The enhanced oxidative stress in

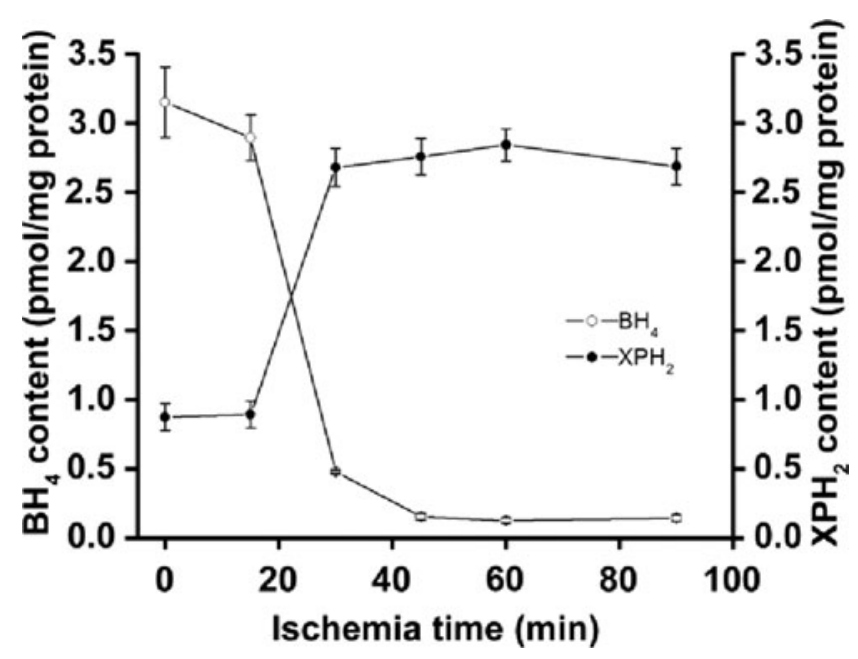

FIG. 11. $\mathrm{BH}_{4}$ levels are depleted in ischemic hearts. The decline of $\mathrm{BH}_{4}$ is paralleled by an increase in $\mathrm{XPH}_{2}$, an irreversibly oxidized product of $\mathrm{BH} 4$. ( $n=5 /$ point). Taken with permission from the Proceedings of the National Academy of Sciences, from Dumitrescu et al. (62). 
diabetes promotes iNOS up-regulation, $\mathrm{BH} 4$ oxidation, and, consequently, iNOS uncoupling, thus further exacerbating the oxidative/nitrosative stress $(186,251)$. However, Okazaki et al. showed that $\mathrm{BH} 4$ treatment was sufficient to restore iNOS coupling in isolated diabetic rat hearts and the iNOSderived NO conferred cardioprotection against I/R injury in terms of both infarct size and left ventricular function $(21,83$, $112,195)$. The cardioprotective effect of BH4 was abrogated by treatment with a thiol-reducing agent (dithiothreitol), but not an NO-sensitive guanylyl cyclase inhibitor (ODQ), suggesting that iNOS-derived NO-mediated cardioprotection occurs through protein $S$-nitrosylation and not cGMPdependent signaling in the diabetic heart (112).

A number of studies have focused on the role of $\mathrm{BH} 4$ in the phenomenon of late-phase ischemic preconditioning (IPC). IPC is an innate phenomenon in which brief exposure to sublethal ischaemia induces a profound protection from a subsequent ischemic insult in various organs, including the heart (180). IPC is associated with two forms of protection: the "early phase" lasting $\sim 2 \mathrm{~h}$ after the preconditioning ischemia followed by a "late phase" of protection occurring a day later and lasting $\sim 3$ days. Studies have implicated NO as an important mediator in IPC, with NO derived from constitutive NOS being implicated in the early phase and NO derived from iNOS being involved in the late phase of IPC (127). The inhibition of BH4 synthesis in rats (using DAHP to inhibit GTPCH) has also been shown to abolish the protective effect of IPC in rat myoardium (259). This study revealed that IPC increases cardiac BH4 through the up-regulation of $\mathrm{GCH} 1$ via the $\mathrm{H}_{2} \mathrm{O}_{2}$-Jak2 signaling pathway. Similarly, in rabbits, Tang et al. (269c) showed that left coronary artery IPC resulted in increased myocardial BH4 content in the ischemic area after I/R injury, but not in the nonischemic zone. They also demonstrated that both pharmacological inhibition of BH4 synthesis and hypercholesterolaemia abolished both the rise in $\mathrm{BH} 4$ and the infarct-limiting effect of late IPC. The increase in ROS associated with hypercholesterolaemia is likely to be responsible for the diminished $\mathrm{BH} 4$ bioavailability in this setting. Recently, Ge et al. (84) used a mouse model of cardiomyocyte-specific GCH1 overexpression to demonstrate that increased $\mathrm{BH} 4$ bioavailability preserves the ability of IPC to elicit myocardial protection in the hyperglycemic state.

\section{E. Cardiac hypertophy and function}

Cardiac hypertrophy is an adaptive response of the heart to pressure overload and is, thus, a common pathological feature of many cardiovascular diseases, including hypertension and myocardial infarction. Although cardiac hypertrophy may initially be beneficial, providing compensation to the stress, sustained hypertrophic stimulation becomes maladaptive, leading to increased morbidity and mortality due to congestive heart failure and sudden death (232). Growing evidence suggests that oxidative and nitrosative stresses modulate the transition from adaptive to maladaptive hypertrophy [reviewed by Takimoto et al. (269a)]. The production of ROS is linked to inducers of hypertrophy such as $\mathrm{G}_{\alpha \mathrm{q}} / \mathrm{G}_{11}$-coupled agonists (e.g., phenylephrine, angiotensin) $(76,183)$, signalling kinases and phosphatases (267), and mechanotransduction (207). ROS have also been shown to induce fetal gene reexpression (a marker of hypertrophy) (301) and to contribute to chamber remodeling by activating MMPs. As such, the role of BH4 and NOS (un)coupling in the pathogenesis of cardiac hypertrophy has been brought into question.

Takimoto and Kass (269b) demonstrated that pressure overload induced by transverse aortic constriction (TAC) in mice reduces cardiac $\mathrm{BH} 4$ levels and triggers eNOS uncoupling, which, in turn, leads to myocyte hypertrophy, cardiac dilation, interstitial fibrosis, and ventricular dysfunction. Perhaps controversially, eNOS-knockout animals
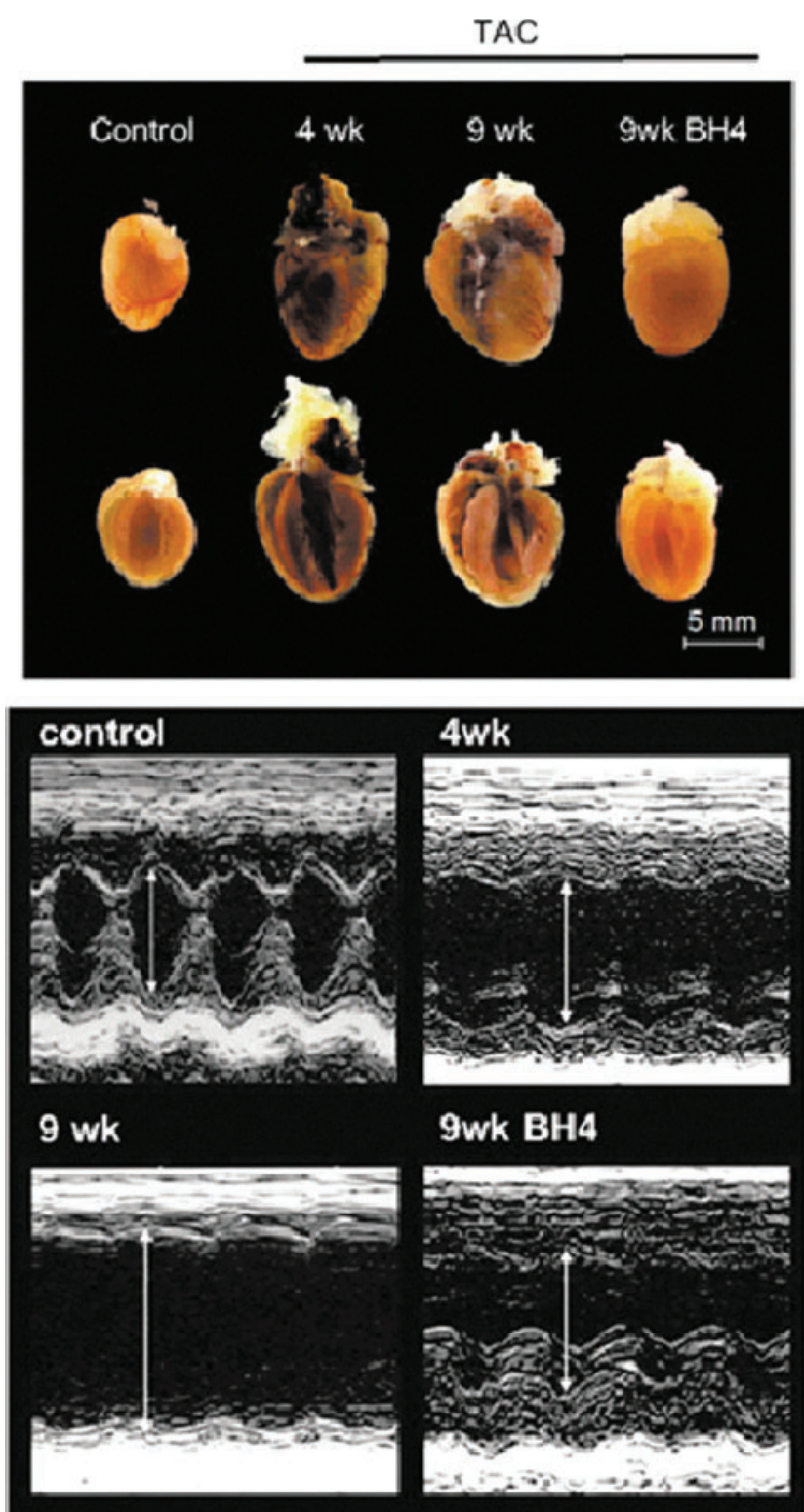

FIG. 12. BH4 treatment reverses advanced hypertrophy caused by sustained pressure overload. Above: TAC(thoracic aortic constriction) stimulated increases in heart weight at 4 weeks were reversed by the subsequent addition of oral $\mathrm{BH} 4$, whereas untreated hearts continued to enlarge. Below: Example M-mode echocardiograms showing increased dilation, wall thickening, and reduced fractional shortening after 4 weeks and 9 weeks of TAC. All parameters were significantly improved by $\mathrm{BH} 4$ treatment. Used with permission from the American Heart Association, from Moens et al. (182). To see this illustration in color, the reader is referred to the web version of this article at www.liebertpub.com/ars 
exhibited neither dilation nor impaired systolic function and only showed mild hypertrophy; however, this is likely, because eNOS-derived ROS is abolished. Treatment with oral $\mathrm{BH} 4$ prevented the NOS uncoupling and reduced the TACinduced hypertrophy in control mice. Furthermore, a separate study by Moens et al. (182) revealed that exogenous BH4 recoupled eNOS, thus reversing pre-existing advanced cardiac hypertrophy and fibrosis caused by TAC-induced pressure overload (Fig. 12).

Most recently, Silberman et al. (247) studied the role of NOS uncoupling in a mouse model of diastolic dysfunction. Diastolic dysfunction can cause heart failure with a preserved ejection fraction, and there is a strong epidemiological association between hypertension and diastolic dysfunction (16). Mild hypertension with diastolic dysfunction in the absence of hypertrophy and systolic dysfunction was generated by unilateral nephrectomy with DOCA-saline treatment (247). The resulting mice had increased cardiac oxidative stress, predominantly from uncoupled nNOS, and an attenuated BH4:oxidized biopterins ratio. Feeding with BH4 improved total cardiac BH4 levels and redox status. Furthermore, treatment with $\mathrm{BH} 4$ (but not $\mathrm{NH} 4$ ) both prevented and reversed diastolic dysfunction. In addition, BH4 treatment in DOCA animals augmented the phosphorylation status of phospholamban, a key regulator of sarcoplasmic reticulum
$\mathrm{Ca}^{2+}$ pump activity and cytosolic $\mathrm{Ca}^{2+}$ levels, suggesting a possible underlying mechanism (247). Similarly, in a separate study, BH4 was able to restore diastolic dysfunction and LV remodeling in ovariectomized mRen2.Lewis rats (which have depleted myocardial $\mathrm{BH} 4$ ) that were associated with a decrease in nNOS-derived $\mathrm{O}_{2}{ }^{-}$production (129).

Importantly, a recent study by Moens et al. (181a) highlighted that the effective dose range of BH4 for ameliorating pressure overload-induced hypertrophy and heart failure may be more limited than expected. On oral administration, BH4 is largely oxidized to $\mathrm{BH} 2$ and biopterin, and the $\mathrm{BH} 2$ can then be re-reduced once in the cell. Since $\mathrm{BH} 2$ can compete with $\mathrm{BH} 4$ to impair NOS coupling, higher doses of $\mathrm{BH} 4$ might tip the balance toward more reduced $\mathrm{BH} 2$ such that any physiological benefit of a higher initial dose of $\mathrm{BH} 4$ is offset. Moens et al. (181a) revealed a bimodal dose response of BH4 for the treatment of hypertrophic heart disease; a mid-range dose of $36 \mathrm{mg} / \mathrm{kg} /$ day $\mathrm{BH} 4$ was found to be beneficial, whereas higher doses (approximately $400 \mathrm{mg} / \mathrm{kg} /$ day BH4) became ineffective. The beneficial doses correlated with an enhanced $\mathrm{BH} 4: \mathrm{BH} 2$ ratio.

Together, these studies highlight the importance of BH4 to maintain NOS coupling in cardiac hypertrophy, failure, and dysfunction and to support BH4 as a potential new therapeutic approach.

Table 3. Comparison of Cardiovascular Phenotypes in Knockout Mouse Models

\begin{tabular}{|c|c|c|}
\hline Mouse model & Cardiovascular phenotype & Reference \\
\hline PTPS KO & $\begin{array}{l}\text { Born with normal mendelian ratio but PTPS } \\
\text { KO mice die within } 48 \mathrm{~h} \text { of birth } \\
\text { Decrease BH4 and catecholamines, with a } \\
\text { decrease in NOS and Th activity } \\
\text { Increased phenylalanine and neopterin } \\
\text { PTPS KO have significantly bradycardia } \\
\text { No gross organ defects }\end{array}$ & $(64,263)$ \\
\hline $\begin{array}{l}\text { Dopamine } \beta \text { hydroxylase } \mathrm{KO} \\
\quad \text { and Tyrosine hydroxylase } \mathrm{KO}\end{array}$ & $\begin{array}{l}\text { Significant embryo lethality } \\
\text { Majority of knockout embryos dead by } \\
\text { E16.5-E18.5 } \\
\text { Significant bradycardia at E12.5 } \\
\text { No gross organ defects } \\
\text { Signs of altered vascular and myocardium } \\
\text { development }\end{array}$ & $(141,273,342)$ \\
\hline Sepiapterin reductase KO & $\begin{array}{l}\text { SR KO born at the expected mendelian ratio } \\
\text { Growth retardation obvious within a few } \\
\text { days of birth, with no gain in body } \\
\text { weight after } 2 \text { weeks } \\
\text { Most animals die at } 1-2 \text { months of age } \\
\text { Decrease of NA, DOPAC, and dopamine } \\
\text { in the brain }\end{array}$ & $(331)$ \\
\hline eNOS KO & $\begin{array}{l}\text { eNOS KO mice are viable, but significant } \\
\text { embryo lethality occurs between E8.5 and } 13.5 \\
\text { Alteration in coronary and pulmonary } \\
\text { vascular development } \\
\text { Ventricular septal defects were observed } \\
\text { along with heart shortening } \\
\text { From E17.5 and after birth, eNOS knockout } \\
\text { mice are significantly smaller than wild type } \\
\text { Uterine arteries from eNOS knockout dams } \\
\text { are significantly smaller and show signs of } \\
\text { impaired smooth muscle cell de-differentiation } \\
\text { and proliferation }\end{array}$ & $(70,102,159,198,284)$ \\
\hline
\end{tabular}

eNOS, endothelial nitric oxide synthase; KO, knockout; PTPS, 6-pyruvoyl tetrahydropterin synthase; SR, sepiapterin reductase. 


\section{F. Cardiac autonomic function}

Many cardiovascular disease states, including heart failure and myocardial infarction, are associated with changes in cardiac autonomic function. Furthermore, abnormalities in the autonomic control of the heart, such as reduced baroreflex sensitivity and heart rate variability, are predictors of adverse events in conditions such as ventricular arrhythmias (37). Evidence suggests that endogenous NO regulates both sympathetic and parasympathetic cardiac control (36). Under physiological conditions, NO appears to inhibit sympathetic activity and to increase vagal tone. In pathophysiological conditions such as diabetes and heart failure, a decreased NO bioavailability is concomitant with autonomic dysfunction.

BH4 is likely to be a key mediator of cardiac autonomic function, as it is a critical cofactor for both $\mathrm{TH}$ and NOS enzymes, thus controlling both L-DOPA-derived and NO neurotransmitter activity $(57,111)$. Zhang et al. (339) investigated whether a common genetic variation of the GCHl gene alters autonomic function in humans. An SNP, $\mathrm{C}+243 \mathrm{~T}$, was found to predict reduced urinary catecholamine excretion and NO production and was associated with decreased baroreflex sensitivity and heart rate variability. In addition, this SNP had a significant association with higher blood pressure in women. Although BH4 levels were not measured in this study, this SNP is in tight linkage disequilibrium with the " $\mathrm{X}$ " GCH1 haplotype described by Tegeder et al. (271) and Antoniades et al. (7), indicating that this observed autonomic phenotype may be BH4 mediated (59).

Adlam et al. (2) studied the effect of BH4 deficiency on the autonomic regulation of heart rate in the hph-1 mouse model. Reduced GCH1 expression and subsequent BH4 deficiency in hph-1 mice was associated with a resting tachycardia before and after exercise training despite normal blood pressure and normal heart rates during exercise. This resting tachycardia was linked to enhanced $\beta$-adrenergic sensitivity with no effect on vagal function (57). The resting tachycardia and increased cardiac sympathetic sensitivity of these BH4-deficient hph-1 mice is similar to that observed in humans with $\mathrm{BH} 4$ deficiency, including patients with dopa-responsive dystonia and those with the C243T polymorphism in $\operatorname{GCH}(305,337)$.

$\mathrm{AF}$, the most common sustained cardiac arrhythmia, has also been linked to a decrease in myocardial BH4 and NOS uncoupling. In both a goat model of pacing-induced long-standing $\mathrm{AF}$ and in patients with persistent AF, Reilly et al. (215) demonstrated increased uncoupled NOS activity and a diminution in both $\mathrm{BH} 4$ bioavailability and the $\mathrm{BH} 4: \mathrm{BH} 2+\mathrm{B}$ ratio.

These insights into the influence of $\mathrm{BH} 4$ on cardiac autonomic function are likely to have important clinical implications, as the autonomic regulation of heart rate plays a fundamental role in cardiovascular health.

\section{Concluding Remarks}

In summary, $\mathrm{BH} 4$ is a critical regulator of cardiovascular homeostasis; abnormalities in the absolute levels and oxidation state of BH4 are a hallmark of vascular and cardiac dysfunction; and current research indicates that maintaining adequate $\mathrm{BH} 4$ levels in the endothelium is likely to be critical in regulating the balance of $\mathrm{NO}$ and $\mathrm{O}_{2}{ }^{-}$synthesis by eNOS. Strategies to maintain vascular $\mathrm{BH} 4$ availability may include measures to increase $\mathrm{BH} 4$ biosynthesis or to reduce oxidative degradation, and ongoing studies attempting to restore in- tracellular BH4 levels via gene therapy and direct supplementation are showing promising results. However, the clinical efficacy of improving BH4 bioavailability also may depend on other biochemical determinants of NOS uncoupling, including cellular concentrations of L-arginine, methylarginines, and oxidized glutathione. Future studies are, therefore, needed to understand how $\mathrm{BH} 4$ bioavailability and these factors interact with one another to determine NOS activity at biochemical, cellular, and systemic levels. To move forward and develop BH4 as a successful therapeutic for cardiovascular disease, we need to better understand the interaction of $\mathrm{BH} 4$ and the NOSs with downstream NO-ROS signaling in both endothelial cells and inflammatory cells. Resulting advances could lead to significant improvements in the treatment of the wide range of cardiovascular disease states in which NOS uncoupling is a central pathogenic mechanism.

\section{Acknowledgments}

The authors wish to thank Ruth Rinze for help with several figures, and they acknowledge support from the British Heart Foundation (BHF) Center of Research Excellence, Oxford. This research was supported by a BHF Center of Research Excellence Intermediate Fellowship award to Mark J. Crabtree (RE/08/004) and a BHF Program Grant (RG/12/5/ 29756).

\section{References}

1. Adlam D, Bendall JK, De Bono JP, Alp NJ, Khoo J, Nicoli T, Yokoyama M, Kawashima S, and Channon KM. Relationships between nitric oxide-mediated endothelial function, eNOS coupling and blood pressure revealed by eNOS-GTP cyclohydrolase 1 double transgenic mice. Exp Physiol 92: 119-126, 2007.

2. Adlam D, Herring N, Douglas G, de Bono J, Casadei B, Paterson DJ, and Channon KM. Regulation of $\beta$-adrenergic control of heart rate by GTP-cyclohydrolase 1 ( $\mathrm{GCH} 1)$ and tetrahydrobiopterin. Cardiovasc Res 93: 694-901, 2012.

3. Ali ZA, Alp N, Tatham AL, Greaves DR, and Channon KM. Increased endothelial tetrahydrobiopterin synthesis reduces vein graft atherosclerosis in ApoE-knockout mice. Circulation 112(17)II, 440, 2005.

4. Ali ZA, Bursill CA, Douglas G, McNeill E, Papaspyridonos M, Tatham AL, Bendall JK, Akhtar AM, Alp NJ, Greaves DR, and Channon KM. CCR2-mediated antiinflammatory effects of endothelial tetrahydrobiopterin inhibit vascular injury-induced accelerated atherosclerosis. Circulation 118: S71-S77, 2008.

5. Alp NJ, McAteer MA, Khoo J, Choudhury RP, and Channon KM. Increased endothelial tetrahydrobiopterin synthesis by targeted transgenic GTP-cyclohydrolase I overexpression reduces endothelial dysfunction and atherosclerosis in ApoE-knockout mice. Arterioscler Thromb Vasc Biol 24: 445-450, 2004.

6. Antoniades C, Shirodaria C, Crabtree M, Rinze R, Alp N, Cunnington C, Diesch J, Tousoulis D, Stefanadis C, Leeson P, Ratnatunga C, Pillai R, and Channon KM. Altered plasma versus vascular biopterins in human atherosclerosis reveal relationships between endothelial nitric oxide synthase coupling, endothelial function, and inflammation. Circulation 116: 2851-2859, 2007. 
7. Antoniades $\mathrm{C}$, Shirodaria $\mathrm{C}$, Van Assche $\mathrm{T}$, Cunnington C, Tegeder I, Lotsch J, Guzik TJ, Leeson P, Diesch J, Tousoulis D, Stefanadis C, Costigan M, Woolf CJ, Alp NJ, and Channon KM. GCH1 haplotype determines vascular and plasma biopterin availability in coronary artery disease effects on vascular superoxide production and endothelial function. J Am Coll Cardiol 52: 158-165, 2008.

8. Antoniades C, Bakogiannis C, Leeson P, Guzik TJ, Zhang $\mathrm{MH}$, Tousoulis D, Antonopoulos AS, Demosthenous M, Marinou K, Hale A, Paschalis A, Psarros C, Triantafyllou C, Bendall J, Casadei B, Stefanadis C, and Channon KM. Rapid, direct effects of statin treatment on arterial redox state and nitric oxide bioavailability in human atherosclerosis via tetrahydrobiopterin-mediated endothelial nitric oxide synthase coupling. Circulation 124: 335-345, 2011.

9. Antoniades C, Cunnington C, Antonopoulos A, Neville M, Margaritis M, Demosthenous M, Bendall J, Hale A, Cerrato R, Tousoulis D, Bakogiannis C, Marinou K, Toutouza M, Vlachopoulos C, Leeson P, Stefanadis C, Karpe F, and Channon KM. Induction of vascular GTPcyclohydrolase I and endogenous tetrahydrobiopterin synthesis protect against inflammation-induced endothelial dysfunction in human atherosclerosis. Circulation 124: 1860-1870, 2011.

10. Arnal JF, Dinh-Xuan AT, Pueyo M, Darblade B, and Rami J. Endothelium-derived nitric oxide and vascular physiology and pathology. Cell Mol Life Sci 55: 10781087, 1999.

11. Aviram M, Rosenblat M, Etzioni A, and Levy R. Activation of NADPH oxidase required for macrophagemediated oxidation of low-density lipoprotein. Metabolism 45: 1069-1079, 1996.

12. Bachschmid M, Schildknecht S, and Ullrich V. Redox regulation of vascular prostanoid synthesis by the nitric oxide-superoxide system. Biochem Biophys Res Commun 338: 536-542, 2005.

13. Bahrami S, Fitzal F, Peichl G, Gasser H, Fuerst W, Banerjee A, Strohmaier W, Redl H, Werner-Felmayer G, and Werner ER. Protection against endotoxemia in rats by a novel tetrahydrobiopterin analogue. Shock 13: 386-391, 2000.

14. Baker MA, Cerniglia GJ, and Zaman A. Microtiter plate assay for the measurement of glutathione and glutathione disulfide in large numbers of biological samples. Anal Biochem 190: 360-365, 1990.

15. Balligand JL, Kelly RA, Marsden PA, Smith TW, and Michel T. Control of cardiac muscle cell function by an endogenous nitric oxide signaling system. Proc Natl Acad Sci U S A 90: 347-351, 1993.

16. Barrett-Connor E and Bush TL. Estrogen and coronary heart disease in women. Jama 265: 1861-1867, 1991.

17. Bec N, Gorren AC, Voelker C, Mayer B, and Lange R. Reaction of neuronal nitric-oxide synthase with oxygen at low temperature. Evidence for reductive activation of the oxy-ferrous complex by tetrahydrobiopterin. J Biol Chem 273: 13502-13508, 1998.

18. Belik J, McIntyre BAS, Enomoto M, Pan J, Grasemann H, and Vasquez-Vivar J. Pulmonary hypertension in the newborn GTP cyclohydrolase I-deficient mouse. Free Radic Biol Med 51: 2227-2233, 2011.

19. Bendall JK, Damy T, Ratajczak P, Loyer X, Monceau V, Marty I, Milliez P, Robidel E, Marotte F, Samuel JL, and
Heymes C. Role of myocardial neuronal nitric oxide synthase-derived nitric oxide in beta-adrenergic hyporesponsiveness after myocardial infarction-induced heart failure in rat. Circulation 110: 2368-2375, 2004.

20. Bendall JK, Alp NJ, Warrick N, Cai S, Adlam D, Rockett K, Yokoyama M, Kawashima S, and Channon KM. Stoichiometric relationships between endothelial tetrahydrobiopterin, eNOS activity and eNOS coupling in vivo: Insights from transgenic mice with endothelial-targeted GTPCH and eNOS over-expression. Circ Res 97: 864871, 2005.

21. Bolli R, Manchikalapudi S, Tang XL, Takano H, Qiu Y, Guo Y, Zhang Q, and Jadoon AK. The protective effect of late preconditioning against myocardial stunning in conscious rabbits is mediated by nitric oxide synthase: evidence that nitric oxide acts both as a trigger and as a mediator of the late phase of ischemic preconditioning. Circ Res 81: 1094-1107, 1997.

22. Bredt DS and Snyder SH. Isolation of nitric oxide synthetase, a calmodulin-requiring enzyme. Proc Natl Acad Sci U S A 87: 682-685, 1990.

23. Bredt DS, Ferris CD, and Snyder SH. Nitric oxide synthase regulatory sites. Phosphorylation by cyclic AMP- dependent protein kinase, protein kinase $\mathrm{C}$, and calcium/calmodulin protein kinase; identification of flavin and calmodulin binding sites. J Biol Chem 267: 10976-10981, 1992.

24. Brenneman AR and Kaufman S. Characteristics of the hepatic phenylalanine-hydroxylating system in newborn rats. J Biol Chem 240: 3617-3622, 1965.

25. Brownlee M, Cerami A, and Vlassara H. Advanced glycosylation end products in tissue and the biochemical basis of diabetic complications. N Engl J Med 318: 13151321, 1988.

26. Buchwalow IB, Podzuweit T, Bocker W, Samoilova VE, Thomas S, Wellner M, Baba HA, Robenek H, Schnekenburger J, and Lerch MM. Vascular smooth muscle and nitric oxide synthase. Faseb J 16: 500-508, 2002.

27. Bune AJ, Brand MP, Heales SJ, Shergill JK, Cammack R, and Cook HT. Inhibition of tetrahydrobiopterin synthesis reduces in vivo nitric oxide production in experimental endotoxic shock. Biochem Biophys Res Commun 220: 1319, 1996.

28. Cai $\mathrm{H}$ and Harrison DG. Endothelial dysfunction in cardiovascular diseases: the role of oxidant stress. Circ Res 87: 840-844, 2000.

29. Cai S, Khoo J, and Channon KM. Augmented BH4 by gene transfer restores nitric oxide synthase function in hyperglycemic human endothelial cells. Cardiovasc Res 65: 823-831, 2005.

30. Carnicer R, Hale AB, Suffredini S, Liu X, Reilly S, Zhang MH, Surdo NC, Bendall JK, Crabtree MJ, Lim GBS, Alp NJ, Channon KM, and Casadei B. Cardiomyocyte GTP cyclohydrolase 1 and tetrahydrobiopterin increase NOS1 activity and accelerate myocardial relaxation. Circ Res 111: 718-727, 2012.

31. Cave AC, Brewer AC, Narayanapanicker A, Ray R, Grieve DJ, Walker S, and Shah AM. NADPH oxidases in cardiovascular health and disease. Antioxid Redox Signal 8: 691-728, 2006.

32. Chalupsky $\mathrm{K}$ and Cai $\mathrm{H}$. Endothelial dihydrofolate reductase: critical for nitric oxide bioavailability and role in angiotensin II uncoupling of endothelial nitric oxide synthase. Proc Natl Acad Sci U S A 102: 9056-9061, 2005. 
33. Chen CA, Lin CH, Druhan LJ, Wang TY, Chen YR, and Zweier JL. Superoxide induces endothelial nitric-oxide synthase protein thiyl radical formation, a novel mechanism regulating eNOS function and coupling. J Biol Chem 286: 29098-29107, 2011.

34. Chen J, Kuhlencordt P, Urano F, Ichinose H, Astern J, and Huang PL. Effects of chronic treatment with L-arginine on atherosclerosis in apoE knockout and apoE/inducible NO synthase double-knockout mice. Arterioscler Thromb Vasc Biol 23: 97-103, 2003.

35. Cho HJ, Martin E, Xie QW, Sassa S, and Nathan C. Inducible nitric oxide synthase: identification of amino acid residues essential for dimerization and binding of tetrahydrobiopterin. Proc Natl Acad Sci U S A 92: 1151411518, 1995.

36. Chowdhary S and Townend JN. Role of nitric oxide in the regulation of cardiovascular autonomic control. Clin Sci (Lond) 97: 5-17, 1999.

37. Clark JB, Palmer CJ, and Shaw WN. The diabetic Zucker fatty rat. Proc Soc Exp Biol Med 173: 68-75, 1983.

38. Cosentino F and Katusic ZS. Tetrahydrobiopterin and dysfunction of endothelial nitric oxide synthase in coronary arteries. Circulation 91: 139-144, 1995.

39. Cosentino F, Hishikawa K, Katusic ZS, and Luscher TF. High glucose increases nitric oxide synthase expression and superoxide anion generation in human aortic endothelial cells. Circulation 96: 25-28, 1997.

40. Cosentino F, Barker JE, Brand MP, Heales SJ, Werner ER, Tippins JR, West N, Channon KM, Volpe M, and Luscher TF. Reactive oxygen species mediate endotheliumdependent relaxations in tetrahydrobiopterin-deficient mice. Arterioscler Thromb Vasc Biol 21: 496-502, 2001.

41. Cosentino F, Hurlimann D, Delli Gatti C, Chenevard R, Blau N, Alp NJ, Channon KM, Eto M, Lerch P, Enseleit F, Ruschitzka F, Volpe M, Luscher TF, and Noll G. Chronic treatment with tetrahydrobiopterin reverses endothelial dysfunction and oxidative stress in hypercholesterolaemia. Heart 94: 487-492, 2008.

42. Crabtree MJ, Smith CL, Lam G, Goligorsky MS, and Gross SS. Ratio of 5,6,7,8-tetrahydrobiopterin to 7,8dihydrobiopterin in endothelial cells determines glucoseelicited changes in $\mathrm{NO}$ vs. superoxide production by eNOS. Am J Physiol Heart Circ Physiol 294: H1530H1540, 2008.

43. Crabtree MJ, Tatham AL, Al-Wakeel Y, Warrick N, Hale AB, Cai S, Channon KM, and Alp NJ. Quantitative regulation of intracellular endothelial nitric oxide synthase (eNOS) coupling by both tetrahydrobiopterin-eNOS stoichiometry and biopterin redox status: Insights from cells with tet-regulated GTP cyclohydrolase I expression. J Biol Chem 284: 1136-1144, 2009.

44. Crabtree MJ, Tatham AL, Hale AB, Alp NJ, and Channon KM. Critical role for tetrahydrobiopterin recycling by dihydrofolate reductase in regulation of endothelial nitricoxide synthase coupling: relative importance of the de novo biopterin synthesis versus salvage pathways. $J$ Biol Chem 284: 28128-28136, 2009.

45. Crabtree MJ and Channon KM. Dihydrofolate reductase is required to maintain endothelial nitric oxide synthase coupling in vivo: Insights from methotrexate-treated $\mathrm{BH} 4$ deficient and GTPCH overexpressing mice. Nitric Oxide 22: S30, 2010.

46. Crane BR, Arvai AS, Ghosh DK, Wu C, Getzoff ED, Stuehr DJ, and Tainer JA. Structure of nitric oxide syn- thase oxygenase dimer with pterin and substrate. Science 279: 2121-2126, 1998.

47. Cromheeke KM, Kockx MM, De Meyer GR, Bosmans JM, Bult H, Beelaerts WJ, Vrints CJ, and Herman AG. Inducible nitric oxide synthase colocalizes with signs of lipid oxidation/peroxidation in human atherosclerotic plaques. Cardiovasc Res 43: 744-754, 1999.

48. Csont T, Viappiani S, Sawicka J, Slee S, Altarejos JY, Batinic-Haberle I, and Schulz R. The involvement of superoxide and iNOS-derived NO in cardiac dysfunction induced by pro-inflammatory cytokines. J Mol Cell Cardiol 39: 833-840, 2005.

49. Cubberley RR, Alderton WK, Boyhan A, Charles IG, Lowe PN, and Old RW. Cysteine-200 of human inducible nitric oxide synthase is essential for dimerization of haem domains and for binding of haem, nitroarginine and tetrahydrobiopterin. Biochem J 323: 141-146, 1997.

50. Cunnington C, Antoniades C, Shirodaria C, Van Assche T, Lee R, Kylintireas I, Lyndsay A, Lee JM, Neubauer S, Choudhury RP, and Channon KM. Systemic and vascular oxidation limits efficacy of oral tetrahydrobiopterin treatment in patients with coronary artery disease. Circulation 125: 1356-1366, 2012.

51. Curtius HC, Heintel D, Ghisla S, Kuster T, Leimbacher W, and Niederwieser A. Tetrahydrobiopterin biosynthesis. Studies with specifically labeled $(2 \mathrm{H}) \mathrm{NAD}(\mathrm{P}) \mathrm{H}$ and $2 \mathrm{H} 2 \mathrm{O}$ and of the enzymes involved. Eur J Biochem 148: 413419, 1985.

52. d'Uscio LV and Katusic ZS. Increased vascular biosynthesis of tetrahydrobiopterin in apolipoprotein E-deficient mice. Am J Physiol Heart Circ Physiol 290: H2466H2471, 2006.

53. Danson EJ, Choate JK, and Paterson DJ. Cardiac nitric oxide: emerging role for nNOS in regulating physiological function. Pharmacol Ther 106: 57-74, 2005.

54. Davis MD, Kaufman S, and Milstien S. Distribution of 4ahydroxytetrahydropterin dehydratase in rat tissues. Comparison with the aromatic amino acid hydroxylases. FEBS Lett 302: 73-76, 1992.

55. Dellinger RP, Levy MM, Carlet JM, Bion J, Parker MM, Jaeschke R, Reinhart K, Angus DC, Brun-Buisson C, Beale R, Calandra T, Dhainaut JF, Gerlach H, Harvey M, Marini JJ, Marshall J, Ranieri M, Ramsay G, Sevransky J, Thompson BT, Townsend S, Vender JS, Zimmerman JL, and Vincent JL. Surviving Sepsis Campaign: international guidelines for management of severe sepsis and septic shock: 2008. Crit Care Med 36: 296-327, 2008.

56. Detmers PA, Hernandez M, Mudgett J, Hassing H, Burton C, Mundt S, Chun S, Fletcher D, Card DJ, Lisnock J, Weikel R, Bergstrom JD, Shevell DE, HermanowskiVosatka A, Sparrow CP, Chao YS, Rader DJ, Wright SD, and Pure E. Deficiency in inducible nitric oxide synthase results in reduced atherosclerosis in apolipoprotein E-deficient mice. J Immunol 165: 3430-3435, 2000.

57. Dhalla NS, Temsah RM, and Netticadan T. Role of oxidative stress in cardiovascular diseases. J Hypertens 18: 655-673, 2000.

58. Dimmeler S, Haendeler J, Nehls M, and Zeiher AM. Suppression of apoptosis by nitric oxide via inhibition of interleukin-1beta-converting enzyme (ICE)-like and cysteine protease protein (CPP)-32-like proteases. J Exp Med 185: 601-607, 1997.

59. Doehring A, Antoniades C, Channon KM, Tegeder I, and Lotsch J. Clinical genetics of functionally mild non- 
coding GTP cyclohydrolase 1 (GCH1) polymorphisms modulating pain and cardiovascular risk. Mutat Res 659: 195-201, 2008.

60. Douglas G, Van Kampen E, Hale AB, McNeill E, Patel J, Crabtree MJ, Ali Z, Hoerr RA, Alp NJ, and Channon KM. Endothelial cell repopulation after stenting determines instent neointima formation: effects of bare-metal vs. drugeluting stents and genetic endothelial cell modification. Eur Heart J 34: 3378-3388, 2013.

61. Drummond GR, Cai H, Davis ME, Ramasamy S, and Harrison DG. Transcriptional and posttranscriptional regulation of endothelial nitric oxide synthase expression by hydrogen peroxide. Circ Res 86: 347-354, 2000.

62. Dumitrescu C, Biondi R, Xia Y, Cardounel AJ, Druhan LJ, Ambrosio G, and Zweier JL. Myocardial ischemia results in tetrahydrobiopterin (BH4) oxidation with impaired endothelial function ameliorated by BH4. Proc Natl Acad Sci U S A 104: 15081-15086, 2007.

63. Dweik RA, Laskowski D, Abu-Soud HM, Kaneko F, Hutte R, Stuehr DJ, and Erzurum SC. Nitric oxide synthesis in the lung. Regulation by oxygen through a kinetic mechanism. J Clin Invest 101: 660-666, 1998.

64. Elzaouk L, Leimbacher W, Turri M, Ledermann B, Burki $\mathrm{K}$, Blau N, and Thony B. Dwarfism and low insulin-like growth factor-1 due to dopamine depletion in Pts-/- mice rescued by feeding neurotransmitter precursors and H4biopterin. J Biol Chem 278: 28303-28311, 2003.

65. This reference has been deleted.

66. Eskurza I, Myerburgh LA, Kahn ZD, and Seals DR. Tetrahydrobiopterin augments endothelium-dependent dilatation in sedentary but not in habitually exercising older adults. J Physiol 568: 1057-1065, 2005.

67. This reference has been deleted.

68. Faggiotto A, Ross R, and Harker L. Studies of hypercholesterolemia in the nonhuman primate. I. Changes that lead to fatty streak formation. Arteriosclerosis 4: 323-340, 1984.

69. Félétou M and Vanhoutte PM. Endothelial dysfunction: a multifaceted disorder (The Wiggers Award Lecture). Am J Physiol 291: H985-H1002, 2006.

70. Feng Q, Song W, Lu X, Hamilton JA, Lei M, Peng T, and Yee S-P. Development of heart failure and congenital septal defects in mice lacking endothelial nitric oxide synthase. Circulation 106: 873-879, 2002.

71. Feron O, Belhassen L, Kobzik L, Smith TW, Kelly RA, and Michel T. Endothelial nitric oxide synthase targeting to caveolae. J Biol Chem 271: 22810-22814, 1996.

72. Fischmann TO, Hruza A, Niu XD, Fossetta JD, Lunn CA, Dolphin E, Prongay AJ, Reichert P, Lundell DJ, Narula SK, and Weber PC. Structural characterization of nitric oxide synthase isoforms reveals striking active-site conservation. Nat Struct Biol 6: 233-242, 1999.

73. Fitzal F, Redl H, Strohmaier W, Werner ER, and Bahrami S. A 4-amino analogue of tetrahydrobiopterin attenuates endotoxin-induced hemodynamic alterations and organ injury in rats. Shock 18: 158-162, 2002.

74. Fleming I, Bauersachs J, Fisslthaler B, and Busse R. $\mathrm{Ca} 2+$-independent activation of the endothelial nitric oxide synthase in response to tyrosine phosphatase inhibitors and fluid shear stress. Circ Res 82: 686-695, 1998.
75. Forstermann $U$ and Munzel T. Endothelial nitric oxide synthase in vascular disease: from marvel to menace. Circulation 113: 1708-1714, 2006.

76. Forstermann U and Sessa WC. Nitric oxide synthases: regulation and function. Eur Heart J 33: 829-837, 837a$837 d, 2012$

77. Franscini N, Blau N, Walter RB, Schaffner A, and Schoedon G. Critical role of interleukin-1beta for transcriptional regulation of endothelial 6-pyruvoyltetrahydropterin synthase. Arterioscler Thromb Vasc Biol 23: e50-e53, 2003.

78. Fukuda Y, Teragawa H, Matsuda K, Yamagata T, Matsuura $\mathrm{H}$, and Chayama K. Tetrahydrobiopterin improves coronary endothelial function, but does not prevent coronary spasm in patients with vasospastic angina. Circ $J$ 66: 58-62, 2002.

79. Fukuda Y, Teragawa H, Matsuda K, Yamagata T, Matsuura $\mathrm{H}$, and Chayama $\mathrm{K}$. Tetrahydrobiopterin restores endothelial function of coronary arteries in patients with hypercholesterolaemia. Heart 87: 264-269, 2002.

80. Furukawa Y, Kish SJ, Bebin EM, Jacobson RD, Fryburg JS, Wilson WG, Shimadzu M, Hyland K, and Trugman JM. Dystonia with motor delay in compound heterozygotes for GTP-cyclohydrolase I gene mutations. Ann Neurol 44: 10-16, 1998.

81. Gao L, Chalupsky K, Stefani E, and Cai H. Mechanistic insights into folic acid-dependent vascular protection: dihydrofolate reductase (DHFR)-mediated reduction in oxidant stress in endothelial cells and angiotensin II-infused mice: a novel HPLC-based fluorescent assay for DHFR activity. J Mol Cell Cardiol 47: 752-760, 2009.

82. Gao L, Pung YF, Zhang J, Chen P, Wang T, Li M, Meza $\mathrm{M}$, Toro L, and Cai H. Sepiapterin reductase regulation of endothelial tetrahydrobiopterin and nitric oxide bioavailability. Am J Physiol Heart Circ Physiol 297: H331H339, 2009.

83. Garthwaite J. Glutamate, nitric oxide and cell-cell signalling in the nervous system. Trends Neurosci 14: 60-67, 1991.

84. Ge ZD, Ionova IA, Vladic N, Pravdic D, Hirata N, Vasquez-Vivar J, Pratt PF Jr., Warltier DC, Pieper GM, and Kersten JR. Cardiac-specific overexpression of GTP cyclohydrolase 1 restores ischaemic preconditioning during hyperglycaemia. Cardiovasc Res 91: 340-349, 2011.

85. Gebicka L and Didik J. Catalytic scavenging of peroxynitrite by catalase. J Inorg Biochem 103: 1375-1379, 2009.

86. Ghosh DK and Stuehr DJ. Macrophage NO synthase: characterization of isolated oxygenase and reductase domains reveals a head-to-head subunit interaction. Biochemistry 34: 801-807, 1995.

87. Gielen S, Schuler G, and Adams V. Cardiovascular effects of exercise training: molecular mechanisms. Circulation 122: 1221-1238, 2010.

88. Giovanelli J, Campos KL, and Kaufman S. Tetrahydrobiopterin, a cofactor for rat cerebellar nitric oxide synthase, does not function as a reactant in the oxygenation of arginine. Proc Natl Acad Sci U S A 88: 7091-7095, 1991.

89. Gordon S. The macrophage: past, present and future. Eur J Immunol 37 Suppl 1: S9-S17, 2007.

90. Gorren AC, List BM, Schrammel A, Pitters E, Hemmens B, Werner ER, Schmidt K, and Mayer B. Tetrahydrobiopterinfree neuronal nitric oxide synthase: evidence for two identical 
highly anticooperative pteridine binding sites. Biochemistry 35: 16735-16745, 1996.

91. Griffith OW. Determination of glutathione and glutathione disulfide using glutathione reductase and 2-vinylpyridine. Anal Biochem 106: 207-212, 1980.

92. Gross SS and Levi R. Tetrahydrobiopterin synthesis: an absolute requirement for cytokine-induced nitric oxide generation by vascular smooth muscle. J Biol Chem 267: 25722-25729, 1992.

93. Gross SS, Jones CL, Hattori Y, and Raman CS. Tetrahydrobiopterin: an essential cofactor of nitric oxide synthase with an elusive role. In: Nitric Oxide: Biology and Pathobiology, edited by Ignarro LJ. Portland, OR: Academic Press, 2000, pp. 167-185.

94. Guerrero F, Thioub S, Goanvec C, Theunissen S, Feray A, Balestra C, and Mansourati J. Effect of tetrahydrobiopterin and exercise training on endotheliumdependent vasorelaxation in SHR. J Physiol Biochem 69: 277-287, 2013.

95. Guzik TJ, Mussa S, Gastaldi D, Sadowski J, Ratnatunga C, Pillai R, and Channon KM. Mechanisms of increased vascular superoxide production in human diabetes mellitus: Role of NAD(P)H oxidase and endothelial nitric oxide synthase. Circulation 105: 1656-1662, 2002.

96. Han RNN, Babaei S, Robb M, Lee T, Ridsdale R, Ackerley C, Post M, and Stewart DJ. Defective Lung Vascular Development and Fatal Respiratory Distress in Endothelial NO Synthase-Deficient Mice: A Model of Alveolar Capillary Dysplasia? Circ Res 94: 1115-1123, 2004.

97. Harada T, Kagamiyama H, and Hatakeyama K. Feedback regulation mechanisms for the control of GTP cyclohydrolase I activity. Science 260: 1507-1510, 1993.

98. Hattori Y, Nakanishi N, Akimoto K, Yoshida M, and Kasai K. HMG-CoA reductase inhibitor increases GTP cyclohydrolase I mRNA and tetrahydrobiopterin in vascular endothelial cells. Arterioscler Thromb Vasc Biol 23: 176-182, 2003.

99. Hattori Y, Hattori S, Wang X, Satoh H, Nakanishi N, and Kasai K. Oral administration of tetrahydrobiopterin slows the progression of atherosclerosis in apolipoprotein E-knockout mice. Arterioscler Thromb Vasc Biol 27: 865870, 2007.

100. Hauer CR, Rebrin I, Thony B, Neuheiser F, Curtius HC, Hunziker P, Blau N, Ghisla S, and Heizmann CW. Phenylalanine hydroxylase-stimulating protein/pterin-4 alphacarbinolamine dehydratase from rat and human liver. Purification, characterization, and complete amino acid sequence. J Biol Chem 268: 4828-4831, 1993.

101. He X, Su F, Velissaris D, Salgado DR, de Souza Barros D, Lorent S, Taccone FS, Vincent JL, and De Backer D. Administration of tetrahydrobiopterin improves the microcirculation and outcome in an ovine model of septic shock. Crit Care Med 40: 2833-2840, 2012.

102. Hefler LA, Reyes CA, O'Brien WE, and Gregg AR. Perinatal development of endothelial nitric oxide synthase-deficient mice. Biol Reprod 64: 666-673, 2001.

103. Heinloth A, Heermeier K, Raff U, Wanner C, and Galle J. Stimulation of NADPH oxidase by oxidized low-density lipoprotein induces proliferation of human vascular endothelial cells. J Am Soc Nephrol 11: 1819-1825, 2000.

104. Heitzer T, Yla-Herttuala S, Luoma J, Kurz S, Munzel T, Just H, Olschewski M, and Drexler H. Cigarette smoking potentiates endothelial dysfunction of forearm resistance vessels in patients with hypercholesterolemia. Role of oxidized LDL. Circulation 93: 1346-1353, 1996.

105. Heitzer T, Brockhoff C, Mayer B, Warnholtz A, Mollnau $\mathrm{H}$, Henne S, Meinertz T, and Munzel T. Tetrahydrobiopterin improves endothelium-dependent vasodilation in chronic smokers: evidence for a dysfunctional nitric oxide synthase. Circ Res 86: E36-E41, 2000.

106. Heitzer T, Krohn K, Albers S, and Meinertz T. Tetrahydrobiopterin improves endothelium-dependent vasodilation by increasing nitric oxide activity in patients with Type II diabetes mellitus. Diabetologia 43: 1435-1438, 2000.

107. Hevel JM and Marletta MA. Macrophage nitric oxide synthase: relationship between enzyme-bound tetrahydrobiopterin and synthase activity. Biochemistry 31: 7160-7165, 1992.

108. Higashi Y, Sasaki S, Nakagawa K, Fukuda Y, Matsuura $\mathrm{H}$, Oshima T, and Chayama K. Tetrahydrobiopterin enhances forearm vascular response to acetylcholine in both normotensive and hypertensive individuals. Am J Hypertens 15: 326-332, 2002.

109. Higashi Y, Sasaki S, Nakagawa K, Kimura M, Noma K, Hara K, Jitsuiki D, Goto C, Oshima T, Chayama K, and Yoshizumi M. Tetrahydrobiopterin improves agingrelated impairment of endothelium-dependent vasodilation through increase in nitric oxide production. Atherosclerosis 186: 390-395, 2006.

110. Hink U, Li H, Mollnau H, Oelze M, Matheis E, Hartmann M, Skatchkov M, Thaiss F, Stahl RA, Warnholtz A, Meinertz T, Griendling K, Harrison DG, Forstermann U, and Munzel T. Mechanisms underlying endothelial dysfunction in diabetes mellitus. Circ Res 88: E14-E22, 2001.

111. Hobbs AJ, Higgs A, and Moncada S. Inhibition of nitric oxide synthase as a potential therapeutic target. Annu Rev Pharmacol Toxicol 39: 191-220, 1999.

112. Holscher C and Rose SP. An inhibitor of nitric oxide synthesis prevents memory formation in the chick. Neurosci Lett 145: 165-167, 1992.

113. Hong HJ, Hsiao G, Cheng TH, and Yen MH. Supplementation with tetrahydrobiopterin suppresses the development of hypertension in spontaneously hypertensive rats. Hypertension 38: 1044-1048, 2001.

114. Hopkins FG. Note on Yellow Pigments in Butterflies. Nature 40: 335, 1889.

115. Hoshiai K, Hattan N, Fukuyama N, Tadaki F, Hida M, Saito A, Nakanishi N, Hattori Y, and Nakazawa H. Increased plasma tetrahydrobiopterin in septic shock is a possible therapeutic target. Pathophysiology 7: 275-281, 2001.

116. Hristov M and Weber C. Differential role of monocyte subsets in atherosclerosis. Thromb Haemost 106: 757762, 2011.

117. Huang A, Zhang YY, Chen K, Hatakeyama K, and Keaney JF, Jr. Cytokine-stimulated GTP cyclohydrolase I expression in endothelial cells requires coordinated activation of nuclear factor-kappaB and Stat1/Stat3. Circ Res 96: 164-171, 2005.

118. Huang PL, Huang Z, Mashimo H, Bloch KD, Moskowitz MA, Bevan JA, and Fishman MC. Hypertension in mice lacking the gene for endothelial nitric oxide synthase. Nature 377: 239-242, 1995.

119. Huie RE and Padmaja S. The reaction of NO with superoxide. Free Radic Res Commun 18: 195-199, 1993. 
120. Hurshman AR, Krebs C, Edmondson DE, Huynh BH, and Marletta MA. Formation of a pterin radical in the reaction of the heme domain of inducible nitric oxide synthase with oxygen. Biochemistry 38: 15689-15696, 1999.

121. Idigo WO, Reilly S, Zhang MH, Zhang YH, Jayaram R, Carnicer R, Crabtree MJ, Balligand JL, and Casadei B. Regulation of endothelial nitric-oxide synthase (NOS) Sglutathionylation by neuronal NOS: evidence of a functional interaction between myocardial constitutive NOS isoforms. J Biol Chem 287: 43665-43673, 2012.

122. Ignarro LJ. Physiology and pathophysiology of nitric oxide. Kidney Int Suppl 55: S2-S5, 1996.

123. Ignarro LJ. Nitric oxide as a unique signaling molecule in the vascular system: a historical overview. J Physiol Pharmacol 53: 503-514, 2002.

124. Ihlemann N, Rask-Madsen C, Perner A, Dominguez H, Hermann T, Kober L, and Torp-Pedersen C. Tetrahydrobiopterin restores endothelial dysfunction induced by an oral glucose challenge in healthy subjects. Am J Physiol Heart Circ Physiol 285: H875-H882, 2003.

125. Iiyama K, Hajra L, Iiyama M, Li H, DiChiara M, Medoff BD, and Cybulsky MI. Patterns of vascular cell adhesion molecule-1 and intercellular adhesion molecule-1 expression in rabbit and mouse atherosclerotic lesions and at sites predisposed to lesion formation. Circ Res 85: 199207, 1999.

126. Ionova IA, Vasquez-Vivar J, Whitsett J, Herrnreiter A, Medhora M, Cooley BC, and Pieper GM. Deficient BH4 production via de novo and salvage pathways regulates NO responses to cytokines in adult cardiac myocytes. Am J Physiol Heart Circ Physiol 295: H2178-H2187, 2008.

127. Iyengar R, Stuehr DJ, and Marletta MA. Macrophage synthesis of nitrite, nitrate, and N-nitrosamines: precursors and role of the respiratory burst. Proc Natl Acad Sci U S A 84: 6369-6373, 1987.

128. James $G$ and Olson EN. Identification of a novel fatty acylated protein that partitions between the plasma membrane and cytosol and is deacylated in response to serum and growth factor stimulation. J Biol Chem 264: 20998-21006, 1989.

129. Jessup JA, Zhang L, Presley TD, Kim-Shapiro DB, Wang $\mathrm{H}$, Chen AF, and Groban L. Tetrahydrobiopterin restores diastolic function and attenuates superoxide production in ovariectomized mRen2.Lewis rats. Endocrinology 152: 2428-2436, 2011.

130. Kang K-T, Sullivan JC, Spradley FT, d'Uscio LV, Katusic ZS, and Pollock JS. Antihypertensive therapy increases tetrahydrobiopterin levels and NO/cGMP signaling in small arteries of angiotensin II-infused hypertensive rats. Am J Physiol 300: H718-H724, 2011.

131. Kang-Decker N, Cao S, Chatterjee S, Yao J, Egan LJ, Semela D, Mukhopadhyay D, and Shah V. Nitric oxide promotes endothelial cell survival signaling through S-nitrosylation and activation of dynamin-2. J Cell Sci 120: 492-501, 2007.

132. Kaptoge S, Di Angelantonio E, Lowe G, Pepys MB, Thompson SG, Collins R, and Danesh J. C-reactive protein concentration and risk of coronary heart disease, stroke, and mortality: an individual participant metaanalysis. Lancet 375: 132-140, 2010.

133. Kase H, Hashikabe Y, Uchida K, Nakanishi N, and Hattori Y. Supplementation with tetrahydrobiopterin prevents the cardiovascular effects of angiotensin II-induced oxidative and nitrosative stress. J Hypertens 23: 1375-1382, 2005.
134. Katusic ZS, Stelter A, and Milstien S. Cytokines stimulate GTP cyclohydrolase I gene expression in cultured human umbilical vein endothelial cells. Arterioscler Thromb Vasc Biol 18: 27-32, 1998

135. Kaufman S. Some metabolic relationships between biopterin and folate: implications for the "methyl trap hypothesis". Neurochem Res 16: 1031-1036, 1991.

136. Kerr S, Brosnan MJ, McIntyre M, Reid JL, Dominiczak $\mathrm{AF}$, and Hamilton CA. Superoxide anion production is increased in a model of genetic hypertension: role of the endothelium. Hypertension 33: 1353-1358, 1999.

137. Khoo JP, Zhao L, Alp NJ, Bendall JK, Nicoli T, Rockett $\mathrm{K}$, Wilkins MR, and Channon KM. A pivotal role for tetrahydrobiopterin in pulmonary hypertension. Circulation 111: 2126-2133, 2005.

138. Kilbourn RG, Traber DL, and Szabo C. Nitric oxide and shock. Dis Mon 43: 277-348, 1997.

139. Klatt P, Schmidt K, Brunner F, and Mayer B. Inhibitors of brain nitric oxide synthase. Binding kinetics, metabolism, and enzyme inactivation. J Biol Chem 269: 1674-1680, 1994.

140. Klatt P, Schmidt K, Lehner D, Glatter O, Bachinger HP, and Mayer B. Structural analysis of porcine brain nitric oxide synthase reveals a role for tetrahydrobiopterin and L-arginine in the formation of an SDS-resistant dimer. Embo J 14: 3687-3695, 1995.

141. Kobayashi K, Morita S, Sawada H, Mizuguchi T, Yamada K, Nagatsu I, Hata T, Watanabe Y, Fujita K, and Nagatsu T. Targeted Disruption of the Tyrosine Hydroxylase Locus Results in Severe Catecholamine Depletion and Perinatal Lethality in Mice. J Biol Chem 270: 27235 27243, 1995.

142. Kuhlencordt PJ, Chen J, Han F, Astern J, and Huang PL. Genetic deficiency of inducible nitric oxide synthase reduces atherosclerosis and lowers plasma lipid peroxides in apolipoprotein E-knockout mice. Circulation 103: 30993104, 2001.

143. Kuhlencordt PJ, Gyurko R, Han F, Scherrer-Crosbie M, Aretz TH, Hajjar R, Picard MH, and Huang PL. Accelerated atherosclerosis, aortic aneurysm formation, and ischemic heart disease in apolipoprotein E/endothelial nitric oxide synthase double-knockout mice. Circulation 104: 448-454, 2001.

144. Kuhlencordt PJ, Hotten S, Schodel J, Rutzel S, Hu K, Widder J, Marx A, Huang PL, and Ertl G. Atheroprotective Effects of Neuronal Nitric Oxide Synthase in Apolipoprotein E Knockout Mice. Arterioscler Thromb Vasc Biol 26: 1539-1544, 2006.

145. Kuzkaya N, Weissmann N, Harrison DG, and Dikalov S. Interactions of peroxynitrite, tetrahydrobiopterin, ascorbic acid, and thiols: implications for uncoupling endothelial nitric-oxide synthase. J Biol Chem 278: 22546-22554, 2003

146. Kwon NS, Nathan CF, and Stuehr DJ. Reduced biopterin as a cofactor in the generation of nitrogen oxides by murine macrophages. J Biol Chem 264: 20496-20501, 1989.

147. Lam CF, Peterson TE, Richardson DM, Croatt AJ, d'Uscio LV, Nath KA, and Katusic ZS. Increased blood flow causes coordinated upregulation of arterial eNOS and biosynthesis of tetrahydrobiopterin. Am J Physiol Heart Circ Physiol 290: H786-H793, 2006.

148. Landmesser U, Dikalov S, Price SR, McCann L, Fukai T, Holland SM, Mitch WE, and Harrison DG. Oxidation of 
tetrahydrobiopterin leads to uncoupling of endothelial cell nitric oxide synthase in hypertension. J Clin Invest 111: 1201-1209, 2003.

149. Laursen JB, Somers M, Kurz S, McCann L, Warnholtz A, Freeman BA, Tarpey M, Fukai T, and Harrison DG. Endothelial regulation of vasomotion in apoE-deficient mice: implications for interactions between peroxynitrite and tetrahydrobiopterin. Circulation 103: 1282-1288, 2001.

150. Lee C-K, Han JS, Won K-J, Jung S-H, Park H-J, Lee HM, Kim J, Park YS, Kim H-J, Park P-J, Park T-K, and Kim B. Diminished expression of dihydropteridine reductase is a potent biomarker for hypertensive vessels. Proteomics 9: 4851-4858, 2009.

151. Leone AM, Palmer RM, Knowles RG, Francis PL, Ashton DS, and Moncada S. Constitutive and inducible nitric oxide synthases incorporate molecular oxygen into both nitric oxide and citrulline. J Biol Chem 266: 23790 23795, 1991.

152. Levy HL, Milanowski A, Chakrapani A, Cleary M, Lee P, Trefz FK, Whitley CB, Feillet F, Feigenbaum AS, Bebchuk JD, Christ-Schmidt H, and Dorenbaum A. Efficacy of sapropterin dihydrochloride (tetrahydrobiopterin, 6R$\mathrm{BH} 4)$ for reduction of phenylalanine concentration in patients with phenylketonuria: a phase III randomised placebo-controlled study. Lancet 370: 504-510, 2007.

153. Li J-M and Shah AM. Mechanism of Endothelial Cell NADPH Oxidase Activation by Angiotensin II. J Biol Chem 278: 12094-12100, 2003.

154. Li L, Rezvan A, Salerno JC, Husain A, Kwon K, Jo H, Harrison DG, and Chen W. GTP cyclohydrolase I phosphorylation and interaction with GTP cyclohydrolase feedback regulatory protein provide novel regulation of endothelial tetrahydrobiopterin and nitric oxide. Circ Res 106: 328-336, 2010.

155. Li L, Chen W, Rezvan A, Jo H, and Harrison DG. Tetrahydrobiopterin deficiency and nitric oxide synthase uncoupling contribute to atherosclerosis induced by disturbed flow. Arterioscler Thromb Vasc Biol 31: 15471554, 2011.

156. Liao S-J, Lin L, Zeng JS, Huang R-X, Channon KM, and Chen AF. Endothelium-targeted transgenic GTPcyclohydrolase I overexpression inhibits neointima formation in mouse carotid artery. Clin Exp Pharmacol Physiol 34: 1260-1266, 2007.

157. Lieu HD, Withycombe SK, Walker Q, Rong JX, Walzem RL, Wong JS, Hamilton RL, Fisher EA, and Young SG. Eliminating atherogenesis in mice by switching off hepatic lipoprotein secretion. Circulation 107: 1315-1321, 2003.

158. Liu Q and Gross SS. Binding sites of nitric oxide synthases. Methods Enzymol 268: 311-324, 1996.

159. Liu Y, Lu X, Xiang F-L, Poelmann RE, Gittenberger-de Groot AC, Robbins J, and Feng Q. Nitric oxide synthase-3 deficiency results in hypoplastic coronary arteries and postnatal myocardial infarction. Eur Heart J 2012. [Epub ahead of print]; DOI: 10.1093/eurheartj/ehs306.

160. Lopez A, Lorente JA, Steingrub J, Bakker J, McLuckie A, Willatts S, Brockway M, Anzueto A, Holzapfel L, Breen D, Silverman MS, Takala J, Donaldson J, Arneson C, Grove G, Grossman S, and Grover R. Multiple-center, randomized, placebo-controlled, double-blind study of the nitric oxide synthase inhibitor 546C88: effect on survival in patients with septic shock. Crit Care Med 32: 21-30, 2004.
161. Luoma JS and Yla-Herttuala S. Expression of inducible nitric oxide synthase in macrophages and smooth muscle cells in various types of human atherosclerotic lesions. Virchows Arch 434: 561-568, 1999.

162. Mack M, Cihak J, Simonis C, Luckow B, Proudfoot AE, Plachy J, Bruhl H, Frink M, Anders HJ, Vielhauer V, Pfirstinger J, Stangassinger M, and Schlondorff D. Expression and characterization of the chemokine receptors CCR2 and CCR5 in mice. J Immunol 166: 4697-4704, 2001.

163. Maier W, Cosentino F, Lutolf RB, Fleisch M, Seiler C, Hess OM, Meier B, and Luscher TF. Tetrahydrobiopterin improves endothelial function in patients with coronary artery disease. J Cardiovasc Pharmacol 35: 173-178, 2000.

164. Mantovani A, Garlanda C, and Locati M. Macrophage diversity and polarization in atherosclerosis: a question of balance. Arterioscler Thromb Vasc Biol 29: 1419-1423, 2009.

165. Marinos RS, Zhang W, Wu G, Kelly KA, and Meininger CJ. Tetrahydrobiopterin levels regulate endothelial cell proliferation. Am J Physiol Heart Circ Physiol 281: H482-H489, 2001.

166. Marletta MA. Nitric oxide synthase structure and mechanism. J Biol Chem 268: 12231-12234, 1993.

167. Martasek P, Miller RT, Liu Q, Roman LJ, Salerno JC, Migita CT, Raman CS, Gross SS, Ikeda-Saito M, and Masters BS. The C331A mutant of neuronal nitric-oxide synthase is defective in arginine binding. $J$ Biol Chem 273: 34799-34805, 1998.

168. Masano T, Kawashima S, Toh R, Satomi-Kobayashi S, Shinohara M, Takaya T, Sasaki N, Takeda M, Tawa H, Yamashita T, Yokoyama M, and Hirata K. Beneficial effects of exogenous tetrahydrobiopterin on left ventricular remodeling after myocardial infarction in rats: the possible role of oxidative stress caused by uncoupled endothelial nitric oxide synthase. Circ J 72: 1512-1519, 2008.

169. Masters BS, McMillan K, Nishimura J, Martasek P, Roman LJ, Sheta E, Gross SS, and Salerno J. Understanding the structural aspects of neuronal nitric oxide synthase (NOS) using microdissection by molecular cloning techniques: molecular dissection of neuronal NOS. Adv Exp Med Biol 387: 163-169, 1996.

170. Masters BS, McMillan K, Sheta EA, Nishimura JS, Roman LJ, and Martasek P. Neuronal nitric oxide synthase, a modular enzyme formed by convergent evolution: structure studies of a cysteine thiolate-liganded heme protein that hydroxylates L-arginine to produce NO. as a cellular signal. [published erratum appears in FASEB J 1996 Jul;10(9):1107]. FASEB J 10: 552-558, 1996.

171. Matsubara $M$ and Akino $M$. On the presence of sepiapterin reductase different from folate and dihydrofolate reductase in chicken liver. Experientia 20: 574-575, 1964.

172. Mayahi L, Heales S, Owen D, Casas JP, Harris J, MacAllister RJ, and Hingorani AD. (6R)-5,6,7,8-tetrahydro-L-biopterin and its stereoisomer prevent ischemia reperfusion injury in human forearm. Arterioscler Thromb Vasc Biol 27: 1334-1339, 2007.

173. McGuire JJ. Anticancer antifolates: current status and future directions. Curr Pharm Des 9: 2593-2613, 2003.

174. McNeill E, Channon KM, and Greaves DR. Inflammatory cell recruitment in cardiovascular disease: murine models and potential clinical applications. Clin Sci 118: 641-655, 2010 . 
175. Meininger CJ, Marinos RS, Hatakeyama K, MartinezZaguilan R, Rojas JD, Kelly KA, and Wu G. Impaired nitric oxide production in coronary endothelial cells of the spontaneously diabetic BB rat is due to tetrahydrobiopterin deficiency. Biochem J 349: 353-356, 2000.

176. Miller JD, Chu Y, Castaneda LE, Serrano KM, Brooks RM, and Heistad DD. Vascular function during prolonged progression and regression of atherosclerosis in mice. Arterioscler Thromb Vasc Biol 33: 459-465, 2013.

177. Milstien S, Jaffe H, Kowlessur D, and Bonner TI. Purification and cloning of the GTP cyclohydrolase I feedback regulatory protein, GFRP. J Biol Chem 271: 19743-19751, 1996.

178. Milstien S and Katusic Z. Oxidation of tetrahydrobiopterin by peroxynitrite: implications for vascular endothelial function. Biochem Biophys Res Commun 263: 681-684, 1999.

179. Mitchell BM, Dorrance AM, and Webb RC. GTP cyclohydrolase 1 inhibition attenuates vasodilation and increases blood pressure in rats. Am J Physiol 285: H2165-H2170, 2003.

180. Mitchell HH, Schonle HA, and Grindly HS. The origin of nitrates in the urine. J Biol Chem 24: 461-490, 1916.

181. Miyoshi T, Li Y, Shih DM, Wang X, Laubach VE, Matsumoto AH, Helm GA, Lusis AJ, and Shi W. Deficiency of inducible NO synthase reduces advanced but not early atherosclerosis in apolipoprotein E-deficient mice. Life Sci 79: 525-531, 2006.

181a. Moens AL, Ketner EA, Takimoto E, Schmidt TS, O’Neill CA, Wolin MS, Alp NJ, Channon KM, and Kass DA. Bi-modal dose-dependent cardiac response to tetrahydrobiopterin in pressure-overload induced hypertrophy and heart failure. J Mol Cell Cardiol 51, 564-569, 2011.

182. Moens AL, Takimoto E, Tocchetti CG, Chakir K, Bedja D, Cormaci G, Ketner EA, Majmudar M, Gabrielson K, Halushka MK, Mitchell JB, Biswal S, Channon KM, Wolin MS, Alp NJ, Paolocci N, Champion HC, and Kass DA. Reversal of cardiac hypertrophy and fibrosis from pressure overload by tetrahydrobiopterin: efficacy of recoupling nitric oxide synthase as a therapeutic strategy. Circulation 117: 2626-2636, 2008.

183. Mollnau H, Wendt M, Szocs K, Lassegue B, Schulz E, Oelze M, Li H, Bodenschatz M, August M, Kleschyov AL, Tsilimingas N, Walter U, Forstermann U, Meinertz T, Griendling K, and Munzel T. Effects of angiotensin II infusion on the expression and function of $\mathrm{NAD}(\mathrm{P}) \mathrm{H}$ oxidase and components of nitric oxide/cGMP signaling. Circ Res 90: E58-E65, 2002.

184. This reference has been deleted.

185. Murohara T, Asahara T, Silver M, Bauters C, Masuda H, Kalka C, Kearney M, Chen D, Symes JF, Fishman MC, Huang PL, and Isner JM. Nitric oxide synthase modulates angiogenesis in response to tissue ischemia. J Clin Invest 101: 2567-2578, 1998.

186. Nagareddy PR, Xia Z, McNeill JH, and MacLeod KM. Increased expression of iNOS is associated with endothelial dysfunction and impaired pressor responsiveness in streptozotocin-induced diabetes. Am J Physiol Heart Circ Physiol 289: H2144-H2152, 2005.

187. Nagatsu T, Levitt M, and Udenfriend S. Conversion of L-tyrosine to 3,4-dihydroxyphenylalanine by cell-free preparations of brain and sympathetically innervated tissues. Biochem Biophys Res Commun 14: 543-549, 1964.

188. Nakashima Y, Plump AS, Raines EW, Breslow JL, and Ross R. ApoE-deficient mice develop lesions of all phases of atherosclerosis throughout the arterial tree. Arterioscler Thromb 14: 133-140, 1994.

189. Nakashima Y, Raines EW, Plump AS, Breslow JL, and Ross R. Upregulation of VCAM-1 and ICAM-1 at atherosclerosis-prone sites on the endothelium in the ApoE-deficient mouse. Arterioscler Thromb Vasc Biol 18: 842-851, 1998.

190. Nichol CA, Lee CL, Edelstein MP, Chao JY, and Duch DS. Biosynthesis of tetrahydrobiopterin by de novo and salvage pathways in adrenal medulla extracts, mammalian cell cultures, and rat brain in vivo. Proc Natl Acad Sci U S A 80: 1546-1550, 1983.

191. Noguchi K, Hamadate N, Matsuzaki T, Sakanashi M, Nakasone J, Sakanashi M, Tsutsui M, and Sakanashi M. Improvement of impaired endothelial function by tetrahydrobiopterin in stroke-prone spontaneously hypertensive rats. Eur J Pharmacol 631: 28-35, 2010.

192. This reference has been deleted.

193. Nystrom T, Nygren A, and Sjoholm A. Tetrahydrobiopterin increases insulin sensitivity in patients with type 2 diabetes and coronary heart disease. Am J Physiol Endocrinol Metab 287: E919-E925, 2004.

194. Nzila A, Ward SA, Marsh K, Sims PF, and Hyde JE. Comparative folate metabolism in humans and malaria parasites (part I): pointers for malaria treatment from cancer chemotherapy. Trends Parasitol 21: 292-298, 2005.

195. Okazaki T, Otani H, Shimazu T, Yoshioka K, Fujita M, Katano T, Ito S, and Iwasaka T. Reversal of inducible nitric oxide synthase uncoupling unmasks tolerance to ischemia/reperfusion injury in the diabetic rat heart. $J \mathrm{Mol}$ Cell Cardiol 50: 534-544, 2011.

196. Oliveira-Dos-Santos AJ, Matsumoto G, Snow BE, Bai D, Houston FP, Whishaw IQ, Mariathasan S, Sasaki T, Wakeham A, Ohashi PS, Roder JC, Barnes CA, Siderovski DP, and Penninger JM. Regulation of T cell activation, anxiety, and male aggression by RGS2. Proc Natl Acad Sci U S A 97: 12272-12277, 2000.

197. Ozaki M, Kawashima S, Yamashita T, Hirase T, Namiki M, Inoue N, Hirata K-i, Yasui H, Sakurai H, Yoshida Y, Masada M, and Yokoyama M. Overexpression of endothelial nitric oxide synthase accelerates atherosclerotic lesion formation in apoE-deficient mice. J Clin Invest 110 : 331-340, 2002.

198. Pallares P, Garcia-Fernandez RA, Criado LM, Letelier CA, Esteban D, Fernandez-Toro JM, Flores JM, and Gonzalez-Bulnes A. Disruption of the endothelial nitric oxide synthase gene affects ovulation, fertilization and early embryo survival in a knockout mouse model. Reproduction 136: 573-579, 2008.

199. This reference has been deleted.

200. Papapetropoulos A, Garcia-Cardena G, Madri JA, and Sessa WC. Nitric oxide production contributes to the angiogenic properties of vascular endothelial growth factor in human endothelial cells. J Clin Invest 100: 3131-3139, 1997.

201. Park J-H, Na H-J, Kwon Y-G, Ha K-S, Lee S-J, Kim C-K, Lee K-S, Yoneyama T, Hatakeyama K, Kim PKM, Billiar $\mathrm{TR}$, and Kim Y-M. Nitric Oxide (NO) pretreatment increases cytokine-induced NO production in cultured rat hepatocytes by suppressing GTP cyclohydrolase I feedback inhibitory protein level and promoting inducible NO synthase dimerization. J Biol Chem 277: 47073-47079, 2002. 
202. Parrillo JE. Myocardial depression during septic shock in humans. Crit Care Med 18: 1183-1184, 1990.

203. Paton JF, Kasparov S, and Paterson DJ. Nitric oxide and autonomic control of heart rate: a question of specificity. Trends Neurosci 25: 626-631, 2002.

204. Pickert G, Lim HY, Weigert A, Haussler A, Myrczek T, Waldner M, Labocha S, Ferreiros N, Geisslinger G, Lotsch J, Becker C, Brune B, and Tegeder I. Inhibition of GTP cyclohydrolase attenuates tumor growth by reducing angiogenesis and M2-like polarization of tumor associated macrophages. Int J Cancer 132: 591-604, 2013.

205. Pieper GM. Acute amelioration of diabetic endothelial dysfunction with a derivative of the nitric oxide synthase cofactor, tetrahydrobiopterin. J Cardiovasc Pharmacol 29: 8-15, 1997.

206. Pierce GL, Jablonski KL, Walker AE, Seibert SM, DeVan AE, Black SM, Sharma S, and Seals DR. Tetrahydrobiopterin supplementation enhances carotid artery compliance in healthy older men: a pilot study. Am $J$ Hypertens 25: 1050-1054, 2012.

207. Pimentel DR, Amin JK, Xiao L, Miller T, Viereck J, Oliver-Krasinski J, Baliga R, Wang J, Siwik DA, Singh K, Pagano P, Colucci WS, and Sawyer DB. Reactive oxygen species mediate amplitude-dependent hypertrophic and apoptotic responses to mechanical stretch in cardiac myocytes. Circ Res 89: 453-460, 2001.

208. Ponnuswamy P, Ostermeier E, Schrottle A, Chen J, Huang PL, Ertl G, Nieswandt B, and Kuhlencordt PJ. Oxidative stress and compartment of gene expression determine proatherosclerotic effects of inducible nitric oxide synthase. Am J Pathol 174: 2400-2410, 2009.

209. Ponnuswamy P, Schrottle A, Ostermeier E, Gruner S, Huang PL, Ertl G, Hoffmann U, Nieswandt B, and Kuhlencordt PJ. eNOS protects from atherosclerosis despite relevant superoxide production by the enzyme in apoE mice. PLoS One 7: e30193, 2012.

210. Porkert M, Sher S, Reddy U, Cheema F, Niessner C, Kolm P, Jones DP, Hooper C, Taylor WR, Harrison D, and Quyyumi AA. Tetrahydrobiopterin: a novel antihypertensive therapy. J Hum Hypertens 22: 401-407, 2008.

211. Portbury AL, Chandra R, Groelle M, McMillian MK, Elias A, Herlong JR, Rios M, Roffler-Tarlov S, and Chikaraishi DM. Catecholamines act via a $\beta$-adrenergic receptor to maintain fetal heart rate and survival. Am $J$ Physiol 284: H2069-H2077, 2003.

212. Presta A, Siddhanta U, Wu C, Sennequier N, Huang L, Abu-Soud HM, Erzurum S, and Stuehr DJ. Comparative functioning of dihydro- and tetrahydropterins in supporting electron transfer, catalysis, and subunit dimerization in inducible nitric oxide synthase. Biochemistry 37: 298310, 1998.

213. Raman CS, Li H, Martasek P, Kral V, Masters BS, and Poulos TL. Crystal structure of constitutive endothelial nitric oxide synthase: a paradigm for pterin function involving a novel metal center. Cell 95: 939-950, 1998.

214. Rees DD, Palmer RM, and Moncada S. Role of endothelium-derived nitric oxide in the regulation of blood pressure. Proc Natl Acad Sci 86: 3375-3378, 1989.

215. Reilly SN, Jayaram R, Nahar K, Antoniades C, Verheule S, Channon KM, Alp NJ, Schotten U, and Casadei B. Atrial sources of reactive oxygen species vary with the duration and substrate of atrial fibrillation: implications for the antiarrhythmic effect of statins. Circulation 124: 1107-1117, 2011.
216. Ren J, Duan J, Thomas DP, Yang X, Sreejayan N, Sowers JR, Leri A, Kajstura J, Gao F, and Anversa P. IGF-I alleviates diabetes-induced RhoA activation, eNOS uncoupling, and myocardial dysfunction. Am J Physiol Regul Integr Comp Physiol 294: R793-R802, 2008.

217. Ribiere C, Jaubert AM, Gaudiot N, Sabourault D, Marcus ML, Boucher JL, Denis-Henriot D, and Giudicelli Y. White adipose tissue nitric oxide synthase: a potential source for NO production. Biochem Biophys Res Commun 222: 706-712, 1996.

218. Ridker PM, Cushman M, Stampfer MJ, Tracy RP, and Hennekens $\mathrm{CH}$. Inflammation, aspirin, and the risk of cardiovascular disease in apparently healthy men. $N \mathrm{Engl}$ J Med 336: 973-979, 1997.

219. Riethmuller C, Gorren AC, Pitters E, Hemmens B, Habisch HJ, Heales SJ, Schmidt K, Werner ER, and Mayer B. Activation of neuronal nitric-oxide synthase by the 5-methyl analog of tetrahydrobiopterin. Functional evidence against reductive oxygen activation by the pterin cofactor. J Biol Chem 274: 16047-16051, 1999.

220. Robbins IM, Hemnes AR, Gibbs JS, Christman BW, Howard L, Meehan S, Cabrita I, Gonzalez R, Oyler T, Zhao L, Du RH, Mendes LA, and Wilkins MR. Safety of sapropterin dihydrochloride (6r-bh4) in patients with pulmonary hypertension. Exp Lung Res 37: 26-34, 2011.

221. Rodriguez-Crespo I, Gerber NC, and Ortiz de Montellano PR. Endothelial nitric-oxide synthase. Expression in Escherichia coli, spectroscopic characterization, and role of tetrahydrobiopterin in dimer formation. J Biol Chem 271: 11462-11467, 1996.

222. Rosenkranz-Weiss P, Sessa WC, Milstien S, Kaufman S, Watson CA, and Pober JS. Regulation of nitric oxide synthesis by proinflammatory cytokines in human umbilical vein endothelial cells. J Clin Invest 93: 2236-2243, 1993.

223. Ross R. Atherosclerosis-an inflammatory disease. $N$ Engl J Med 340: 115-126, 1999.

224. Rossig L, Haendeler J, Hermann C, Malchow P, Urbich C, Zeiher AM, and Dimmeler S. Nitric oxide down-regulates MKP-3 mRNA levels: involvement in endothelial cell protection from apoptosis. J Biol Chem 275: 2550225507, 2000.

225. Satoh M, Fujimoto S, Arakawa S, Yada T, Namikoshi T, Haruna Y, Horike H, Sasaki T, and Kashihara N. Angiotensin II type 1 receptor blocker ameliorates uncoupled endothelial nitric oxide synthase in rats with experimental diabetic nephropathy. Nephrol Dial Transplant 23: 38063813, 2008.

226. Schmidt TS, McNeill E, Douglas G, Crabtree MJ, Hale AB, Khoo J, O'Neill CA, Cheng A, Channon KM, and Alp NJ. Tetrahydrobiopterin supplementation reduces atherosclerosis and vascular inflammation in apolipoprotein E-knockout mice. Clin Sci 119: 131-142, 2010.

227. Schoedon G, Troppmair J, Fontana A, Huber C, Curtius H, and Niederwieser A. Biosynthesis and metabolism of pterins in peripheral blood mononuclear cells and leukemia lines of man and mouse. Eur J Biochem 166: 303310, 1987.

228. Schumacher M, Halwachs G, Tatzber F, Fruhwald FM, Zweiker R, Watzinger N, Eber B, Wilders-Truschnig M, Esterbauer $\mathrm{H}$, and Klein W. Increased neopterin in patients with chronic and acute coronary syndromes. J Am Coll Cardiol 30: 703-707, 1997.

229. Sears CE, Bryant SM, Ashley EA, Lygate CA, Rakovic S, Wallis HL, Neubauer S, Terrar DA, and Casadei B. Car- 
diac neuronal nitric oxide synthase isoform regulates myocardial contraction and calcium handling. Circ Res 92: e52-e59, 2003.

230. Seddon MD, Chowienczyk PJ, Brett SE, Casadei B, and Shah AM. Neuronal nitric oxide synthase regulates basal microvascular tone in humans in vivo. Circulation 117: 1991-1996, 2008.

231. This reference has been deleted.

232. Sessa WC, Barber CM, and Lynch KR. Mutation of $\mathrm{N}$-myristoylation site converts endothelial cell nitric oxide synthase from a membrane to a cytosolic protein. Circ Res 72: 921-924, 1993.

233. Setoguchi S, Mohri M, Shimokawa H, and Takeshita A. Tetrahydrobiopterin improves endothelial dysfunction in coronary microcirculation in patients without epicardial coronary artery disease. J Am Coll Cardiol 38: 493-498, 2001.

234. Setoguchi S, Hirooka Y, Eshima K, Shimokawa H, and Takeshita A. Tetrahydrobiopterin improves impaired endothelium-dependent forearm vasodilation in patients with heart failure. J Cardiovasc Pharmacol 39: 363-368, 2002.

235. This reference has been deleted.

236. Shah AM and MacCarthy PA. Paracrine and autocrine effects of nitric oxide on myocardial function. Pharmacol Ther 86: 49-86, 2000.

237. Shen RS, Alam A, and Zhang YX. Inhibition of GTP cyclohydrolase I by pterins. Biochim Biophys Acta 965: 915, 1988.

238. Sherer Y and Shoenfeld Y. Mechanisms of disease: atherosclerosis in autoimmune diseases. Nat Clin Pract Rheumatol 2: 99-106, 2006.

239. Shimizu S, Ishii M, Kawakami Y, Momose K, and Yamamoto T. Protective effects of tetrahydrobiopterin against nitric oxide-induced endothelial cell death. Life Sci 63: 1585-1592, 1998.

240. Shimizu S, Ishii M, Kawakami Y, Kiuchi Y, Momose K, and Yamamoto T. Presence of excess tetrahydrobiopterin during nitric oxide production from inducible nitric oxide synthase in LPS-treated rat aorta. Life Sci 65: 2769-2779, 1999.

241. Shimizu S, Yasuda M, Ishii M, Nagai T, Kiuchi Y, and Yamamoto T. Stimulation of in vitro angiogenesis by tetrahydrobiopterin in bovine aortic endothelial cells. Jpn J Pharmacol 80: 177-180, 1999.

242. Shimizu S, Shiota K, Yamamoto S, Miyasaka Y, Ishii M, Watabe T, Nishida M, Mori Y, Yamamoto T, and Kiuchi Y. Hydrogen peroxide stimulates tetrahydrobiopterin synthesis through the induction of GTP-cyclohydrolase I and increases nitric oxide synthase activity in vascular endothelial cells. Free Radic Biol Med 34: 1343-1352, 2003.

243. Shimizu S, Ishii M, Miyasaka Y, Wajima T, Negoro T, Hagiwara T, and Kiuchi Y. Possible involvement of hydroxyl radical on the stimulation of tetrahydrobiopterin synthesis by hydrogen peroxide and peroxynitrite in vascular endothelial cells. Int J Biochem Cell Biol 37: 864$875,2005$.

244. Shimizu S, Hiroi T, Ishii M, Hagiwara T, Wajima T, Miyazaki A, and Kiuchi Y. Hydrogen peroxide stimulates tetrahydrobiopterin synthesis through activation of the Jak2 tyrosine kinase pathway in vascular endothelial cells. Int J Biochem Cell Biol 40: 755-765, 2008.

245. Shinozaki K, Nishio Y, Okamura T, Yoshida Y, Maegawa H, Kojima H, Masada M, Toda N, Kikkawa R, and Ka- shiwagi A. Oral administration of tetrahydrobiopterin prevents endothelial dysfunction and vascular oxidative stress in the aortas of insulin-resistant rats. Circ Res 87: 566-573, 2000.

246. Shinozaki K, Nishio Y, Yoshida Y, Koya D, Ayajiki K, Masada M, Kashiwagi A, and Okamura T. Supplement of tetrahydrobiopterin by a gene transfer of GTP cyclohydrolase I cDNA improves vascular dysfunction in insulin-resistant rats. J Cardiovasc Pharmacol 46: 505$512,2005$.

247. Silberman GA, Fan TH, Liu H, Jiao Z, Xiao HD, Lovelock JD, Boulden BM, Widder J, Fredd S, Bernstein KE, Wolska BM, Dikalov S, Harrison DG, and Dudley SC, Jr. Uncoupled cardiac nitric oxide synthase mediates diastolic dysfunction. Circulation 121: 519$528,2010$.

248. Sindler AL, Delp MD, Reyes R, Wu G, and Muller-Delp JM. Effects of ageing and exercise training on eNOS uncoupling in skeletal muscle resistance arterioles. J Physiol 587: 3885-3897, 2009.

249. Smith TW, Balligand JL, Kaye DM, Wiviott SD, Simmons WW, Han X, Michel T, Singh K, and Kelly RA. The role of the NO pathway in the control of cardiac function. J Card Fail 2: S141-S147, 1996.

250. Sommer F, Klotz T, Steinritz D, and Bloch W. Evaluation of tetrahydrobiopterin (BH4) as a potential therapeutic agent to treat erectile dysfunction. Asian J Androl 8: 159167, 2006.

251. Soskic SS, Dobutovic BD, Sudar EM, Obradovic MM, Nikolic DM, Djordjevic JD, Radak DJ, Mikhailidis DP, and Isenovic ER. Regulation of Inducible Nitric Oxide Synthase (iNOS) and its Potential Role in Insulin Resistance, Diabetes and Heart Failure. Open Cardiovasc Med J 5: 153-163, 2011.

252. Spieker LE, Luscher TF, and Noll G. Current strategies and perspectives for correcting endothelial dysfunction in atherosclerosis. J Cardiovasc Pharmacol 38 Suppl 2: S35-S41, 2001.

253. Stauss HM, Nafz B, Mrowka R, and Persson PB. Blood pressure control in eNOS knock-out mice: comparison with other species under NO blockade. Acta Physiol Scand 168: 155-160, 2000.

254. Stoodley M, Weihl CC, Zhang ZD, Lin G, Johns LM, Kowalczuk A, Ghadge G, Roos RP, and Macdonald RL. Effect of adenovirus-mediated nitric oxide synthase gene transfer on vasospasm after experimental subarachnoid hemorrhage. Neurosurgery 46: 1193-1202; discussion 1202-1193, 2000.

255. Stout RD, Jiang C, Matta B, Tietzel I, Watkins SK, and Suttles J. Macrophages sequentially change their functional phenotype in response to changes in microenvironmental influences. J Immunol 175: 342-349, 2005.

256. Stroes E, Kastelein J, Cosentino F, Erkelens W, Wever R, Koomans H, Luscher $\mathrm{T}$, and Rabelink T. Tetrahydrobiopterin restores endothelial function in hypercholesterolemia. J Clin Invest 99: 41-46, 1997.

257. This reference has been deleted.

258. Stroes E, Hijmering M, van Zandvoort M, Wever R, Rabelink TJ, and van Faassen EE. Origin of superoxide production by endothelial nitric oxide synthase. FEBS Lett 438: 161-164, 1998.

259. Stuehr DJ and Marletta MA. Further studies on murine macrophage synthesis of nitrite and nitrate. IARC Sci Publ 84: 335-339, 1987. 
260. Stuehr DJ and Ikeda-Saito M. Spectral characterization of brain and macrophage nitric oxide synthases: cytochrome P-450-like hemeproteins that contain a flavin semiquinone radical. J Biol Chem 267: 20547-20550, 1992.

261. Sugioka K, Naruko T, Matsumura Y, Shirai N, Hozumi T, Yoshiyama M, and Ueda M. Neopterin and atherosclerotic plaque instability in coronary and carotid arteries. $J$ Atheroscler Thromb 17: 1115-1121, 2010.

262. Sugiyama T, Levy BD, and Michel T. Tetrahydrobiopterin recycling, a key determinant of endothelial nitric-oxide synthase-dependent signaling pathways in cultured vascular endothelial cells. J Biol Chem 284: 12691-12700, 2009.

263. Sumi-Ichinose C, Urano F, Kuroda R, Ohye T, Kojima M, Tazawa M, Shiraishi H, Hagino Y, Nagatsu T, Nomura T, and Ichinose $\mathrm{H}$. Catecholamines and serotonin are differently regulated by tetrahydrobiopterin. A study from 6pyruvoyltetrahydropterin synthase knockout mice. $J$ Biol Chem 276: 41150-41160, 2001.

264. This reference has been deleted.

265. Sunderkotter C, Nikolic T, Dillon MJ, Van Rooijen N, Stehling M, Drevets DA, and Leenen PJ. Subpopulations of mouse blood monocytes differ in maturation stage and inflammatory response. J Immunol 172: 4410-4417, 2004.

266. Szabo C, Bryk R, Zingarelli B, Southan GJ, Gahman TC, Bhat V, Salzman AL, and Wolff DJ. Pharmacological characterization of guanidinoethyldisulphide (GED), a novel inhibitor of nitric oxide synthase with selectivity towards the inducible isoform. Br J Pharmacol 118: 1659-1668, 1996.

267. Takano H, Zou Y, Hasegawa H, Akazawa H, Nagai T, and Komuro I. Oxidative stress-induced signal transduction pathways in cardiac myocytes: involvement of ROS in heart diseases. Antioxid Redox Signal 5: 789-794, 2003.

268. Takaya T, Hirata K, Yamashita T, Shinohara M, Sasaki N, Inoue N, Yada T, Goto M, Fukatsu A, Hayashi T, Alp NJ, Channon KM, Yokoyama M, and Kawashima S. A specific role for eNOS-derived reactive oxygen species in atherosclerosis progression. Arterioscler Thromb Vasc Biol 27: 1632-1637, 2007.

269. Takeda M, Yamashita T, Shinohara M, Sasaki N, Takaya $\mathrm{T}$, Nakajima K, Inoue N, Masano T, Tawa H, SatomiKobayashi S, Toh R, Sugiyama D, Nishimura K, Yokoyama M, Hirata KI, and Kawashima S. Plasma Tetrahydrobiopterin/Dihydrobiopterin Ratio. Circ J 73: 955962, 2009.

269a. Takimoto E, Champion HC, Li M, Ren S, Rodriguez ER, Tavazzi B, Lazzarino G, Paolocci N, Gabrielson KL, Wang Y, and Kass, DA. Oxidant stress from nitric oxide synthase-3 uncoupling stimulates cardiac pathologic remodeling from chronic pressure load. J Clin Invest 115, 1221-1231, 2005.

269b. Takimoto E, and Kass DA. Role of oxidative stress in cardiac hypertrophy and remodeling. Hypertension 49, 241-248, 2007.

269c. Tang XL, Takano H, Xuan YT, Sato H, Kodani E, Dawn B, Zhu Y, Shirk G, Wu WJ, and Bolli R. Hypercholesterolemia abrogates late preconditioning via a tetrahydrobiopterin-dependent mechanism in conscious rabbits. Circulation 112, 2149-2156, 2005.

270. Tayeh MA and Marletta MA. Macrophage oxidation of Larginine to nitric oxide, nitrite, and nitrate. Tetrahydrobiopterin is required as a cofactor. J Biol Chem 264: 19654-19658, 1989.
271. Tegeder I, Costigan M, Griffin RS, Abele A, Belfer I, Schmidt H, Ehnert C, Nejim J, Marian C, Scholz J, Wu T, Allchorne A, Diatchenko L, Binshtok AM, Goldman D, Adolph J, Sama S, Atlas SJ, Carlezon WA, Parsegian A, Lotsch J, Fillingim RB, Maixner W, Geisslinger G, Max $\mathrm{MB}$, and Woolf CJ. GTP cyclohydrolase and tetrahydrobiopterin regulate pain sensitivity and persistence. Nat Med 12: 1269-1277, 2006.

272. Tegeder I, Adolph J, Schmidt H, Woolf CJ, Geisslinger G, and Lotsch J. Reduced hyperalgesia in homozygous carriers of a GTP cyclohydrolase 1 haplotype. Eur J Pain 12: 1069-1077, 2008

273. Thomas SA, Matsumoto AM, and Palmiter RD. Noradrenaline is essential for mouse fetal development. Nature 374: 643-646, 1995.

274. Thony B, Auerbach G, and Blau N. Tetrahydrobiopterin biosynthesis, regeneration and functions. Biochem J 347: $1-16,2000$.

275. Thöny B and Blau N. Mutations in the BH4-metabolizing genes GTP cyclohydrolase I, 6-pyruvoyl-tetrahydropterin synthase, sepiapterin reductase, carbinolamine-4a-dehydratase, and dihydropteridine reductase. Hum Mutat 27: 870-878, 2006.

276. Tiefenbacher CP, Chilian WM, Mitchell M, and DeFily DV. Restoration of endothelium-dependent vasodilation after reperfusion injury by tetrahydrobiopterin. Circulation 94: 1423-1429, 1996.

277. Tiefenbacher CP, Bleeke T, Vahl C, Amann K, Vogt A, and Kubler W. Endothelial dysfunction of coronary resistance arteries is improved by tetrahydrobiopterin in atherosclerosis [In Process Citation]. Circulation 102: 2172-2179, 2000.

278. Tokuoka SM, Kita Y, Shindou H, and Shimizu T. Alkylglycerol monooxygenase as a potential modulator for PAF synthesis in macrophages. Biochem Biophys Res Commun 436: 306-312, 2013.

279. Tso PH, Wang Y, Wong SY, Poon LS, Chan AS, and Wong YH. RGS19 enhances cell proliferation through its C-terminal PDZ motif. Cell Signal 22: 1700-1707, 2010.

280. Ueda S, Matsuoka H, Miyazaki H, Usui M, Okuda S, and Imaizumi T. Tetrahydrobiopterin restores endothelial function in long-term smokers. J Am Coll Cardiol 35: 7175,2000 .

281. Upmacis RK, Crabtree MJ, Deeb RS, Shen H, Lane PB, Benguigui LE, Maeda N, Hajjar DP, and Gross SS. Profound biopterin oxidation and protein tyrosine nitration in tissues of ApoE-null mice on an atherogenic diet: contribution of inducible nitric oxide synthase. Am J Physiol Heart Circ Physiol 293: H2878-H2887, 2007.

282. Valdembri D, Serini G, Vacca A, Ribatti D, and Bussolino F. In vivo activation of JAK2/STAT-3 pathway during angiogenesis induced by GM-CSF. FASEB J 16: 225227, 2002.

283. Vallance P and Leiper J. Cardiovascular biology of the asymmetric dimethylarginine:dimethylarginine dimethylaminohydrolase pathway. Arterioscler Thromb Vasc Biol 24: 1023-1030, 2004.

284. van der Heijden OW, Essers YP, Fazzi G, Peeters LL, De Mey JG, and van Eys GJ. Uterine artery remodeling and reproductive performance are impaired in endothelial nitric oxide synthase-deficient mice. Biol Reprod 72: 11611168, 2005.

285. This reference has been deleted. 
286. Van Vliet BN, Chafe LL, and Montani J-P. Characteristics of $24 \mathrm{~h}$ telemetered blood pressure in eNOS-Knockout and C57B1/6J control mice. J Physiol 549: 313-325, 2003.

287. Vasquez-Vivar J, Kalyanaraman B, Martasek P, Hogg N, Masters BS, Karoui H, Tordo P, and Pritchard KA, Jr. Superoxide generation by endothelial nitric oxide synthase: the influence of cofactors. Proc Natl Acad Sci U S A 95: 9220-9225, 1998.

288. Vasquez-Vivar $\mathrm{J}$ and Kalyanaraman B. Generation of superoxide from nitric oxide synthase. FEBS Lett 481: 305-306, 2000.

289. Vasquez-Vivar J, Kalyanaraman B, and Kennedy MC. Mitochondrial aconitase is a source of hydroxyl radical. An electron spin resonance investigation. $J$ Biol Chem 275: 14064-14069, 2000.

290. Vasquez-Vivar J, Whitsett J, Martasek P, Hogg N, and Kalyanaraman B. Reaction of tetrahydrobiopterin with superoxide: EPR-kinetic analysis and characterization of the pteridine radical. Free Radic Biol Med 31: 975-985, 2001.

291. Vasquez-Vivar J, Duquaine D, Whitsett J, Kalyanaraman B, and Rajagopalan S. Altered tetrahydrobiopterin metabolism in atherosclerosis: implications for use of oxidized tetrahydrobiopterin analogues and thiol antioxidants. Arterioscler Thromb Vasc Biol 22: 1655-1661, 2002.

292. Vasquez-Vivar J, Martasek P, Whitsett J, Joseph J, and Kalyanaraman B. The ratio between tetrahydrobiopterin and oxidized tetrahydrobiopterin analogues controls superoxide release from endothelial nitric oxide synthase: an EPR spin trapping study. Biochem J 362: 733-739, 2002.

293. Vasquez-Vivar J, Kalyanaraman B, and Martasek P. The role of tetrahydrobiopterin in superoxide generation from eNOS: enzymology and physiological implications. Free Radic Res 37: 121-127, 2003.

294. Vasquez-Vivar J, Martasek P, and Kalyanaraman B. Superoxide generation from nitric oxide synthase: role of cofactors and protein interaction. In: Biological Magnetic Resonance, edited by Eaton SR, Eaton GR, and Berliner LJ. New York, NY: Kluwer, 2005, pp. 75-91.

295. Vásquez-Vivar J, Whitsett J, Derrick M, Ji X, Yu L, and Tan S. Tetrahydrobiopterin in the prevention of hypertonia in hypoxic fetal brain. Ann Neurol 66: 323-331, 2009.

296. Verma S, Lovren F, Dumont AS, Mather KJ, Maitland A, Kieser TM, Triggle CR, and Anderson TJ. Tetrahydrobiopterin improves endothelial function in human saphenous veins. J Thoracic Cardiovasc Surg 120: 668671, 2000.

297. Walter R, Linscheid P, Blau N, Kierat L, Schaffner A, and Schoedon G. Induction of tetrahydrobiopterin synthesis in human umbilical vein smooth muscle cells by inflammatory stimuli. Immunol Lett 60: 13-17, 1998.

298. Wang CH, Li SH, Weisel RD, Fedak PW, Hung A, Li RK, Rao V, Hyland K, Cherng WJ, Errett L, Leclerc Y, Bonneau D, Latter DA, and Verma S. Tetrahydrobiopterin deficiency exaggerates intimal hyperplasia after vascular injury. Am J Physiol Regul Integr Comp Physiol 289, R299-R304, 2005

299. Wang S, Xu J, Song P, Wu Y, Zhang J, Chul Choi H, and Zou M-H. Acute inhibition of guanosine triphosphate cyclohydrolase 1 uncouples endothelial nitric oxide synthase and elevates blood pressure. Hypertension 52: 484490, 2008

300. Wang X, Hattori Y, Satoh H, Iwata C, Banba N, Monden T, Uchida K, Kamikawa Y, and Kasai K. Tetra- hydrobiopterin prevents endothelial dysfunction and restores adiponectin levels in rats. Eur J Pharmacol 555: 48-53, 2007.

301. Wang ZQ, Wei CC, Ghosh S, Meade AL, Hemann C, Hille R, and Stuehr DJ. A conserved tryptophan in nitric oxide synthase regulates heme-dioxy reduction by tetrahydrobiopterin. Biochemistry 40: 12819-12825, 2001.

302. Watschinger K, Keller MA, Golderer G, Hermann M, Maglione M, Sarg B, Lindner HH, Hermetter A, WernerFelmayer G, Konrat R, Hulo N, and Werner ER. Identification of the gene encoding alkylglycerol monooxygenase defines a third class of tetrahydrobiopterin-dependent enzymes. Proc Natl Acad Sci U S A 107: 13672-13677, 2010.

303. Watschinger $\mathrm{K}$ and Werner ER. Alkylglycerol monooxygenase. IUBMB Life 65: 366-372, 2013.

304. Watt WB. Pteridine components of wing pigmentation in the butterfly colias eurytheme. Nature 201: 1326-1327, 1964.

305. Wei CC, Wang ZQ, Wang Q, Meade AL, Hemann C, Hille R, and Stuehr DJ. Rapid kinetic studies link tetrahydrobiopterin radical formation to heme-dioxy reduction and arginine hydroxylation in inducible nitric-oxide synthase. J Biol Chem 276: 315-319, 2001.

306. Weinmann A, Post M, Pan J, Rafii M, O’Connor DL, Unger S, Pencharz P, and Belik J. Tetrahydrobiopterin is present in high quantity in human milk and has a vasorelaxing effect on newborn rat mesenteric arteries. Pediatr Res 69: 325-329, 2011.

307. Wenzel P, Daiber A, Oelze M, Brandt M, Closs E, Xu J, Thum T, Bauersachs J, Ertl G, Zou MH, Forstermann U, and Munzel T. Mechanisms underlying recoupling of eNOS by HMG-CoA reductase inhibition in a rat model of streptozotocin-induced diabetes mellitus. Atherosclerosis 198: 65-76, 2008.

308. Wenzel P, Schulz E, Oelze M, Müller J, Schuhmacher S, Alhamdani MSS, Debrezion J, Hortmann M, Reifenberg K, Fleming I, Münzel T, and Daiber A. AT1-receptor blockade by telmisartan upregulates GTP-cyclohydrolase I and protects eNOS in diabetic rats. Free Radic Biol Med 45: 619-626, 2008.

309. Werner ER, Werner-Felmayer G, and Wachter H. Tetrahydrobiopterin and cytokines. Proc Soc Exp Biol Med 203: 1-12, 1993.

310. Werner ER, Pitters E, Schmidt K, Wachter H, WernerFelmayer G, and Mayer B. Identification of the 4-amino analogue of tetrahydrobiopterin as a dihydropteridine reductase inhibitor and a potent pteridine antagonist of rat neuronal nitric oxide synthase. Biochem J 320(Pt 1): 193196, 1996.

311. Werner ER, Werner-Felmayer G, Wachter H, and Mayer B. Biosynthesis of nitric oxide: dependence on pteridine metabolism. Rev Physiol Biochem Pharmacol 127: 97$135,1996$.

312. Werner ER, Werner-Felmayer G, and Mayer B. Tetrahydrobiopterin, cytokines, and nitric oxide synthesis. Proc Soc Exp Biol Med 219: 171-182, 1998.

313. Werner ER, Bahrami S, Heller R, and Werner-Felmayer G. Bacterial lipopolysaccharide down-regulates expression of GTP cyclohydrolase I feedback regulatory protein. J Biol Chem 277: 10129-10133, 2002.

314. Werner ER and Werner-Felmayer G. Biopterin analogues: novel nitric oxide synthase inhibitors with immunosuppressive action. Curr Drug Metab 3: 119-121, 2002. 
315. Werner ER, Blau N, and Thony B. Tetrahydrobiopterin: biochemistry and pathophysiology. Biochem J 438: 397414, 2011.

316. Werner-Felmayer G, Werner ER, Weiss G, and Wachter H. Modulation of nitric oxide synthase activity in intact cells by intracellular tetrahydrobiopterin levels. Adv Exp Med Biol 338: 309-312, 1993.

317. Widder JD, Chen W, Li L, Dikalov S, Thony B, Hatakeyama K, and Harrison DG. Regulation of tetrahydrobiopterin biosynthesis by shear stress. Circ Res 101: 830-838, 2007

318. This reference has been deleted.

319. Wilcox JN, Subramanian RR, Sundell CL, Tracey WR, Pollock JS, Harrison DG, and Marsden PA. Expression of multiple isoforms of nitric oxide synthase in normal and atherosclerotic vessels. Arterioscler Thromb Vasc Biol 17: 2479-2488, 1997.

320. Worthley MI, Kanani RS, Sun Y-H, Sun Y, Goodhart DM, Curtis MJ, and Anderson TJ. Effects of tetrahydrobiopterin on coronary vascular reactivity in atherosclerotic human coronary arteries. Cardiovasc Res 76: 539-546, 2007.

321. This reference has been deleted.

322. Wright CJ, Agboke F, Chen F, La P, Yang G, and Dennery PA. NO inhibits hyperoxia-induced NF-kappaB activation in neonatal pulmonary microvascular endothelial cells. Pediatr Res 68: 484-489, 2010.

323. Wu CC and Yen MH. Nitric oxide synthase in spontaneously hypertensive rats. J Biomed Sci 4: 249-255, 1997.

324. Wyss CA, Koepfli P, Namdar M, Siegrist PT, Luscher TF, Camici PG, and Kaufmann PA. Tetrahydrobiopterin restores impaired coronary microvascular dysfunction in hypercholesterolaemia. Eur J Nucl Med Mol Imaging 32: 84-91, 2005.

325. Xia N, Daiber A, Habermeier A, Closs EI, Thum T, Spanier G, Lu Q, Oelze M, Torzewski M, Lackner KJ, Münzel T, Förstermann U, and Li H. Resveratrol reverses endothelial nitric-oxide synthase uncoupling in apolipoprotein E knockout mice. J Pharmacol Exp Ther 335: 149-154, 2010.

326. Xie H-H, Zhou S, Chen D-D, Channon KM, Su D-F, and Chen AF. GTP Cyclohydrolase I/BH4 Pathway Protects EPCs via Suppressing Oxidative Stress and Thrombospondin-1 in Salt-Sensitive Hypertension. Hypertension 56: 1137-1144, 2010.

327. Xie L, Smith JA, and Gross SS. GTP cyclohydrolase I inhibition by the prototypic inhibitor 2, 4-diamino-6-hydroxypyrimidine. Mechanisms and unanticipated role of GTP cyclohydrolase I feedback regulatory protein. J Biol Chem 273: 21091-21098, 1998.

328. Xie Q and Nathan C. The high-output nitric oxide pathway: Role and regulation. J Leukocyte Biol 56: 576-582, 1994.

329. Yamamizu K, Shinozaki K, Ayajiki K, Gemba M, and Okamura T. Oral administration of both tetrahydrobiopterin and L-arginine prevents endothelial dysfunction in rats with chronic renal failure. $J$ Cardiovasc Pharmacol 49: 131-139, 2007.

330. Yamashiro S, Noguchi K, Matsuzaki T, Miyagi K, Nakasone J, Sakanashi M, and Koja K. Beneficial effect of tetrahydrobiopterin on ischemia-reperfusion injury in isolated perfused rat hearts. J Thorac Cardiovasc Surg 124: 775-784, 2002.
331. Yang Q, Botto LD, Erickson JD, Berry RJ, Sambell C, Johansen H, and Friedman JM. Improvement in stroke mortality in Canada and the United States, 1990 to 2002. Circulation 113: 1335-1343, 2006.

332. Yang Y-M, Huang A, Kaley G, and Sun D. eNOS uncoupling and endothelial dysfunction in aged vessels. Am J Physiol 297: H1829-H1836, 2009.

333. Yang Z-w, Zhang A, Altura BT, and Altura BM. Hydrogen peroxide-induced endothelium-dependent. Gen Pharmacol 33: 325-336, 1999.

334. Yoneyama T, Brewer JM, and Hatakeyama K. GTP cyclohydrolase I feedback regulatory protein is a pentamer of identical subunits. Purification, cDNA cloning, and bacterial expression. J Biol Chem 272: 9690-9696, 1997.

335. Yoshida Y-I, Eda S, and Masada M. Alterations of tetrahydrobiopterin biosynthesis and pteridine levels in mouse tissues during growth and aging. Brain Dev 22: 45-49, 2000.

336. Youn JY, Wang T, Blair J, Laude KM, Oak J-H, McCann LA, Harrison DG, and Cai H. Endothelium-specific sepiapterin reductase deficiency in DOCA-salt hypertension. Am J Physiol 302: H2243-H2249, 2012.

337. Yumoto T, Sagami I, Daff S, and Shimizu T. Roles of the heme proximal side residues tryptophan409 and tryptophan421 of neuronal nitric oxide synthase in the electron transfer reaction. J Inorg Biochem 82: 163-170, 2000.

338. Zembowicz A, Hatchett RJ, Jakubowski AM, and Gryglewski RJ. Involvement of nitric oxide in the endotheliumdependent relaxation induced by hydrogen peroxide in the rabbit aorta. Br J Pharmacol 110: 151-158, 1993.

339. Zhang L, Rao F, Zhang K, Khandrika S, Das M, Vaingankar SM, Bao X, Rana BK, Smith DW, Wessel J, Salem RM, Rodriguez-Flores JL, Mahata SK, Schork NJ, Ziegler MG, and O'Connor DT. Discovery of common human genetic variants of GTP cyclohydrolase 1 (GCH1) governing nitric oxide, autonomic activity, and cardiovascular risk. J Clin Invest 117: 2658-2671, 2007.

340. Zhang Z, Wang M, Xue S-J, Liu D-H, and Tang Y-B. Simvastatin Ameliorates Angiotensin II-Induced Endothelial Dysfunction Through Restoration of Rho-BH4-eNOS-NO Pathway. Cardiovasc Drugs Ther 26: 31-40, 2012.

341. Zhou M, Diwu Z, Panchuk-Voloshina N, and Haugland RP. A stable nonfluorescent derivative of resorufin for the fluorometric determination of trace hydrogen peroxide: applications in detecting the activity of phagocyte NADPH oxidase and other oxidases. Anal Biochem 253: 162-168, 1997.

342. Zhou Q-Y, Quaife CJ, and Palmiter RD. Targeted disruption of the tyrosine hydroxylase gene reveals that catecholamines are required for mouse fetal development. Nature 374: 640-643, 1995.

343. Ziegler I, Schott K, Lubbert M, Herrmann F, Schwulera $\mathrm{U}$, and Bacher A. Control of tetrahydrobiopterin synthesis in $\mathrm{T}$ lymphocytes by synergistic action of interferongamma and interleukin-2. J Biol Chem 265: 17026-17030, 1990.

344. Zorzi G, Redweik U, Trippe H, Penzien JM, Thony B, and Blau N. Detection of sepiapterin in CSF of patients with sepiapterin reductase deficiency. Mol Genet Metab 75: 174-177, 2002.

345. Zou MH, Shi C, and Cohen RA. Oxidation of the zincthiolate complex and uncoupling of endothelial nitric oxide synthase by peroxynitrite. J Clin Invest 109: 817-826, 2002. 


\section{Address correspondence to: Dr. Mark J. Crabtree Division of Cardiovascular Medicine British Heart Foundation Centre of Research Excellence University of Oxford John Radcliffe Hospital Oxford OX3 9DU United Kingdom}

E-mail: mark.crabtree@well.ox.ac.uk

Date of first submission to ARS Central, August 15, 2013; date of final revised submission, November 1, 2013; date of acceptance, December 2, 2013.

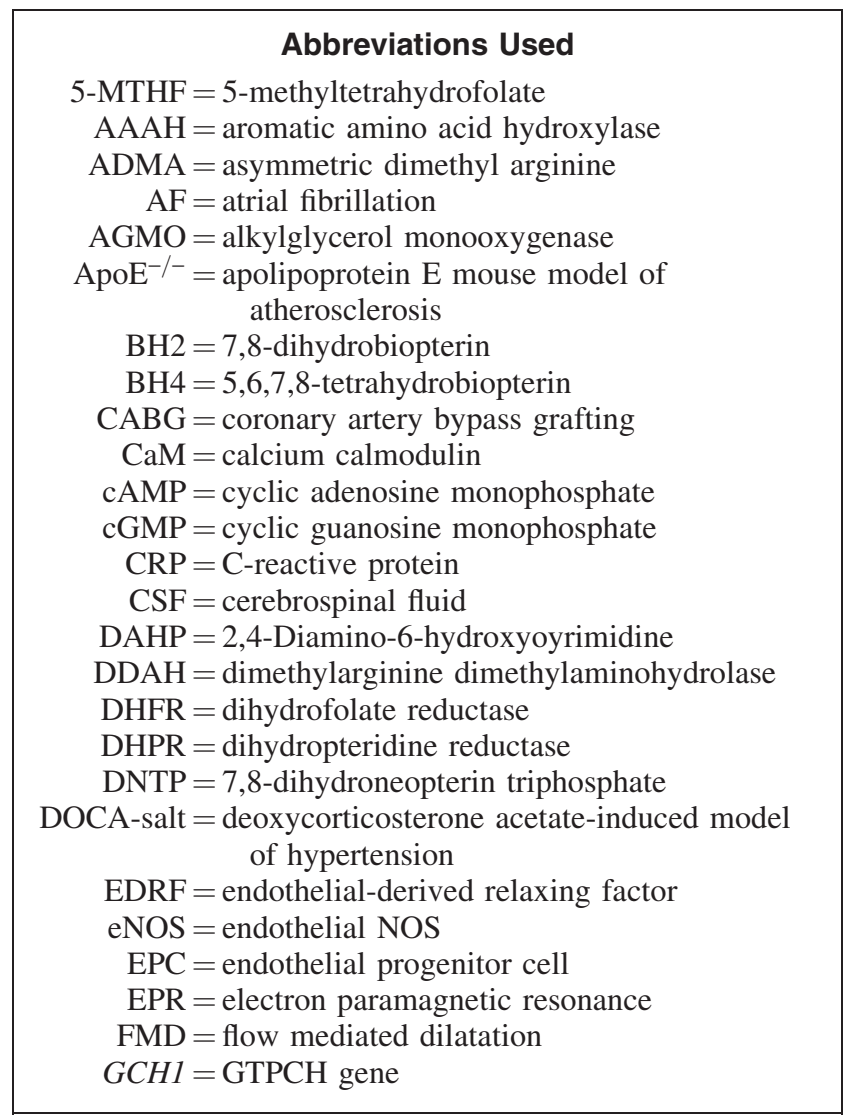

$\mathrm{GCH}-\mathrm{Tg}=$ mouse model overexpressing $\mathrm{GTPCH}$ within the endothelium

$\mathrm{GFRP}=\mathrm{GTPCH}$ feedback regulatory protein

$\mathrm{GTP}=$ guanosine triphosphate

$\mathrm{GTPCH}=\mathrm{GTP}$ cyclohydrolase I

$\mathrm{H}_{2} \mathrm{O}_{2}=$ hydrogen peroxide

hph-1 = hyperphenylalaninemic mouse mutant model of BH4 deficiency

HUVEC $=$ human umbilical vein endothelial cell

$\mathrm{I} / \mathrm{R}=$ ischemia-reperfusion

$\mathrm{IFN}=$ interferon

IL-6 = interleukin-6

iNOS $=$ inducible NOS

IPC $=$ ischemic preconditioning

$\mathrm{LDL}=$ low-density lipoprotein

L-DOPA $=$ L-3,4-dihydroxyphenylalanine

$\mathrm{L}-\mathrm{NAME}=\mathrm{N}(\mathrm{G})$-nitro-L- arginine methyl ester

LPS $=$ lipopolysaccharide

mGCH-Tg = mouse model overexpressing GTPCH within the myocardium

MTX $=$ methotrexate

$\mathrm{NADPH}=$ nicotinamide adenine dinucleotide phosphate

NH4 $=5,6,7,8$-tetrahydro-D-neopterin

$\mathrm{nNOS}=$ neuronal NOS

$\mathrm{NO}=$ nitric oxide

$\mathrm{NO}_{2}{ }^{-}=$nitrite

$\mathrm{NO}_{3}{ }^{-}=$nitrate

$\mathrm{NOS}=$ nitric oxide synthase

$\mathrm{O}_{2}{ }^{-}=$superoxide

ODQ $=1 \mathrm{H}-(1,2,4)$ oxadiazolo[4,3-a]quinoxalin-1-one

$\mathrm{ONOO}^{-}=$peroxynitrite

$\mathrm{PAF}=$ platelet activating factor

$\mathrm{PCD}=$ pterin-4a-carbinolamine dehydratase

$\mathrm{PRMT}=$ protein arginine $\mathrm{N}$-methyltransferase

PTPS $=6$-pyruvoyl tetrahydropterin synthase

q-BH2 = quinonoid $\mathrm{BH} 2$

$\mathrm{RNS}=$ reactive nitrogen species

$\mathrm{ROS}=$ reactive oxygen species

$\mathrm{sGC}=$ soluble guanylate cyclase

$\mathrm{SNP}=$ single nucleotide polymorphisms

$\mathrm{SR}=$ sepiapterin reductase

$\mathrm{STZ}=$ streptozotocin

$\mathrm{TAC}=$ transverse aortic constriction

$\mathrm{TH}=$ tyrosine hydroxylase

VCAM-1 $=$ vascular cell adhesion molecule 1 $\mathrm{WT}=$ wild type 